\title{
WestVirginiaUniversity
}

THE RESEARCH REPOSITORY @ WVU

Graduate Theses, Dissertations, and Problem Reports

2014

\section{Early School Leaving: A Narrative Inquiry of the School Dropout}

John E. Stallings Jr.

West Virginia University

Follow this and additional works at: https://researchrepository.wvu.edu/etd

\section{Recommended Citation}

Stallings, John E. Jr., "Early School Leaving: A Narrative Inquiry of the School Dropout" (2014). Graduate Theses, Dissertations, and Problem Reports. 271.

https://researchrepository.wvu.edu/etd/271

This Dissertation is protected by copyright and/or related rights. It has been brought to you by the The Research Repository @ WVU with permission from the rights-holder(s). You are free to use this Dissertation in any way that is permitted by the copyright and related rights legislation that applies to your use. For other uses you must obtain permission from the rights-holder(s) directly, unless additional rights are indicated by a Creative Commons license in the record and/ or on the work itself. This Dissertation has been accepted for inclusion in WVU Graduate Theses, Dissertations, and Problem Reports collection by an authorized administrator of The Research Repository @ WVU.

For more information, please contact researchrepository@mail.wvu.edu. 
Early School Leaving: A Narrative Inquiry of the School Dropout

John E. Stallings, Jr.

Dissertation submitted to the College of Education and Human Services at West Virginia University in partial fulfillment of the requirements for the degree of

\author{
Doctor of Education \\ in \\ Educational Leadership Studies \\ Sharon Hayes, Ph.D., Chair \\ Joy Faini-Saab, Ed.D. \\ Lynne Schrum, Ph.D. \\ Ernest Goeres, Ph.D. \\ Richard Walls, Ph.D.
}

Department of Educational Leadership Studies

Morgantown, West Virginia

2013

Copyright 2013 John E. Stallings, Jr.

John.Stallings@mail.wvu.edu 


\section{Abstract \\ Early School Leaving: A Narrative Inquiry of the School Dropout}

John E. Stallings, Jr.

By

December 2013

Chair: Sharon Hayes

Major: Educational Leadership Studies

In the field of education, student performance has become an integral component when determining the effectiveness of schools, levels of student engagement, and a measure of the learning that is occurring in schools. In particular, certain criteria have been identified as appropriate measures for monitoring the effectiveness of school systems, individual school programs, and teacher merit. Included in these specific areas to be monitored are graduation and or dropout rates. While these have become a part of the major focus of those monitoring the effectiveness of schools across the country, it seems that little has been done to investigate what may be contributing to the phenomenon.

Thus far, most studies of the phenomenon of early school leaving, otherwise known as school dropout, seems to have become complacent and has therefore settled on merely identifying labels for the characteristics and or symptoms of this growing silent epidemic, Milliken (2007). While being able to identify or recognize such things as what symptoms may foretell the possibility that students in danger of academic failure may decide to dropout, I posit that a great deal more can be learned about the growing disparity between graduation and school dropout rates. This can be done by investigating the phenomenon through the lens of those who have actually made the decision to drop out.

My personal belief is that there is much to be said about discovering what may be contributing to those symptoms which may be contributing to early school leaving beyond the labeling of characteristics. I further believe that it will require attention from more than the classroom teachers' attempt to respond to the emotional needs of their students; however, this is an important step to the process.

My study is the result of my personal convictions that more needs to be understood about the underlying contributors to such things as poor attendance, inappropriate behavior, and or coursework failure. Therefore, the following questions have guided my research: (1) What contributes to an individual's decision to leave school early? and (2) How does the decision to leave school early affect the later life of the school dropout?

This research is framed in social constructivism and employed audio-taped interview sessions and transcripts of stories shared by participants pertaining to their experiences prior to enrolling in school, while attending school as well as what life has been like since each actually dropped out. The individual's constructed understandings of the complicating actions, evaluations of those action and subsequent resolutions have been used to reveal each person's positioning as a result of those experiences. 
This research has provided evidence of what may be contributing to such things as feelings of marginalization, abandonment and disequilibrium from a very young age through the present. Using this information may be useful when reflecting on policy and practice that may need to be more sensitive to those factors that actually may be contributing to decision to leave school early. In addition, this information may be useful when rethinking the current trend that continues the operation of a deficit model wherein blaming the victim seems to be the typical response to the growing dilemma of school dropout. Further, this information has implications for teacher education, professional development and community awareness training practices that could serve the individual needs of our students as well as needs of the community at large. However, the responsibilities for these initiatives can only be addressed in a cooperative, collaborative fashion.

Keywords:

Dropout, Early School Leaving, Complicating Actions, Themes, Poverty Marginalization, Victimization, Narrative Inquiry, Constructed Meaning, Equilibrium and Disequilibrium 
(C) 2013 John E. Stallings, Jr. 
For Margaret, Ryan and Drew

Thanks for your constant encouragement, patience and belief in me. 


\section{Acknowledgements}

I would like to thank the members of my doctoral committee - Sharon Hayes, Joy Fainin-Saab, Lynne Schrum, Ernest Goeres, and Richard Walls. Your advice, encouragement, and patience have enriched and validated my interest in education and the important work of ensuring that all learners are recognized as valuable and filled with potential.

I want to extend a special thanks to Sharon who has served me well as the chair of my committee with the very important reflective lens and mentoring needed when addressing research initiatives such as this. Your guidance has been an integral part of my doctoral journey and I look forward to additional opportunities to work with, and learn from, you as my friend and professional colleague.

I am also very grateful to the members of my immediate family, who have quietly encouraged me to pursue and fulfill my desire to continue exploring educational opportunities even after I retired from a full career as a teacher, principal and central office administrator. Perhaps this journey demonstrates my commitment to life-long learning.

I am especially grateful to my wife, Margaret, who has remained an ever-present source of strength and encouragement, always the cheer-leader who knows what to say and when to say it. Because of you, I have always known what it is to be supported and that even the seemingly out of reach opportunities are reachable. Thank you for holding me up during our journey together.

Finally, I would like to thank the individuals who agreed to be a part of my study. It was a privilege to work with each of you. I appreciated your willingness to trust me 
with your most personal stories. Because of your trust, I have learned a great deal about the frustrations and circumstances that can influence individuals to leave school early, as well as appreciating the sense of resolve each of you has demonstrated throughout your individual journeys. I wish each of you much success in the future. My hope is that the knowledge that has been gained from your stories can help increase the understanding of the early school leaving phenomenon and impact future decisions pertaining to such things as school policy and practice in productive ways. 


\section{Table of Contents}

Acknowledgements .................................................. vii

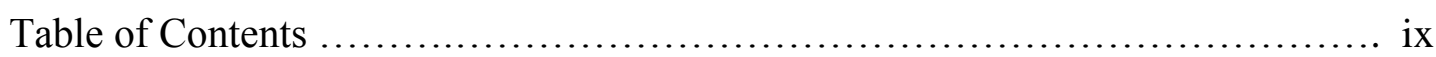

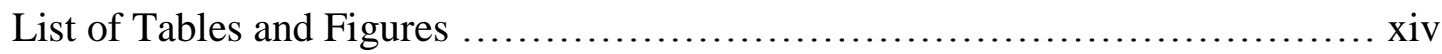

Chapter One: Introduction ........................................... 1

A Chronologic View of Dropping Out $\ldots \ldots \ldots \ldots \ldots \ldots \ldots \ldots \ldots . \ldots 4$

Understanding the Dropout ............................... 9

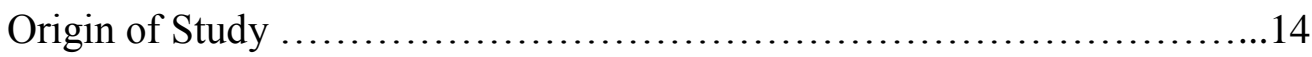

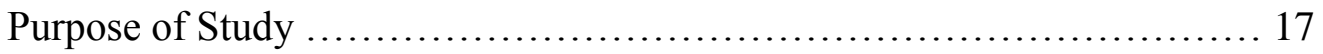

Research Questions ............................................. 18

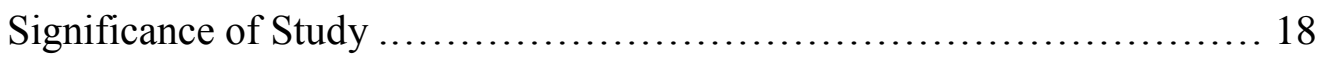

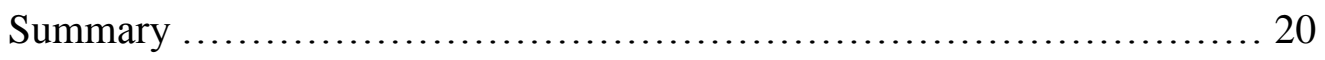

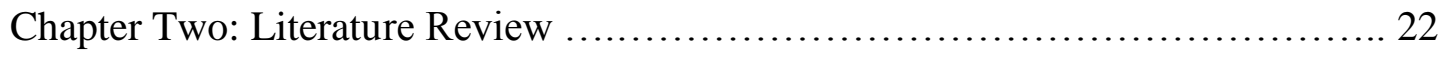

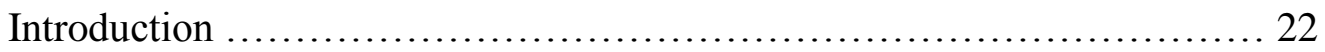

A Method of Searching the Literature ............................... 23

A Brief Longitudinal Consideration of the School Dropout Dilemma ........24

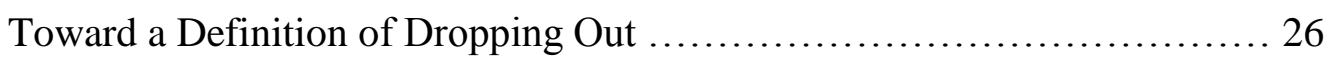

An Investigation of Multiple Perspectives of Dropping Out ............... 28

Dropping Out of School - A Socio-Cultural Perspective ............ 29

Dropping Out of School - Students' Perspective ................. 30

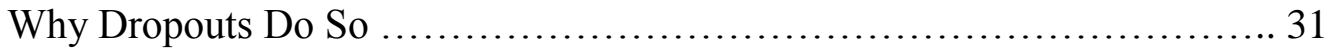

Reasons for Dropping Out Often Overlooked or Ignored:

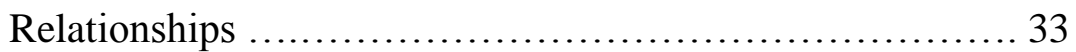


Reasons for Dropping Out Often Overlooked or Ignored:

Gifted Dropouts ........................................ 36

Bronfenbrenner's Ecology of Human Development ........................ 37

Consideration of Piaget's Theory of Cognitive Development - Stages of

Equilibrium and Disequilibrium ................................41

Building on the Strengths of Two Theoretical Perspectives ..................43

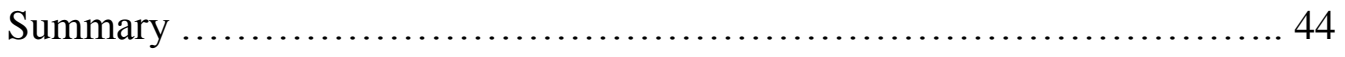

Chapter Three Content - Methodology ................................... 45

Chapter Three: Methods and Materials .............................................. 46

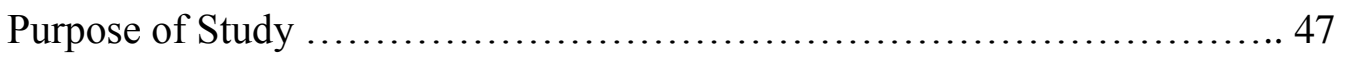

Theoretical Perspective: Social Constructivism ............................ 49

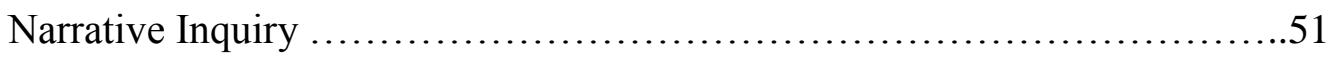

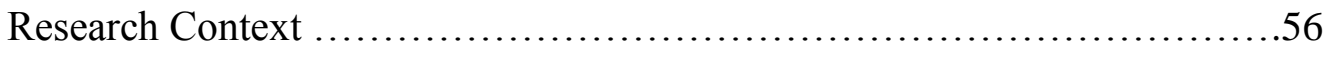

North Central County ......................................... 57

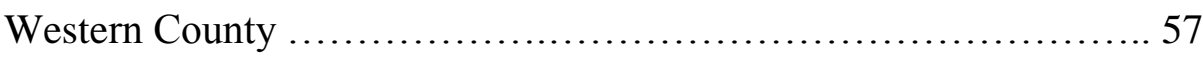

Participants and Their Roles .................................... 59

The Researcher and His Roles ..................................... 64

Subjectivities and Positioning of the Researcher ...................66

Data Collection .................................................... 75

Data Sources: Participant Interviews .............................76

Data Sources: Documents .................................... 80

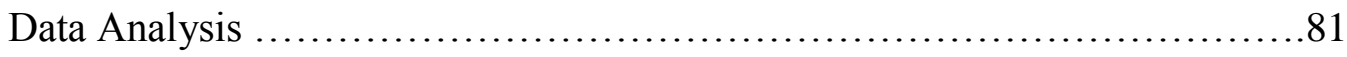

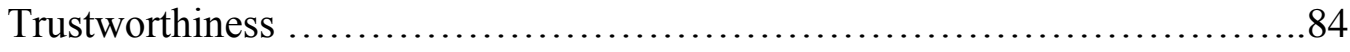




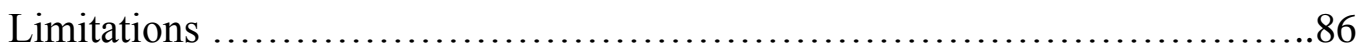

Limitations - Data Collection Methods .............................. 86

Limitations - Subjectivities of the Researcher ...................... 88

Limitations - Positioning: Of, and Interactions Between, the

Researcher and Participants ............................ 88

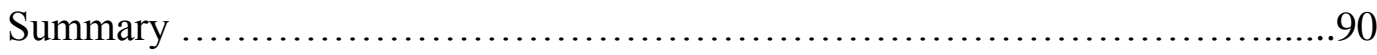

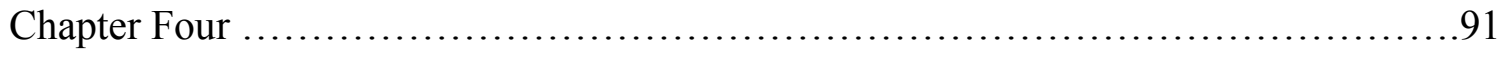

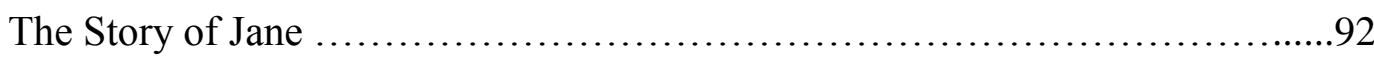

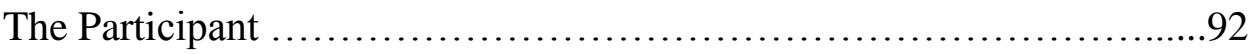

The Context ............................................................92

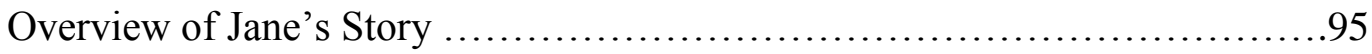

Jane's Experiences of Home ….................................. 95

Jane's School Experience ........................................104

Life After Leaving School Early ...................................113

Concluding Thoughts ....................................................116

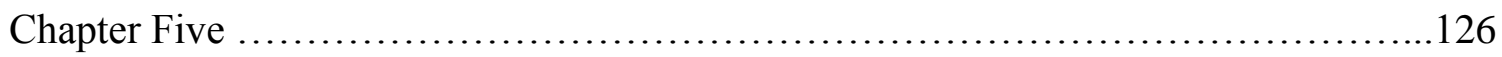

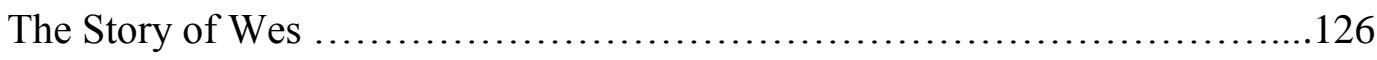

The Participant ................................................. 127

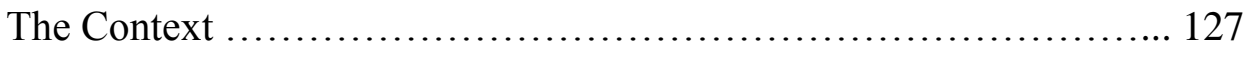

Overview of Wes's Story ....................................................

Wes's Experiences of Home .......................................131

Wes's School Experience ............................................ 136

Life After Leaving School Early ..................................141 
Concluding Thoughts …............................................... 145

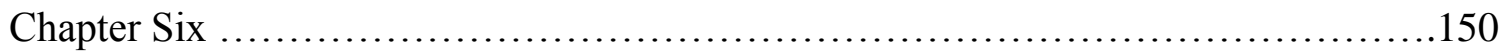

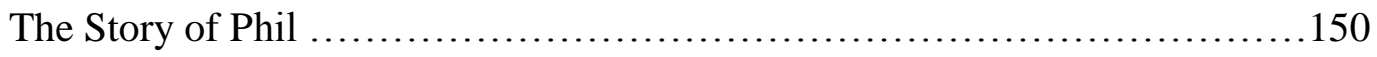

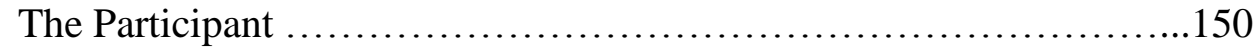

The Context .................................................... 151

Overview of Phil's Story .............................................. 153

Phil's Experiences of Home .....................................154

Phil's School Experience ..............................................156

Life After Leaving School Early ................................... 162

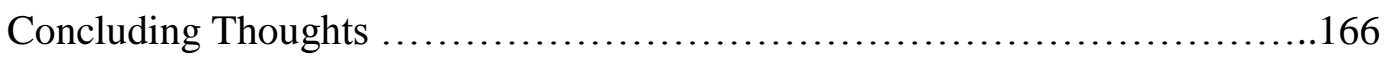

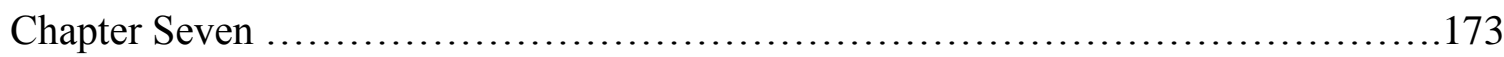

The Story of Rocky .................................................. 174

The Participant ................................................... 174

The Context .................................................... 175

Overview of Rocky's Story .............................................. 178

Rocky's Experiences of Home ......................................179

Rocky's School Experience ....................................182

Life After Leaving School Early ..................................188

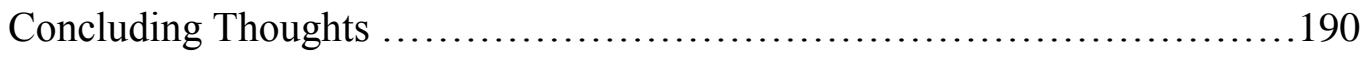

Chapter Eight: Discussion .................................................. 196

Rethinking the Dropout Dilemma .......................................196

Differences and Overlapping Circumstances .............................198

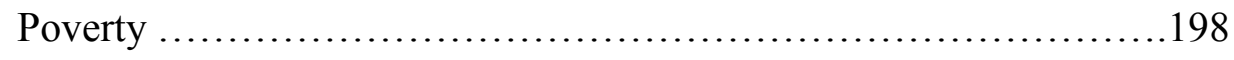


Rationale for Leaving School ..................................201

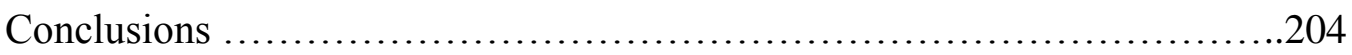

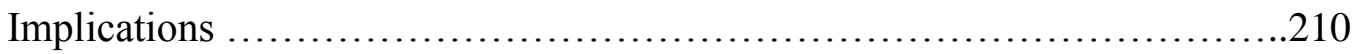

Emotional Connectivity ...................................212

Shared Communal Effort and Responsibilities ...................214

Issues of Accessibility .....................................214

Shared Decision-Making ................................... 215

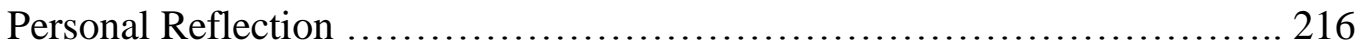

Appendices ........................................................... 219

Appendix A: Letter of Invitation and Informed Consent .................220

Appendix B: Script - Interview One: Experiences At Home .............. 221

Appendix C: Script - Interview Two: School Experiences ...................... 222

Appendix D: Script - Interview Three: Life After Leaving School Early ......223

Appendix E: Letter of Authorization to Review School Records .............224

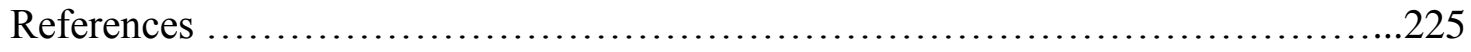

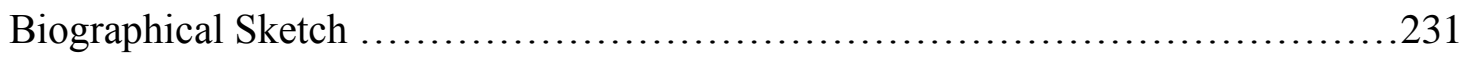




\section{Tables and Figures}

Tables:

Table 2.1 - U.S. vs. West Virginia's Dropout Rate Statistics

(1972-1984 and 2012)

Table 3.1 - School District Graduation and Dropout Rate Trend Data .......... 58

Table 3.2 - Timetable/Reiterative Process for Data Collection and Analysis ....83

Table 4.1 - United States Poverty Thresholds for 1973 ...................... 93

Table 4.2 - Vignettes and Themes from Jane's Journey:

The Early Years

96

Table 4.3 - Vignettes and Themes from Jane's Journey:

The School Experience

Table 4.4 - Vignettes and Themes from Jane's Journey:

Life After Leaving School Early

Table 5.1 - United States Poverty Thresholds for 1959

Table 5.2 - Vignettes and Themes from Wes's Journey:

The Early Years

Table 5.3 - Vignettes and Themes from Wes's Journey:

The School Experience

Table 5.4 - Vignettes and Themes from Wes's Journey:

Life After Leaving School Early

Table 6.1 - United States Poverty Thresholds for 1992

Table 6.2 - Vignettes and Themes from Phil's Journey:

The Early Years 
Table 6.3 - Vignettes and Themes from Phil's Journey:

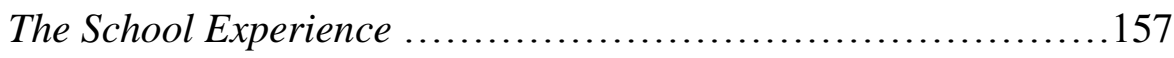

Table 6.4 - Vignettes and Themes from Phil's Journey:

Life After Leaving School Early ..................................163

Table 7.1 - United States Poverty Thresholds for 1995 .......................177

Table 7.2 - Vignettes and Themes from Rocky's Journey:

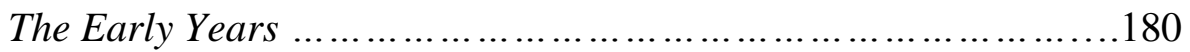

Table 7.3 - Vignettes and Themes from Rocky's Journey:

The School Experience ...........................................183

Table 7.4 - Vignettes and Themes from Rocky's Journey:

Life After Leaving School Early ..................................188

Figures:

Figure 2.1 - A Conceptual Model: Bronfenbrenner's (1979)

Ecology of Human Development ...............................40

Figure 2.2 - Stages of Equilibrium and Disequilibrium:

Piaget (1896-1980): Theory of Cognitive Development 


\section{Chapter One \\ Introduction}

Whenever someone mentions "the three-Rs", Reading, Writing and Arithmetic come to mind. When people talk about schooling, they typically reflect on their own experiences either as a former student or as the parent or other relative of a student. One of the definitive signs of a successful educational experience, in addition to student performance data, is the acquisition of a high school diploma. However, if such a document is important to success, how is it that the dropout phenomenon is increasing yet little is being done to address it?

Data pertaining to the number of individuals that complete a traditional PreK-12 school program is typically recorded as graduation rates. A report issued by the Alliance for Excellent Education (2009) organization indicates that graduation rates are usually considered a fundamental indicator of the successfulness of our nation's public school system. As a part of the No Child Left Behind Act of 2001 (NCLB), graduation rate is one of a number of criteria used to gauge a school's adequate yearly progress (AYP). As a result, AYP is not accomplished whenever the dropout rates are high. Therefore, graduation rates can suggest whether or not a school system is doing what it is intended to do: enroll, engage and educate youth to be productive members of society. The high school dropout rate can be a telling indicator of how well this expectation is being met and whether problems may exist in particular schools or districts.

Even though consideration of a high school's graduation rate is included in the language of the NCLB Act as one of the primary monitored benchmarks with regard to acquisition of AYP, over the past decade, "only seven states showed an increase in high school completion rates; the remaining states declined" (Barton, 2006, p. 15). 
Unfortunately, West Virginia is not one of those states that showed the increase being reported at that time. The NCLB Act requires states, school districts and individual schools to implement policies and practices to ensure that students continue to demonstrate proficient skills. However, statistics reveal that a significant number of students continue to lack minimal proficiency. As a result, the high school completion rate has not rallied as required by the NCLB mandate. When this occurs dropouts seek assistance from a variety of social support systems. Consequently, reliance on social support systems has increased. An increased need for support can also cause crime throughout communities to climb. These rising crime-related activities often include involvement of those who have previously dropped out of school.

In some instances, the schools with higher dropout rates have been labeled as dropout factories. This reputation does nothing for the morale of anyone associated with these locations. As a part of a story that focused on high school dropout rates in the U.S., Layton (2010) reported that Robert Balfanz, Director of the Everyone Graduates Center at Johns Hopkins University, had indicated that "the number of kids attending these dropout factories has decreased by approximately one third" and that there have been what he called "points to progress in which states have either demonstrated reform efforts, closed or are giving student learners some other more successful school option" (para. 3). However, this trend does not eliminate the urgency of discovering still more of what is contributing to the dropout dilemma. From a research lens, an important way of understanding dropping out should be possible by asking dropouts about their individual experiences. 
The scope of the dropout problem is a troubling notion because it tends to lead to such things as issues of poverty and crime, and many more of the nation's youth are dropping out during high school than had been reported in the past. (Alliance for Excellent Education, 2009)

According to some reports, nearly one third of our students, approximately 1.3 million per year, are dropping out of school prior to achieving their high school diploma (Alliance for Excellent Education, 2009). We say that dropping out is wrong but do we understand why it is occurring? Having a good understanding of what causes someone to dropout would be helpful in terms of understanding the issue more completely.

While the problem of school dropout has existed for some time, understanding it from the perspective of the dropout is nearly absent from the discussion. As suggested by Freire (2005) because of the difficult, complex and fundamental nature of the relationship, it should be something about which we think constantly (p. 107).

Often it is assumed that students who disengage from school are irresponsible and lack motivation, when in fact other potentially unaddressed contributing factors may be present. The downward spiral that results continues to impact the educational community in negative ways. As a part of his Metropolitan Schools programs and described in his work entitled The Big Picture, (2004) Littky demonstrated that responsible educators recognize the benefits of an emotional connectivity between a student and others in the school. Without the presence of a felt emotional connection, certain students may choose to disengage from school activities and eventually disconnect from the educational pursuit altogether. When this happens, students often drop out. 
For those whom the system seems to have failed, it is possible that little can be done to correct the past. This suggests that not enough has been done to understand dropping out through the lens of the dropout. Therefore, discovering more about what is contributing to this dilemma would be helpful. As a researcher one cannot look at this issue merely through the typical school system lens, as has been previously done. Freire's suggestion of the importance of seeking the dropout's story through his or her lens is appropriate for research of this nature. Given that direction, it is important to become familiar with how the phenomenon of dropping out was viewed across time.

\section{A Chronologic View of Dropping Out}

Some of our country's earliest educational designs were such that an education was defined somewhat differently than that which we know today. The significance of this disparity includes the fact that while the population being served has changed, there are a number of instances that suggest not much has been done regarding delivery models practiced in our schools today.

The Jeffersonian model for the provision of educational opportunities that was established during the earliest years of our country provided instruction intended to ensure acquisition of basic literacy and numeracy skills in order to contribute to the common good. These basic skills were what he called components of "an education for life, providing the requisite skills for daily life of the yeoman farmer and for the wife and mother of the household in the early American republic" (Tozer, Violas, \& Senese, 2008, p. 34). Beyond that basic education, male students from more affluent families were afforded opportunities to continue the educational path in order to prepare a pool of potential candidates capable of consideration for future leadership responsibilities. Those 
individuals were then afforded opportunities for study at the university level. Although instructional deliveries of the past were intended to be delivered to the masses, they were designed with a much different goal in mind than our present system. In keeping with the philosophy behind the Jeffersonian model for education where only the offspring of the elite would be considered worthy of holding positions of power, only certain individuals were given a chance to progress beyond the basic school level. Hence, graduation and dropout rates were not a major focus, as they served no purpose.

Over time, subsequent school programming shifted from the original narrow view that limited extended opportunities for an education to offspring of the elite. This was done in order to accommodate needs for increasing educational levels that were introduced during the industrial revolution. As more immigrants were flowing into the country, most of whom had little familiarity with the English language or American culture, an attempt to ensure a more universal basic educational experience was necessary. Being hired to work in factories and mills meant that you had sufficient basic skills to complete required tasks independently. At that time of significant expansion of employment opportunities, once again, school dropout was not a concern. It became easy not to be concerned about those who may have fallen between the cracks or chose to leave a particular school or workplace. There were other work-related opportunities for them that did not require a high school diploma elsewhere. This seemed to work until attention was focused on such things as child labor laws and compulsory attendance regulations. The shift of attention to protection of our youth included an expectation that everyone of school age would be provided educational opportunities beyond basic skills acquisition. 
Once the suggestion of possible world dominance was introduced through the Russian launch of the sputnik satellite, the United States suddenly became concerned about the educational program and introduced additional course requirements in the subjects of Science and Mathematics. Along with this emphasis programs grew to embody requirements of an extension of time students were to spend in school. As a part of newly established attendance regulations schools soon found that not every student was interested in what was being offered and expected of them. When these individuals began to create distraction and started to dropout, many schools discovered that they were often glorified. It seemed that every community had a representative population who simply chose not to persist in school until graduation. However, in some ways their departure was welcomed because it minimized distractions in the classroom. Therefore, once again, the fact that young people were dropping out of school was not seen as problematic.

It wasn't until sometime in the early 1980's when our country began to realize the potential cost that ignoring the importance of minimal universal education might bring about. In A Nation At Risk (1983), our educational and political leaders began to realize that more needed to be done to ensure that all of our citizens were better educated in order for the country to remain competitive on the global stage. Included in those changes was the philosophy that everyone had a right to opportunities to experience the full spectrum of available educational opportunities. Responsibility to ensure the availability of those opportunities, therefore, fell to the school system. As a result, the amount and rigor being packed into an educational experience, as well as the length of time students were expected to attend, has also increased in intensity. 
While responsibilities for students and school systems have continued to increase, noticeably less change has occurred in the structure of the school model. Additionally, as a growing number of students are making the decision to leave school prior to acquiring a diploma, suspicion of possible dysfunction within the school system increases. Yet, finding a means for reversing the dropout trend has continued to prove elusive. For some reason, increasing numbers of students are disengaging and dropping out while the primary focus of school policy and practice has continued to be on statistics and not the students' perspective.

Recent numbers indicate that depending on the region of the country, as many as two-to-four out every ten of our students are not making it to high school graduation. A $60 \%-80 \%$ success rate should never be considered an acceptable record when it comes to the educational needs of our young as it suggests a potential compromise of our country's ability to compete globally equal to levels previously enjoyed. A decline of this nature could have costly consequences pertaining to opportunities for wealth and independence otherwise available to those who persist through graduation. With this in mind, the intent of this study is to investigate the dropout dilemma through the lens of individuals who have dropped out in order to discover why it is occurring. This also has potential for determining if a need exists for policy and practice changes that could have a positive impact on schools, our students, and the country as a whole.

Often called the silent epidemic (Milliken, 2007, p. xxi), school dropout sometimes seems to be one of those topics most people would simply prefer not to talk about. In some instances, school dropout is viewed as expected and inevitable for certain students in our schools. However, there is much more to the dropout dilemma than 
merely that which some take away from the potentially frustrating work involving students at-risk of failure. This was the view of Freire (2005) who cautions that in reality students do not simply drop out of school for no reason at all as if they just decided not to stay (p. 2). Everyone stands to benefit if the school dropout problem were eliminated. This could be realized as resources previously needed to support dropout-related dependency on social programs could be re-directed to support other important public system initiatives.

While espousing to be a society that is one of the more powerful and prosperous on a global scale, much of which can be attributed to an emphasis placed on such things as the importance of a strong educational system, much remains to be done to understand the issue of school dropout issue. If left unaddressed, however, this situation could easily continue to deplete the resource coffers of social services and overall economic circumstances of the country, as well as compromise the status of the previously mentioned international standing in a very short time.

From a financial standpoint, it is estimated that the average dropout will earn approximately $\$ 130,000$ less over the course of his or her lifetime than a typical graduating counterpart. This disparity could equate to millions of lost wages and result in significantly decreased tax revenue dollars thus available for other legitimate uses. It has also been estimated that "transforming just one student from a dropout to a graduate could yield as much as $\$ 200,000$ in higher tax revenue and savings over the course that person's life" (Layton, 2010, para. 18). In accordance with a report from the National Public Radio broadcast (2010), it is estimated that West Virginia dropouts from the 20092010 school year alone will cost approximately $\$ 55$ million in overall healthcare 
expenses over the course of their lifetime. From an academic standpoint, the United States as a whole has continued to fall in international ranking. In addition, economic circumstances throughout the country suggest that growing numbers of American citizens are expected to fall below the poverty level, require public assistance, and become a drain on increasingly limited resources.

Having left school prematurely, many of those who decide to dropout find themselves without anything to occupy their time and no employment opportunities. According to Barton (2006) "at the same time high school completion rates have fallen, labor market prospects for dropouts are becoming increasingly dire” (p. 15).

Understanding the Dropout. While researchers have previously viewed the dropout as a unit of study, seldom have they elicited the dropouts' story from the dropouts' perspective. Consideration should be given to an investigation of potential contributors to decisions to dropout through the lens of some who have previously done so. Bennett (2011) suggests this when stating:

It is possible that problems faced by children grow out of conflict between their worldview and the school's culture, or of negative prejudices on the part of teachers and classmates. It is also possible that their failure is due to a mismatch between teaching and learning styles, or to some special personal qualities that need to be understood. Teachers must be sensitive to all the possibilities, which is not an easy task. Although teachers often have no idea about what their students' home conditions are like, they make assumptions. (p. 282) 
Some of the most descriptive characteristics of an at-risk student as well as potential dropouts include such things as: coming from low-income or single-parent families, earning poor grades in school, frequent absenteeism, frequently changing schools and, of course, experiences of marginalization. Also included should be consideration of such things as low performance and grade retention. Additionally, Bennett (2011) cautioned that "students identified as having emotional and behavioral disabilities may also be some of those who are more likely than not to be receiving unsatisfactory grades, who may drop out, and who may be incarcerated" (p. 282).

Much of the research available on the topic of school dropout looks at the traditional school system and alleges the existence of a disconnection between it and a dysfunction of certain students. Primary indicators of potential dropouts identified as early warning signs include: Poor Attendance; Behavioral issues; and Coursework difficulties, sometimes referred to as the ABCs of dropout prevention (Legters and Balfanz, 2007, p. 20). As a part of an article on finding ways to get schools back on track with regard to graduation, Balfanz (2011) suggested that when hoping to have a positive impact the school dropout issue an early warning system needs to be in place (p. 56). This early warning system should be linked to a comprehensive prevention and intervention system across the attendance, behavior, and course performance domains.

Balfanz (2011) also suggests that the decision to dropout is usually due to those individuals' inability to perform well and ignores the possibility that school dropout may have something to do with components of the process of schooling as a contributing factor. Although the ABCs of school dropout prevention have been identified as the primary indicators for the occurrence, there seems to be a void in deeper investigations of 
what lies behind each of these factors. Information of this sort may be revealed through conversations with the dropouts themselves.

There has been far less information that explores possible reasons for school dropout through the lens of the student. It may be beneficial for the instructor and student to collaboratively investigate possible causes for the alleged primary indicators for potential school dropouts. In a recent study Corrigan and Chapman (2008) focused on the benefits from trust established between teachers and learners and reported that when it comes to instructional effectiveness, rather than considering what could accomplished collaboratively, in a number of instances instructors typically overlooked potential benefits from doing so.

In addition, another such recommendation presented by Freire (2005) confirmed this view when he cautioned educators about the importance of connecting with the student learner. Freire's (2005) recommendation included the importance of taking the time to hear what others we meet may have to say, without being prejudiced by who they are or their academic standing. In addition, he felt it was an individual's duty to do so without any imposed sense of elitism as this is more in line with the concept of a democracy (p. 72).

There can be any number of contributors to attendance issues beyond mere truancy. Irregular attendance, either as absences or tardiness, may be the result of inaccessibility or differences in familial priorities and needs. It does not seem likely that students simply decide to stop attending school as suggested by this information. As advised by Freire (2005), one should always consider the possible poor conditions to which many students of schools in marginalized areas of the city are subjected. 
Likewise, we should not overlook such things as the precariousness of their living conditions, deficiencies in food availability, or the day to day limitations regarding opportunities for reading activities and time spent in school (pp. 140-141). In addition, Freire (2005) reminds us that understanding of the scope of the violence and death to which students are often subjected should be sought by those who work with them (pp.140-141). It is important to first understand some of the intricacies of a student's circumstances and his or her ability to participate in activities before assuming that their lack of doing so is willful or defiant. It is also important to consider the cause of problematic behavioral issues. Doing so can identify whether they are the result of malice and forethought or a reaction from stress brought about by the pressures of some external influence.

Equally important would be recognition that while coursework failure is seen as another of the predictive indicators for potential dropouts, it could be informative to investigate if and how responses to identified deficiencies might serve the needs of the learner in question. This was indicated when Freire (2005) states:

It is necessary, however, that teachers understand that the students' syntax; their manners, tastes, and ways of addressing teachers and colleagues; and the rules governing their fighting and playing among themselves are all part of their cultural identity, which never lacks an element of class. All of that has to be accepted. Only as learners recognize themselves democratically and see that their right to say ' $\mathrm{I}$ be' is respected will they become able to learn the dominant grammatical reasons why they should say 'I am'. (p. 89) 
Recognizing and responding to such characteristics may do a great deal toward minimizing or eliminating what is otherwise compromising a student's ability to actively and successfully participate in his or her school experience. As Freire (2005) also indicates, the breakdown in relationships between an educator and his or her student learners can be one of the worst occurrences for all involved (p. 99). Implied in each of these statements is the importance of including the individual who is consuming said opportunities in discussion about the impact being made on him or her in order to better understand it.

It may beneficial to all concerned to include inquiry with the students themselves as to what is, or may have been contributing to decisions to drop out. Freire (2005) seemed to understand this when he indicates that:

As educators charged with the responsibility to ensure that our children are provided an appropriate educational experience, it is important to take seriously the need to become familiar with our students' realities. Without doing so, our access to how and what they think and learn will be difficult to achieve and any successful academic progress will be significantly compromised if not impossible. (p. 102)

Increased compulsory school age requirements have been initiated to address the problem. This may afford schools more time to try to address some of the issues. However, simply mandating a longer requirement for students to remain in school with the hope that this will discourage students from dropping out may be naïve. Inviting former school dropouts to discuss their educational journeys offers potential for helping 
to improve understanding of the issue of dropping out. Doing so is the underlying goal of this study.

\section{Origin of Study}

As I revisit various aspects of my past experiences; as a teacher and administrator in the public school sector, subsequent post-graduate employment responsibilities, and my more recent return to higher education to pursue a doctoral degree, my understanding of how the typical educational program should work has been influenced. It seems that my perception of reality and perhaps what I have recently come to understand about the educational process is what Webster and Mertova (2007) call a personal "sea change" (p. 28).

Over the course of my career in public education, various opportunities have presented themselves that have contributed to this personal sea change. As a teacher and principal at the elementary level, it was clear that particular students were not performing as expected in accordance with his or her grade level. When this was discovered any number of responses typically occurred that did little to actually assist in reversing the students' trajectory for success. The fact that the system seemed to move forward without ensuring that everything that could be done was indeed put into motion continues to concern me. As an educator, we are expected to ensure that our students can be successful. Unless professional educators and parents come together to discuss possible contributors to a child's problems, little progress can be expected. In such a circumstance the potential for student failure and subsequent decisions to drop out of school will remain ever-present. 
Realizing this prompted my interest in the growing dilemma of school dropout as well as in learning how we might address the issue. Contributing to this interest were a few chance meetings with an individual who, without provocation, shared that he had previously dropped out of school. This individual stated that his decision to drop out was because, "every time I asked for help, nothing was ever done", (K. M., personal communication, Fall 2009). As a result, some of what I felt during each of these chance encounters with this self-revealed former dropout included a sense of guilt and embarrassment. Listening to his story it became apparent that the support system that he previously needed had failed him.

As I reflected on what I had gained from the stories shared by this individual, I was reminded of previous attempts to address the problem that occurred during my work in the public school system. These were in the form of meetings designed to bring together representatives of community organizations felt to be closely involved and or responsible for the oversight of educating the students from the local school district. Those invited to attend this forum included: the Superintendent of Schools, central office administrators, the Director of Attendance for the county school district, principals, school counselors and the Faculty Senate Chairperson from each school. Additional invitees included representatives from the county Department of Health and Human Resources responsible for collaborating with the Director of Attendance for the local Board of Education, the Circuit Court Judge for the county district, and his Prosecuting Attorney and County Probation Officer.

During the initial meeting it was my job to facilitate discussion and elicit clarifications regarding which organization would be responsible for each step in the 
process being established. It was believed that without this assurance, attempts to assist identified at-risk students would continue to be ineffective. Unfortunately, however the assumption of a central commitment to what should have been on-going agreement was not sustained. This resulted in a significant gap in data collection as well as loss of focus and progress pertaining to the dropout issue in the county.

School dropout has become something to be expected, a situation that makes arresting the trend all the more difficult. Many professional educators tend to brag about their alleged ability to identify students who are destined to drop out well before these students are eligible to do so. This inappropriate expression of pride is often accompanied by a lack of action to prevent the assumed inevitability. Boasting of this nature contributes to little or no change on behalf of the students at-risk of failure.

In some instances parents may contribute to the school dropout dilemma when remaining silent about the importance of staying in school. This silence can actually encourage their child to dropout. Consequently both parent and child settle for what feels at the time to be an easier means to bringing an end to possible on-going frustration at school and at home. It is important, however, to recognize that some parents simply do not have the knowledge to effectively combat the frustrations that occur when their child is constantly experiencing difficulties at school. This can be especially true if parents were previously unsuccessful with their own school experiences.

As Albert Einstein once suggested, a practice of doing the same thing and expecting a different result is the definition of crazy. However, the practice of soliciting input from, and responding to, our students' constructed meaning of school and dropping out would assist service providers in preparing to support students at risk. 
While reading numerous texts pertaining to school dropout and possible causes, I was influenced about the importance of seeking information from those who are living the experiences being studied. One very influential example of this process of "researching lived experiences" was introduced by VanMann (1990). Further demonstration of this particular process was done by Kozol (2006) through his study of homelessness in America entitled, Rachel and Her Children. Kozol's (2006) study delves into the experiences of being homeless through the constructed meanings of homeless individuals. As a result others are provided a far better understanding of what it means to be homeless. Reflecting on Kozol's work, I realized the importance of asking individuals who have previously dropped out of school rather than persisting through high school graduation about their life journey. I believed that exploring this realm through the constructed meaning that each dropout may share could reveal potentially overlooked knowledge about the experience of dropping out.

\section{Purpose of Study}

The purpose of this study is to understand dropping out through the lens of school dropouts. As the potential for students to contribute understanding of their own circumstances can often be overlooked, the contribution that they may make could be extremely revealing and actually be the missing link when it comes to understanding dropping out of school. Information of this nature could also be helpful in assisting educators and educational policy makers when making decisions pertaining to resource allocations. In addition, it could assist with decisions regarding more effective ways to prevent at-risk students from dropping out. 


\section{Research Questions}

This study is framed within a constructionist epistemology, as a social constructivist perspective may provide a better understanding of what contributes to students' decisions to drop out of school. Information of this nature may only be available through the stories of dropouts and their perspective, or constructed meaning, of experiences related to their educational journey that ended prematurely. Without this information, others can only speculate about causes for what is often called the silent epidemic. Assumptions alone rarely result in needed understanding of given circumstances.

Freire (2005) once reminded,

One of the challenges for progressive educators is not to dismiss the possible contributions available from students considered to be at risk of failure. Their socio-economic status, living conditions, or appearance should not influence our decision pertaining to the value of what they may have to contribute to our search for understanding them. (p. 120)

With this in mind, the research questions to be used to guide this study are:

1. What contributes to an individual's decision to leave formal education prior to graduation?

2. How does the decision to leave school early affect the later life of a school dropout?

\section{Significance of Study}

As cautioned by Freire (2005):

It is important to keep in mind that it would be ill-advised for a nation to credit itself with such attributes as having a wild passion for knowledge without also 
reinventing itself and without consideration of taking risks in creative ways. (p. 69)

This should include re-thinking how schools should respond to the needs of students who may be at risk of school failure. Important contributions from this inquiry should expand understanding of the school dropout dilemma. Understanding that is possible by reflecting on the dropout's constructed meaning of dropping out should also assist in identification of appropriate instructional delivery strategies, policies, and practices for meeting student needs.

Additionally, it has the potential for ensuring the presence of positive emotional connections between each student and others in his or her school environment. By understanding the perceptions of the at-risk student, appropriate professional development concepts might also be identified. As a result, chances for better decisions pertaining to academic support and instruction for students at-risk of school failure could set the stage for a programmatic sea change to also occur. In addition, this research holds significance for the field of education and future researchers' view of dropping out.

Dropping out of school is typically viewed as the result of failed educational experiences. One consequence of dropping out is usually an increased burden on society. Further, the cost of one person's decision to drop out of school potentially extends beyond the need for more social programs and jail cells to health-related ramifications. This was referenced by Freire (2005) who indicates that decisions to drop out of school are typically not something that occurs overnight, but instead evolve over time (p. 2). As a result, this study is intended to increase our understanding of the dropout dilemma through information gathered from stories shared by school dropouts. 


\section{Summary}

As suggested by Barton (2006):

The growing demands for high school reform have emphasized the need for higher achievement levels for students who graduate from high school. ... Any reform initiatives that do not also make inroads on the dropout situation can hardly be considered successful. (p. 17)

Not understanding the school dropout dilemma can be exacerbated when we fail to seek information from those who possess expertise about the topic. Who better to assist with this understanding than those who have experienced it? Likewise, it is important not to dismiss others' ability to contribute knowledge simply based on perceptions we may have of them.

Instead, it is important to ask what people may know about a given topic in order to ensure that available understanding can be gained. This is precisely what has been missing in previously conducted research regarding the growing dilemma of school dropout. As a part of this work, I discuss issues that are part the school dropout dilemma. Included are critiques and cautions by individuals considered to be some of the giants in the field pertaining to the importance of establishing a trusting relationship with our students. Yet, much remains to be understood about the topic of dropping out.

All too often students are giving up on their educational potential. It may be possible that the very program structure intended to "enroll, engage and educate youth to be productive members of society" (Alliance for Excellent Education, 2009), is actually preventing some individuals from being successful. This, too, is yet to be determined. 
A great deal of effort has been invested in finding reasons for students' decisions to give up on their pursuit of a high school diploma. The conventional view is that primary contributors for school dropout include: poor attendance, inappropriate behavior, and unsuccessful coursework, or some combination of the three. However, these primary contributors to school dropout should be considered pieces of the puzzle and fall short of explaining the full picture of the dilemma. It is also important not to make assumptions based on a limited understanding of the school dropout issue. Additional information pertaining to dropping out can be obtained by simply asking the dropouts who have experienced the circumstances that brought about their decision to do so. My interest in studying the dropout dilemma through the lens of some who have ended their educational journey as a dropout was prompted as a result of this potential for discovery. In addition, I am hopeful that the work completed through this study will provide a deeper understanding of what dropping out means. 


\section{Chapter Two: Literature Review}

In this chapter I provide an overview of literature and research used to explore the phenomenon of dropping out of school. It includes a definition of dropping out and an explanation of the characteristics considered to be typical of the school dropout. In addition, a review of various perspectives of dropping out is provided. This is done as a means of comparison between what may be considered contemporary determinants for dropping out and those often overlooked.

Having addressed the topic and definition of dropping out, this chapter follows with an address of the systems theory used in this research study to investigate dropping out through the lens of school dropouts' life experiences and their constructed meaning of those experiences. Further, explanations of Bronfenbrenner's (1979) theoretical perspective introduced through his work entitled, Ecology of Human Development, as well as Jean Piaget's Theory of Cognitive Development, in particular his proposed stages of equilibrium and disequilibrium, upon which this study is based, are overviewed. Finally, an overview of what can be found in Chapter Three - Methodology of this study is provided.

\section{Introduction}

Studies conducted to date that focused on school dropout have addressed the topic in a variety of ways, included in research reports, journal articles, and book chapters. Information of this nature has been delivered as empirical or conceptual in nature. Of particular interest is that the majority of the available research has focused on student attendance, student behavior or academic performance and the influence these characteristics can have on students' ability to be successful in school and decisions 
regarding their pursuit of a high school diploma. Legters and Balfanz (2007) refer to these characteristics as the ABCs of school dropout prevention (p. 20).

While available literature on the phenomenon of dropping out of school can be helpful in recognizing the issue as problematic, what seems to be missing from the investigation of the school dropout dilemma is an effort to delve into the issue through the lens of the actual dropout. Therefore, in addition to seeking labels for the typical dropout, I believe that investigating the school dropout dilemma through the lens of those who have lived the experience of dropping out offers opportunities for understanding the underlying contributors to this phenomenon. It is in that vein that this study is intended.

\section{A Method of Searching the Literature}

In order to identify the literature that was available at the time of this inquiry, I began an investigation of resources primarily through the Ebscohost electronic library of academic materials database. When conducting this initial search, I used the categories: “school dropout”, “dropout prevention”, and "high school dropout.” Subsequently, as selected articles began to suggest additional terms that seemed to be indicative of more current terms for the school dropout dilemma being investigated, I included the additional search term of "early school leaving." Further, in an attempt to gain a better sense of how the school dropout issue may have been addressed during more distant periods of our country's history as opposed to more recent times, my search also focused on issues such as longitudinal views of school dropout, recommendations for school reform efforts, and the impacts of these reforms on potential dropouts.

My search was focused on articles that were categorized as qualitative rather than quantitative. This was done as my interest was in investigating the phenomenon of 
school dropout through the dropout's lens and his or her constructed meaning of experience, rather than tracking the number of instances of early school leaving. For the most part, articles that were selected were identified as qualitative by the authors themselves. I did not include studies that used mainly quantitative data.

Throughout my initial search, I did not identify authors by name. However, as some of the scholars were cited in multiple studies, my search included investigation of additional work in which those individuals may have been involved. This was done in an effort to broaden my awareness of their contribution to better understanding the school dropout dilemma.

The majority of the articles reviewed included statements within the abstract that clarified such things as the purpose of the study and the research question(s) used to drive that investigation. As a result I was able to narrow my review to the reports with a focus similar to my study's research questions. This was not done to dismiss the potential value added contribution by the articles believed to be dissimilar to my research focus. Rather, it was my intent to keep the focus of my study as specific as possible in order to orient potential readers.

\section{A Brief Longitudinal Consideration of the School Dropout Dilemma}

Although the No Child Left Behind Act of 2001 (NCLB) has provided a renewed focus on those students who choose to leave school early, school dropout is, in fact, not a new phenomenon. For decades, concern about how to address the dilemma of early school leaving has baffled all stakeholders including educational policy makers, school personnel, family members of dropouts, and in many instances, the dropouts themselves, albeit in different ways. Identifying the ways in which to reform schools so that all 
students are able to complete their educations through high school graduation continues to be an issue schools struggle to address and some feel that how we might eliminate this dilemma may always remain a mystery.

As early as the 1900s, when more formalized schools were being constructed in an attempt to accommodate the growing numbers of students, only about one in ten students remained in school through his or her graduation from high school, (Tozer, Violas, \& Senese, 2007). Since that time, numerous studies have embarked on attempts to discover ways to address the issue of school dropout and understand what influences students to leave school early. According to a study conducted by the Kansas City Schools (1946), "Dislike of school, dislike of subjects, and ways in which the school can be more helpful points unmistakably to the teacher as the major factor in determining the pupil's like or dislike of both school and subjects and in causing his withdrawal from school" (pp. 53-54).

Subsequent to the Kansas City study, Gragg (1949), challenged the public school system to discover the potential reasons for a student's choice to leave school early, rather than simply focusing on labeling and counting students as dropouts. He also suggested that, "If one wishes to do something about dropouts, he must work on the situation well in advance of the time the pupil leaves school" (p. 31). Thus, the dropout dilemma was identified as problematic early in the twentieth century, but we have yet to identify and implement resolutions that address the needs of all students.

Clearly the issue of school dropout is not a new phenomenon; instead it continues to baffle scholars and practitioners in the field of human development, educational policy and curriculum and instruction. A number of early studies suggested a need to focus on 
preventing students from leaving school early, rather than exploring the factors that might be contributing to the phenomenon. A study by the National Child Labor Committee (1951) credited school superintendents with "Laying the rise in dropouts to draft expectations, restlessness and insecurity" (p. 148). The Committee suggested that students needed better guidance and counseling and school officials needed to consider the use of promotional devices to encourage students to stay in school. However, subsequent studies focused on exploring the experiences and circumstances that might contribute to a student's decision to leave school early, as well as and the potential impact of the decision to drop out on the individuals who choose to do so, as well as society in general including: Piaget (1967), Bronfenbrenner (1979), National Studies (A Nation At Risk, 1983), as well as work by ReMcDill, Natriello and Pallas (1985) and Rumberger's (1987).

\section{Toward a Definition of Dropping Out}

According to Rumberger (1987), “A 'dropout' is generally defined as a residual status, indicating someone who has not graduated from, or is not currently enrolled in, a full-time, state-approved education program" (p. 105). Further, "Dropping out of high school culminates a long-term process of disengagement from school and has profound social and economic consequences for students, their families, and their communities" (Christle, Jolivette, \& Nelson, 2007, p. 325). The aforementioned definition reflects the typical understanding of the phenomenon of dropping out of school.

An important clarification regarding dropping out includes the fact that decisions to do so can occur at any time rather than only after one reaches some official age of eligibility to do so. Said official age has traditionally been thought to be once an 
individual has reached his or her sixteenth birthday. West Virginia recently increased the eligibility requirement for dropping out to age seventeen in an effort to reduce the occurrence of dropping out in the state. This was done in response to speculation that if students reach their junior year in high school, the chances for persistence through graduation are enhanced.

In an attempt to build upon earlier concerns pertaining to school drop in the country, the introduction of NCLB further emphasized the need to collect and monitor data pertaining to dropout rates. This initiative also included the recording of graduation rates, summative assessment data, as well as college attendance records as a means for determining adequate yearly progress (AYP). This was done as means to re-emphasize the importance of measuring success in schools and focus attention on the growing achievement gap among a variety of categories including such things as race, students with disabilities, and social-economic status. High school graduation is expected to occur after a traditional four year high school program experience. In this regard a dropout is typically further defined as any student who, once enrolled in a school as a freshman, fails to graduate with his or her classmates from that original ninth grade group.

Although the aforementioned are the typical definitions used for a school dropout, it is also important to recognize that other circumstances can exist that influence significantly younger individuals to disengage from school. While these individuals may not be recorded as dropouts until several years after their disengagement began, a downward spiral that starts at the earlier age can compromise educational opportunities as well as potentially impact an individuals' financial potential (Christie, et al., 2007, p. 235). There are ramifications related to the school dropout phenomenon that should not 
be overlooked. According to Christle, et al. (2007), "Dropping out of high school is a serious problem, not only for the individual, the school system, and the community, but also for society" (p. 325). In addition, Christle, et al. (2007) continues this caution by stating:

The relationship between school experiences and dropout has rarely been considered. The contribution of the larger community also has been overlooked as contributing to the risk of dropping out of school (e.g., a business leaving the area, resulting in increased unemployment and poverty and a negative impact on local schools). (p. 326)

\section{An Investigation of Multiple Perspectives of Dropping Out}

Boostup.org (2013) provides current data pertaining to the national and statespecific dropout rates. Table 2.1 depicts that information as it pertains to West Virginia for recent (2012) dropout rates as well as a comparison of the overall U.S. dropout rate and the average dropout rate for the state of West Virginia between 1972 and 1984 and is provided merely as a frame of reference regarding the change, although only slight, over time.

Table 2.1

U.S. vs. West Virginia's Dropout Rate Statistics (1972-1984 and 2012)

\begin{tabular}{ccccc} 
Average Dropout Rate & $\underline{1972}$ & $\underline{1982}$ & $\underline{1984}$ & $\underline{2012}$ \\
United States & $22.8 \%$ & $27.2 \%$ & $29.1 \%$ & $25.0 \%$ \\
West Virginia & $28.1 \%$ & $25.2 \%$ & $26.9 \%$ & $23.0 \%$ \\
\hline Sources: & Boostup.org (2013, Dropout Rates), and U.S. Department of Education (January 1984 \& 1986), State \\
Education Statistics, Washington, DC: U.S. Department of Education. [As reported in: Rumberger, R. W., (1987). \\
High school dropouts: A review of issues and evidence. Review of Educational Research, 57(2), 101-121.]
\end{tabular}


This study intends to investigate dropping out through the perspective of individuals who have actually done so. Similarly, I have found that a number of other researchers have considered this option when investigating the dropout phenomenon. As a result, the following includes some of what may have already been discovered.

\section{Dropping Out of School - A Socio-Cultural Perspective}

Gallagher (2002) felt that it would be important to consider students' socialcultural perspective as a means for discovering what she considered "a greater understanding of the meaning of dropping out within the context of school" (p. 36).

Accordingly, Gallagher (2002) states:

Rarely are non-graduates contacted for information about their academic histories.

Though official reasons for dropping out are dutifully assigned to each student by administrators or their designees according to the codes provided by the State Department of Education, local school officials often understand little about why students really left school. (p. 36)

While the phenomenon of dropping out of school may have been occurring since the beginning of the formalized schooling opportunity concept was initiated in the U.S., concern over the negative impact that choosing not to persist through graduation has increased over time. As such, monitoring of records that reflect the graduation and dropout rates of America's schools was something that was practiced as early as the 1940's and 50's, when more attention was being given to the importance of skilled labor that needed to be available and typically resulted from those completing high school. Since that time, as a result of such reports as A Nation At Risk (1983), our country's status with regard to educational success, etc., introduced a more significant attempt to 
ensure that schools were producing graduates as opposed to losing students through school dropout. It seems, however, that although those efforts were intended to bring about significant change with regard to the numbers of students successfully completing a high school experience, in many instances schools were simply not producing the number of graduates that were expected. Hence, the more recent attempt to bring that goal to fruition through the passage of NCLB.

As mentioned previously, attention to details pertaining to whether or not schools were maintaining or losing student enrollment has taken a variety of forms. In some instances, school dropout was not seen as a concern simply because not everyone was expected to participate in available schooling opportunities in the first place. Subsequent to that era, even though schooling was offered to the general population, expectations for everyone to remain in school after having received the basic skills needed to function in the labor market were rare. Hence the more recent interest in understanding the phenomenon of dropping out.

\section{Dropping Out of School - Students' Perspective}

Phelan, Davidson, and Cao (1992) report “Students' perspectives on school and learning, rather than being at odds with those of teachers, are remarkably similar" (p. 695). Further, it was pointed out by Phelan et al. (1992) that:

A great deal of attention has recently been focused on conditions outside schools that affect students' academic performance and their engagement in learning. Divorce, poverty, gang involvement, teenage pregnancy, immigrant status, substance abuse, and myriad other social factors are frequently cited as reasons why so many adolescents fail academically or drop out of school. . . A focus 
solely on external conditions diverts energy and attention from the circumstances within schools and classrooms that can have a positive impact on the economic circumstances that place them 'at-risk' of school failure. (pp. 695-696)

In addition, Phelan et al. (1992) report "While high-achieving students turn frequently to their friends and parents for assistance, low achievers withdraw or allow priorities other than schoolwork to take precedence ... falling further and further behind" (p. 700).

\section{Why Dropouts Do So}

There are many explanations for dropping out of school. In fact, as indicated by Rumberger (1987), "No one really knows what causes students to drop out of high school. Dropouts themselves report themselves report a number of different reasons for leaving school, with marked differences reported by different social groups" (p. 109). What seems to be fairly universal, however, is the belief that because students are not willing to work hard and persevere, they place themselves at risk for failure and their frustrations resulting from that failure cause them to give up. This issue can be cyclical in nature. When school work is difficult or boring it can be frustrating, and as frustration or stress occurs one often tries to find distance from the uncomfortable situation. Frustration resulting from experiences of difficulty can also be expressed in acts of inappropriate behavior.

As mentioned earlier, Legters and Balfanz (2007) characterize these circumstances as the ABCs of school dropout prevention (p. 20). However, according to a recent report by the Boostup.org organization, 
For students to succeed, they need to be in school. Many people think that attendance only matters in the higher grades, but that's not true. Consistent attendance is very important for younger students too. An estimated 5 million to 7.5 million students miss 18 or more days of school each year. That's about 10 to 15 percent of U.S. students. (Boostup.org, 2013, facts)

It is also important to remember that "When students leave school, it's usually not a decision they made overnight. Typically it's a process that happens over time" (Boostup.org, 2013, facts).

Others tend to see the problem of school dropout as systemic or programmatic failure. During the past four decades a good deal of research was done with regard to the effective schools initiative by Lezotte (1997) and reported in his book, Learning For All. These individuals share that a significant amount of information is already available pertaining to what needs to be done with regard to changing how our school system operates in order to ensure the success of our students. In addition, they reported that the pivotal issue about school reform is not whether one knows what to do or how to do it, rather it is whether or not we have the conviction to make the changes we already know that need to be made (Lezotte, 1997). Rather than blaming either the victim or the program, I suggest that there is far more that can be learned about the phenomenon of dropping out of school by inviting the actual dropouts to the table. This is not a new perspective, as demonstrated by the examples that follow, however, it is one that should be considered and explored more fully. 


\section{Reasons for Dropping Out Often Overlooked or Ignored - Relationships}

According to Powers (2004) "The primary reason why students persist [in school] is because they find their educations meaningful" (p. 6). This is not to indict either party in the partnership that must exist during an educational experience. Not everything interests everyone and everyone has his or her own interests. However, as discovered by Powers (2004) "The most critical people in terms of student success and retention are the faculty" with whom they interact (p. 6).

Powers (2004) also reports, "Folks who have researched student persistence and retention ... have consistently found that faculty influence is key" (p. 6). In addition, Croninger and Lee (2001) indicate that, "Even when students enter high school with a history of academic difficulties, direct guidance and support from teachers can make an important difference in their willingness to persist through graduation" (p. 570). These revelations can serve as examples of some of what we may be missing when attempting to understand the act of dropping out of school in the first place. Further, Hamre and Pianta (2001) found, "The majority of research of teacher-child relationship and school outcomes in the early elementary years has focused on children's socio-emotional and behavioral adaptation" (p. 626). In addition, when investigating why students choose to drop out of school, Drewry, Berge, and Driscoll (2010) found, "Social circumstances that influence a student's tendency to drop out of high school may be related to the level of social capital found in a student's family, or community" (p. 500).

The social capital issue also impacts a student's feeling of belonging and or his or her willingness to attempt association with others in the school. In addition, issues of accessibility to activities, programs, and available supports, if/when needed, can also be a 
compromising circumstance. Issues of this nature are often overlooked when considering reasons for school dropout. However, it is possible that Drewry, et al. (2010) were on the right track when they assumed "Students who have dropped out of school have something important to say about the social components they [students] perceived as being lacking from their educational process" (p. 503).

It was especially interesting to see that their data collection was qualitative in nature and involved analysis of stories of experiences from students who had dropped out, rather than relying on databases generated from such things as statistical reports of dropout trends. Some of their findings suggest that often students who do not have a relationship with members of their families or communities who have the capacity to assist them with endeavors to complete school (Drewry, et al., 2010, p. 515). Further, Drewry, et al. (2010) also report, "Students often had access to social capital within their reach but did not use it in a manner that would have been an effective means of helping them to complete school” (p. 515). In addition, Drewry, et al. (2010) indicate, "Although students may not have established relationships with a variety of school-based personnel, these relationships may not be adequate to reduce the tendency to drop out of school. Many of the relationships they described were dysfunctional" (pp. 515-516).

In addition to the aforementioned discoveries made by Drewry, et al. (2010), there are numerous other considerations that contribute to early school leaving. As described by Horvat and Davis (2011):

In determining how to navigate in social worlds, individuals follow their own internalized interpretation of societal rules. .. The habitus provides a 
subconscious understanding through time of the rules of social interaction in a particular field. It is the 'common sense' way of operating in the world. (p. 144) As such, consideration needs to be given to the individual's constructed meaning or interpretation of his or her experiences within the context of that personal habitus.

Croninger and Lee (2001) report, "Although academic risk has the largest impact on the probability that students dropout, social risk is also associated with elevated probabilities of school failure" (p. 570). This supports the need to consider more than the previously mentioned contemporary ABCs of school dropout prevention that were characterized in 2007 by Legters and Balfanz, as it tends to portray those characterizations as inconclusive. Accordingly, Croninger and Lee (2001) also share:

Even when students have access to caring and supportive teachers, the environments in which they live may still overwhelm them and perhaps even the adults upon whom they rely for support. Inequities in the scope of all forms of capital available to students and teachers may partially account for the difference in the high school completion rates of socially advantaged and disadvantaged students. (p. 570)

Therefore, investigating an individual's decision to drop out through shared stories of experiences that occurred while in school as well as at home prior to dropping out could unlock some important clues relating each one's rationale for not persisting through graduation. To that end, I posit that it makes sense to give the school dropout the opportunity to tell his or her own story in order to gain an appreciation of the circumstances that can influence one's decision to drop out. 


\section{Reasons for Dropping Out Often Overlooked or Ignored - Gifted Dropouts}

Hansen and Toso (2007) conducted a study of dropouts from a population seldom considered as one where dropping out of school occurs: students identified as gifted. As a part of this 2007 study, gifted students were offered an opportunity to describe some of their experiences and explore what those students described as, "Low level curriculum and a culture that disrespected them" (p. 31). What Hansen and Toso (2007) found was that "Gifted dropouts showed signs of frustration with school as early as the elementary years, felt disrespected by teachers, were frustrated with busy work, and resented that teachers confused students who conformed (emphasis added) with students who were gifted" (p. 33).

In addition, Hansen and Toso (2007) report, "Most [dropouts in the study] lacked a sense of belonging at school, positive relationships with teachers, challenge, and respect for values held in high esteem at school (e.g., popularity, conformity, and sports)" (p. 34). These and other studies have revealed that not all dropouts have the same characteristics such as those typically suggested as being universal (i.e., ABCs) of the school dropout. Beyond this consideration of individuals' relationship with their school experiences, I feel that timing for decisions to dropout cannot be assumed to occur at a certain age.

As a part of their exploration of dropping out through the stories shared by gifted dropouts, Hansen and Toso (2007) discovered that "Most of the dropouts reported difficulties as early as elementary school" ... “[Gifted dropouts] reported feelings of insecurity about friendships or acceptance by classmates, and lack of motivation to do busy work (emphasis added)" (p. 36). Additional explorations with gifted dropouts, Zabloski and Milacci (2012) also discovered: 
[Gifted dropouts'] life stories revealed that many times they felt abandoned, rejected, or even abused by those they trusted with their emotion and intellect, and that betrayal may have played a part in their withdrawal from the relationship and eventually from school. (p. 187)

Further, Zabloski \& Milacci (2012) found "The stories being shared during interviews with gifted students who had dropped out emphasized that much of what they saw as boring dealt more with whom they interacted as opposed to what was being done" (p.187). As such, it was "The lack of relationships with others, rather than difficulties with subject matter that seemed more problematic and contributory to decisions to leave school” (Zabloski \& Milacci, 2012, p. 187).

\section{Bronfenbrenner's Ecology of Human Development}

Qualitative inquiry can benefit from this understanding in that there is a difference in the type of thinking that is involved in making sense of what is happening in various circumstances. This is of no less importance when investigating possible influences individuals' life experiences may have had on their decision to stay in school as well as when they believed it was time to drop out. Bronfenbrenner's (1979) Ecology of Human Development is therefore being used as a means for investigating dropping out in order to discover the influences, immediate, indirect, or external, that may have existed in the lives of the participants in this study.

According to Crotty (1998), "Constructivism points up the unique experience of each of us" (p. 58). In addition, one's perception of truth is constructed by that individual as a result to having experienced or interacted within a particular environment or set of circumstances. As such, constructivism is one way of understanding that can result from 
an individual's constructed meaning of experiences with his or her environment and how those experiences are interpreted or defined by the particular individual involved. This process allows the participants being studied to share the constructed meaning of those experiences through his or her unique lens. Therefore, from a constructivist perspective, one means for discovering what makes individuals drop out of school could be to invite those who have actually done so to share information about their life experiences that preceded that decision.

With this in mind, I believe that placing the school dropout at the center of Bronfenbrenner's (1979) Ecology of Human Development model and considering what has been shared will help uncover possible influences on the dropout's decision not to persist in school through graduation. Therefore, this study utilized Bronfenbrenner's (1979) Ecology of Human Development model as a means for investigating shared stories of one's life experiences and the potential influences each had on decisions to drop out of school. This model offers an interesting interpretation for studying potential influences one's environment has on his or her development. Further, it proposes that individuals are typically influenced either by immediate or indirect interaction with circumstances of their surroundings.

One conceptualization of his theoretical model consists of a series of concentric circles that are nested and contain the individual or subject being studied within the innermost circle. As such, the inner-most circle, or microsystem, represents influences from more immediate surroundings, the mesosystem involves a combination of two or more microsystems, and the more distant outer surrounding circles represent what he called the exosystem. Bronfenbrenner (1979) builds upon work Lewin (1951) referred to as life 
space or psychological field and who believed the position the environment of greatest relevance for scientific understanding of behavior and development is reality not as it exists in the so-called objective world but as it appears in the mind of the person (p. 23). Bronfenbrenner (1979) also provides the following definitions for the sub-parts of his theoretical model as:

1. Microsystem - A pattern of activities, roles, and interpersonal relations experienced by the developing person in a given setting with particular physical and material characteristics.

2. Mesosystem - The interrelations among two or more settings in which the developing person actively participates (such as, for a child, the relations among home, school, and neighborhood peer group; for an adult, among family, work, and social life). Typically occurs when the developing person moves into a new setting.

3. Exosystem - One or more setting that do not involve the developing person as an active participant, but in which events occur that affect, or are affected by, what happens in the setting containing the developing person. (pp. 22-25)

As a result, Bronfenbrenner's model allows the subject of a study (e.g., the school dropout) to be placed in the center-most circle (microsystem) in order to consider interactions between the individual and possible external influences.

Figure 2.1 illustrates a conceptualization of Bronfenbrenner's theoretical model of the Ecology of Human Development and includes various components and labels. The external categories more immediately surrounding and influencing the subject (i.e., the microsystem) are typically considered to be his or her family, school, peers and 
neighbors. Having placed the former dropout in the center-most portion of

Bronfenbrenner's model, one can begin to consider how various circumstances that existed prior to his or her decision to drop out may have influenced the decision to do so. Influences between and among the various components of the microsystem can often be reciprocal rather than one-directional. As a result, it is possible that at any given time, the action of any one component can influence the circumstances of another.

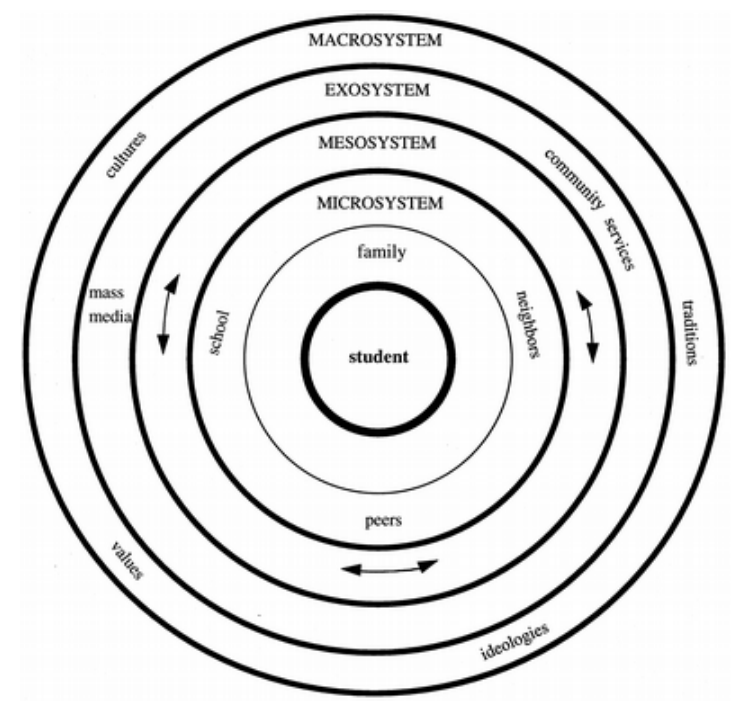

Figure 2.1 - A Conceptualization Model of Bronfenbrenner's (1979) Ecology of Human Development. Image captured from: http://www.google.com/search?q=bronfenbrenner's+theory\&hl=en\&tbo=u\&rlz=1I7GCN

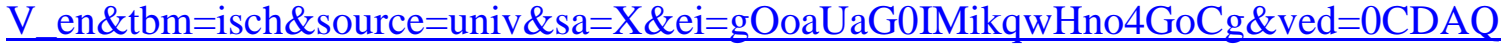
$\underline{\mathrm{sAQ} \& \mathrm{biw}=1280 \& \mathrm{bih}=626}$

Subsequently, still larger circles of potentially influential categories (i.e., components of the mesosystem) exist and encircle the microsystem. As such, the actions of individual components, and or interactions between or among various others, have the potential for influencing any number of the components contained within the entirety of the model (i.e., exosystem). In the instance of this study, once constructed meanings of 
shared stories from participating former school dropouts have been collected, the influences of one component on another can be considered.

I propose that there can be any number of instances wherein occurrences between various components illustrated by the Bronfenbrenner model have influenced decisions to drop out of high school. Therefore, I suggest that there are multiple influences for an individual to decide that dropping out is his or her only option depending on where that individual may be at the time of that circumstance. Additionally, the influence of time, as well as the stages of equilibrium or disequilibrium that are a part of Piaget's Theory of Cognitive Development, need to be considered in addition to the external components of Bronfenbrenner's model. Any combination of the aforementioned influences may explain responses that ended individual dropouts' persistence to high school graduation.

\section{Consideration of Piaget's Theory of Cognitive Development - Stages of Equilibrium and Disequilibrium}

In addition to Bronfenbrenner's (1979) Ecology of Human Development, I believe that Jean Piaget's Theory of Cognitive Development also warrants consideration for investigating dropping out through the lens of the dropout. Addressing this work in summarized form, McLeod (2012) offers an explanation of Piaget's Theory of Cognitive Development that resulted from his [Piaget's] work pertaining to the developmental stages of children (pp. 1-8). As such, McLeod (2012) reflects on Piaget's introduction of a phenomenon that helps explain some of the influences that occur when an individual is attempting to learn new concepts (p. 1). Accordingly, of equal importance was Piaget's belief that those influences can either contribute or serve as a barrier to learning 
(McLeod, 2012, p. 3). As such, I suggest that there is more to be learned about what contributes to decisions to drop out of school.

McLeod (2012), further shares that Piaget also indicated that during certain points in one's learning process the conditions surrounding the introduction of any new concept to be learned can influence skill acquisition. Accordingly, when an individual has acquired specific skills that may be prerequisite to the more current task, he or she typically has no difficulty learning that new skill. As a result he or she is considered to experience a "state of equilibrium" (p. 3). This experience is a part of a normal sequence of skill acquisition. Stress is minimal and the learner is usually willing to continue with additional tasks. When, however, an individual is confronted with a task that requires prerequisite knowledge or skill that has not been mastered he or she typically experiences a "state of disequilibrium" (p. 3). If allowed to remain unchecked, this state of disequilibrium can foster confusion, which leads to frustration that can result in disengagement from the learning process altogether.

McLeod (2012) further credits Piaget with his "Extensive and ground-breaking research on child development and the major impact it has had on teaching and learning practices" (p. 2). This impact was the result of Piaget's introduction of what he [Piaget] called the processes of equilibrium and disequilibrium, an integral component of his work. McLeod (2012) further indicates that Piaget's theory includes three basic components: (1) schemas, (2) processes that enable the transition from one stage to another, and (3) the various stages of development (p. 2).

Figure 2.2 illustrates an example of the equilibrium and disequilibrium stages that typically occur during one's cognitive development skill acquisition spiral. Depending 
on the timing of newly introduced information, one's prior experience or preparation for comprehension of a particular skill influences skill acquisition in one of the two ways: (1) in a stage of equilibrium (when the individual typically progresses successfully and without stress), or (2) in a stage of disequilibrium (during which he or she lacks prerequisite skills or understanding, hesitates and becomes overwhelmed). In some instances the stress level that occurs during a state of disequilibrium can cause one to give up on the pursuit of the new task altogether.

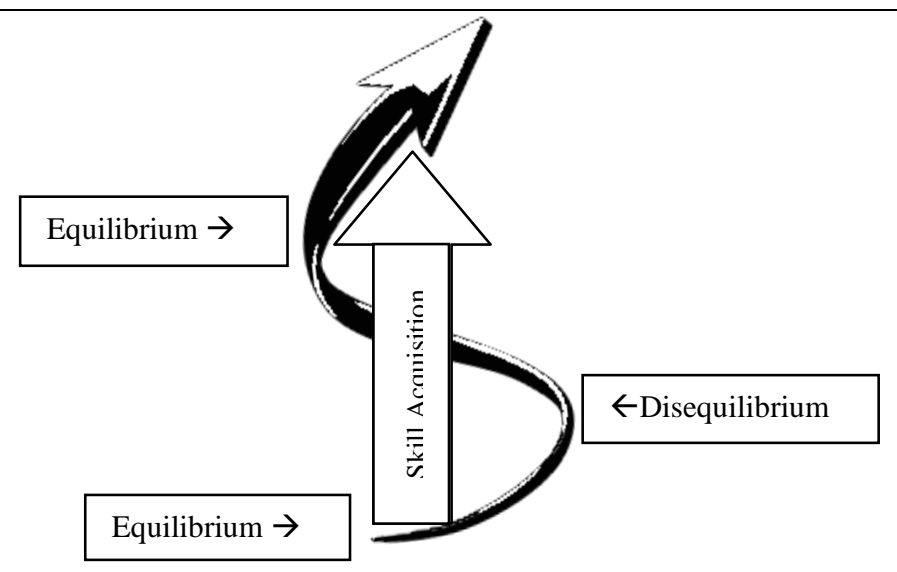

Figure 2.2 - Stages of Equilibrium and Disequilibrium - Piaget's (1896-1980) Theory of Cognitive Development. Progress and speed of movement up the spiral of learning is dependent on an individual's prior knowledge or experience, as well as the timing of introduction and expectations of the new task(s). Being confronted by new tasks can result in a state of equilibrium (i.e., successful skill acquisition as a result of preparedness) or disequilibrium (i.e., disorientation and potential failure to acquire the new skill due to unpreparedness).

\section{Building on the Strength of Two Theoretical Perspectives}

Considering both Bronfenbrenner's theoretical perspective and Piaget's theory pertaining to learning and the influences of external conditions, it makes sense to investigate dropping out through the lens of individuals who have done so including if and or what influences may have existed during their life experiences that dissuaded them from persisting through school to graduation. Both Urie Bronfenbrenner and Jean Piaget invested their life's work studying slightly different yet complementary views 
pertaining to the processes, sequences, and potential influences involving stages of human growth and development. Therefore, this study considers the work of both of those individuals who should be considered to be giants in their respective field when investigating the phenomenon of dropping out.

\section{Summary}

As shared by Christle et al. (2007), "Dropping out of school is a complex social problem for which there is no simple solution.... Dropping out of school is not an impulsive action, but rather a cumulative process" (p. 334). Relationships, circumstances and any number of other contributing factors may influence an individual to decide that persisting in school through graduation is simply not for them. In addition, it is imperative that no one reason be used to explain the dropping out phenomenon, as to do so would be misleading and irresponsible.

The aforementioned demonstrates why it is important that all previously identified and perhaps popular explanations for the phenomenon of dropping out should not be considered as the explanation. Therefore, I submit that investigating dropping out requires a continuum of characteristics to be considered without imposing any one set of characteristics in a universal manner. With that in mind, my study proposes an investigation of a variety of circumstances in an attempt to minimize any potential for generalization. What is intended is the possible discovery of still more explanations for why students may be deciding to dropout. This is being done in an attempt to discover additional ways that school systems might better address the provision of appropriate educational environments that meet the many varied needs of the students enrolled at any given time. 


\section{Chapter Three Content - Methodology}

Chapter Three that follows addresses the materials and methodology portion of the study. In this chapter I cover such things as the purpose of my study, an understanding of narrative inquiry as it fits in qualitative research, as well as the intended participants and rationale for their inclusion. Included are descriptions of my epistemology and theoretical perspectives used to drive an investigation of the dropping out phenomenon, as well as the data collection and analysis procedures that were used. In addition, I provide an overview of the context for this inquiry and the positioning of the intended participants and myself as researcher, as well as my subjectivities, the perceived limitations and proposed trustworthiness of this study that I believe exist. 


\section{Chapter Three: Materials and Methods}

Qualitative inquiry is utilized by researchers interested in gathering a deeper understanding of any phenomenon including human behavior. According to Denzin and Lincoln (2005), qualitative research is "a situated activity that locates the observer in the world" .. . "consists of a set of interpretive, material practices that make the world visible" and turns the world into "a series of representations" (p. 3). In addition, "Qualitative researchers study things in their natural settings, attempting to make sense of, or interpret, phenomena in terms of the meanings people bring them" (Denzin \& Lincoln, 2005, p. 3). Thus, qualitative inquiry is well suited for my study as it is conducted in an exploratory manner and investigates, by way of such things as notes and other data collected through interviews and observations, the inquiry subject's decisions and what may have influenced or prompted those decisions. In fact, qualitative inquiry provided a space in which the perspectives of particular dropouts were shared and explored. Understanding the perspectives of those who made the decision to leave school early is especially important because, as previously addressed in chapter one, Freire (2005) indicates that:

One of the challenges for progressive educators is not to dismiss the possible contributions available from students considered to be at risk of failure, and that their socio-economic status, living conditions, or appearance should not influence our decision pertaining to the value of what they may have to contribute to our search for understanding them. (p. 120)

With all of this in mind, I believe that a qualitative approach was best suited for this study as it offers the potential for better understanding the experiences and 
perspectives of those who have made the decision to drop out rather than persist in school through graduation. Therefore, this chapter addresses the qualitative methodology used to conduct this study and includes a description of the purpose of my study, the research questions used to guide my investigation, an explanation of the social constructionist theoretical framework and constructivist epistemology in which this study is situated, descriptions of the context and participants, along with methods used for data collection and analysis. This chapter also addresses such things as the importance of recognizing potential influences that a researcher's subjectivity may have on the qualitative work being conducted, as well as possible limitations that exist in this particular research study's methods and design.

\section{Purpose of Study}

The purpose of my study is to explore the phenomenon of leaving school early through the lens of school dropouts. I decided to investigate this particular topic as a result of a combination of my personal beliefs about the issue of dropping out of school, previous conversations with former colleagues, and my own encounters with actual school dropouts. Each experience led me to believe that, depending on one's circumstance, the concept of dropping out tends to be understood in very different ways.

What seemed most apparent to me is that when beginning to explore the topic of dropping out, the voices of dropouts did not appear to have been given much attention or they were missing altogether. When asked about their decision not to persist in school through graduation, some of those students who were considered to be gifted individuals voiced frustrations regarding experiences of dysfunction and a lack of valuable positive relationships at school. However, while some research is available that has solicited 
contributions from certain populations (such as gifted students who had previously dropped out) about their perspective on the dropout phenomenon it appears that literature addressing the perspectives from a broader variety of actual school dropouts has been limited. Therefore, seeking information pertaining to early school leaving that gives consideration to what may have prompted a varied school dropouts (beyond just gifted individuals) to do so could contribute to a better understanding of the phenomenon altogether.

During initial review of the literature available on the topic, I discovered that a vast amount of existing research on school dropouts has focused on one of three main assumptions: (1) students' decisions not to attend school regularly, (2) a perception that dropouts are typically known to have poor behavior, or (3) that dropouts simply performed poorly on academic tasks. Legters and Balfanz (2007) named the combination of the three primary characteristics as the "ABCs of school dropout prevention" (p. 20).

While those categories may help identify typical characteristics of those who have previously dropped out, it is my assertion that it is also important to delve more deeply into the underlying contributors to a dropout's decision to leave school early. With this in mind, it is my belief that investigating the occurrence of dropping out through the individual lenses of participants who have dropped out of school prior to graduation has potential to reveal important circumstances not yet identified by previously conducted research studies. The additional information gained through this investigation may increase understanding of the previously identified characteristics of dropping out by revealing possible underlying circumstances. Furthermore, rather than blaming the 
victim, it is important to look for how structures of school may contribute to an individual's decision to leave school early.

To that end, I believe that the stories shared by actual dropouts could reveal previously missing links when it comes to understanding why students make the decision to leave school early rather than persisting through graduation. As such, this work will involve an investigation of participants' life journey experiences prior to dropping out of school and the possible influence those experiences had on their life after doing so. Therefore, my study will be guided by the following research questions:

1. What contributes to an individual's decision to leave formal education prior to graduation?

2. How does the decision to leave school early affect the later life of a school dropout?

\section{Theoretical Perspective: Social Constructivism}

A constructionist epistemology informed my study as I was interested in how my participants made meaning of their school experiences and how these experiences influenced their decisions to leave school early. As such, the constructed meaning or interpretation of the world in which each participant has engaged can assist in better understanding the incidence of school dropout. Constructionism rejects the objectivist epistemology view of human knowledge that suggests that truth awaits us to discover it. Rather, the constructionist epistemology promotes the idea that there is no meaning without the mind. "Meaning is not discovered, but constructed" (Crotty, 1998, p. 42). Guba and Lincoln (1990) indicate, "Knowledge is defined in terms of human constructions, and hence, humans are acknowledged as the creators, not simply the 
discoverers or the receivers, of knowledge" (p. 148). It is the interaction with various contexts or phenomena that prompts an individual to construct what he interprets to be truth about said experience.

In addition, I employ social constructivism as a theoretical framework for my study. This is in keeping with Guba and Lincoln (1990) who state, "Constructivism aims neither to predict and control the 'real' world nor to transform it, but rather to reconstruct the 'world' at the only point at which it exists: In the minds of constructors, human beings" (p. 147). Crotty (1998) adds to this understanding when he indicates "Constructivism points up the unique experience of each of us" (p. 58). Thus, reality and knowledge are constructed by human beings who are situated in particular contexts (Au, 1998; Guba \& Lincoln, 1990). Constructivism, therefore, is a belief that the only reality one can know is that which is represented by human thought. Hence, one's perception of truth is constructed as a result of having experienced or interacted within a particular environment or set of circumstances and how that experience is interpreted or defined in the mind of the particular individual involved.

Crotty (1998) also explains that research in a constructivist vein "Invites us to approach the object of a study in a radical spirit of openness to its potential for new or richer meaning. ... [Constructivist research] is an invitation to reinterpretation" (p. 51). In keeping with this understanding, seeking information through the lenses of individuals who have dropped out of school offers possibilities for reinterpretation of previous notions regarding dropping out as well as additional explanations of what may contribute to individuals' decisions to do so. Further, Crotty (1998), shares that "Our culture influences our constructions and provides us with a certain view of the world" (p.51). 
With that in mind, it is plausible that a social constructivist perspective offers a better way to understand what has contributed to students' decisions to drop out of school, as it will take into account the influence of the cultures/contexts in which the individual was situated. Additionally, the social constructivist perspective offers an opportunity for the researcher to discover more about the individuals' understandings of their experiences and the influence of specific contexts on those experiences and understandings. Therefore, this study also explores the influence of particular setting (e.g., the classroom) on the stories dropouts tell and the ways in which they have constructed meanings of the experiences that contributed to their decisions to end their educational journeys prematurely. As van Langenhove and Harré (1999) indicate, "By locating social phenomena within the places and times of the natural world, the door is opened for the unnoticed transposing of properties of material things and their relations to the social realm” (p. 14). Thus, I offered my participants opportunities to reflect on their respective life experiences and the constructed meanings of those experiences, and encourage them to reflect on the ways in which those experiences influenced their decision to leave school early.

\section{Narrative Inquiry}

According to Grbich (2007), "Much of our communication is through stories and that these are revealing of our experiences, interpretations and priorities" (p. 124). In some aspects, it appears that human beings may be one of the more sophisticated and socially oriented species. This is especially true when it comes to spoken language. As such, humans have developed communication skills that are used to exchange thoughts and intentions through verbal language, a capability unlike any other species. 
Storytelling, both verbal and nonverbal, has been a means for sharing information since before the earliest record of humankind. This has included everything from the exchange of utterances intended to be directive in nature, to pictorial etchings depicting specific events, through modern electronic recordings of messages used for social and educational purposes. Storytelling serves as a means of communication between individuals in order to teach and recall information. It is a means for passing important concepts from one generation to the next in an attempt to ensure that more than those immediately present can benefit from the sharing of that knowledge.

As such, humans are considered to be storytelling organisms who lead storied lives. Furthermore, these stories can be used as a means of better understanding the intent of others (Savin-Badin \& Van Niekerk, 2007, p. 461-464). Patton (2002) tells us, "A variety of information-sharing paths exist (i.e., personal narratives, family stories, ... life histories) and that each can reveal cultural and social patterns through the lens of individual experiences" (p. 115). This form of information-sharing can occur either as a demonstration or simply by telling.

Clandinin and Connelly (2000) help clarify the importance of information-sharing of experiences when stating:

As social scientists, experience is the key term. Education and educational studies are a form of experience. Narrative is the best way of representing and understanding experience. Experience is what we study, and we study it narratively because narrative thinking is a key form of experience and a key way of writing and thinking about it. (pp. 17-18) 
In addition, Labov (2002) defines a narrative of personal experience as "A report of a sequence of events that have entered into the biography of the speaker by a sequence of clauses that correspond to the original events" (p. 2). Further, Hardy, Gregory, and Ramjeet (2009), share, "Narratives are life-based stories, told by one person to another or to other people" (p. 8). Bruner (2004) indicates that as part of study of life as narrative, "We seem to have no other way of describing 'lived time' save in the form of narrative" (p. 692). Hardy, et al. (2009) also tell us, "Having individuals' stories recorded, increases their sense of self-worth and personal validation" (p. 17).

What we know about the telling of stories is that people typically choose specific details based on their understanding or constructed meaning of an experience and their stream of consciousness. In addition, the individuals' consciousness tends to give access to the most complicated social and educational issues, because "Social and educational issues are abstractions based on the concrete experience of people" (Seidman, 1998, p. 1). Accordingly, Seidman (1998) also shares, "Recounting narratives of experience has been the major way throughout recorded history that humans have made sense of their experience" (p. 2).

According to Savin-Baden and Van Niekerk (2007), stories explored through narrative inquiry are a means of understanding experience "As lived and told" (p. 459). These narratives are considered to be life stories told by the individuals who have experienced them and that are reported through their specific lens and are influenced by the constructed meaning that emerges from each. However, Savin-Baden and Van Niekerk (2007) caution that it is important to keep in mind that while undertaking narrative inquiry, "The researcher should acknowledge that people are both living their 
stories in an ongoing experiential text and telling their stories in words as they reflect on life" and "Stories are both connected to, and representative of, identities" (p. 463). As a result, the relationship between the narrative inquiry and the people it focuses on continues to reveal helpful information that enhances understanding of the topic being studied.

Sparkes and Smith (2008) also caution:

The use of narrative study of lives has emerged in recent years as an interdisciplinary effort to write, interpret, and disseminate people's stories to different audiences, with special attention paid to the groups and people whose lives and whose stories have historically been ignored or marginalized. (pp. 309310)

Savin-Baden and Van Niekerk (2007) refer to narrative inquiry as "A means for studying human experiences" (p. 461). Narrative inquiry that includes interviewing former dropouts about their respective life experiences addresses this idea. In addition, Czarniawska (2004) states, “The learning function of the narrative provides the learner with vicarious experience ..." (p. 34). Hence, the constructed meaning that is shared through this process often reveals how an individual has interpreted his or her experiences, relationships, and the possible responses to their environment.

Further, Patton (2002) explains:

Social constructivists' case studies, findings, and reports are explicitly informed by attention to praxis and reflexivity, that is, understanding how one's own experiences and background affect what one understands and how one acts in the world, including acts of inquiry. (p. 546) 
As Sparkes and Smith (2008) indicate, "Narrative constructivism suggests that narratives and people's life stories are psychosocial or inter-subjectively created" (p. 297). This involves the belief that one's mind is influenced by experiences along with the social relationships that occur during those experiences. Sparkes and Smith (2008) also share that from a constructivist perspective "Narrative woven into the fabric of life itself is a cognitive structure that guides action and or is personally absorbed into one's own functioning" (p. 297). Likewise, Savin-Baden and Van Niekerk (2007) indicate that narrative inquiry tends to be, "Positioned within a constructivist stance with reflexivity, interpretivism and representation being primary features of the approach" (p. 460).

Narrative inquiry offers an opportunity for a researcher to appreciate what those lived experiences entailed, albeit vicariously, as a result of hearing the interpretations or constructed meanings available through the shared stories offered by those who have actually lived them. As such, utilizing the narrative approach to studying the occurrence of dropping out of school offers a way to explore the meaning dropouts have constructed from their experiences. Thus, an inquiry that elicits information sharing through stories or narratives is a means for gaining a better understanding of another individual's perception of the experiences being shared.

Studying stories available through narrative information provided by those who have experienced whatever it is that has caused them to disengage from school and eventually drop out could help uncover useful and previously missing information about dropping out. Without this important information, we risk making useless and unproductive assumptions about the subject. To that end, I believe that an investigation of dropping out of school, through the lens of those who have previously dropped out, 
holds the key to discovering previously unexplored and underlying contributors to the occurrence of dropping out. This can be done by using analysis of narratives resulting from interviews with individuals who have previously dropped out of school. To that end, this study focuses on exploring how an individual's understanding of experiences with school may have influenced his or her decision to leave school prior to graduating.

\section{Research Context}

Patton (2002) references work contributed by Lawrence-Lightfoot (1997) as an illustration of the critical nature of documentation of context and organizational culture. Lawrence-Lightfoot's illustration (as cited in Patton, 2002, p. 63) tells us:

By context, I [Sara Lawrence-Lightfoot] mean the setting - physical, geographic, temporal, historical cultural, aesthetic - within which action takes place. Context becomes the framework, the reference point, the map, the ecological sphere; it is used to place people and action in time and space and as a resource for understanding what they say and do. The context is rich in clues for interpreting the experience of actors in the setting. We have no idea how to decipher or decode an action, a gesture, a conversation, or an exclamation unless we see it embedded in context. (p. 41)

Because our lives are influenced by the context in which we live, it is important to be mindful that the stories being shared can offer different explanations for similar decisions. In order to further emphasize this point, Patton (2002) indicates, "Context as a part of any qualitative study is a critical component" (p. 63). With that in mind, it is appropriate to identify individuals from various walks of life (i.e., either having been successful or unsuccessful since dropping out) in order to ensure that the study contains a 
variety of contexts through which the phenomenon of dropping out is explored. The concept of context, therefore, is to be considered an integral component of any qualitative inquiry. What follows is information that addresses (1) a description of the context for this study, (2) an explanation of the purposeful sampling process used in this study, and (3) descriptions of the participants through whom the topic of dropping out of school is explored.

\section{North Central County}

According to the 2010 census, North Central County [pseudonym] has a population of approximately 16,895 of which the county seat records 5,489 of those residents. In addition, information retrieved from the West Virginia Department of Education web-site (2012) indicated that the North Central County school district reported a 2011-2012 school year student enrollment of approximately 2,385 students. The North Central County school district consists of three elementary schools (each serving grades PreK-4), one middle school (serving grades 5-8), and one secondary/technical center-vocational school (serving grades 9-12).

At the time of this study, the latest reported poverty rate (Free/Reduced Meals eligibility) indicated that $50 \%$ of those enrolled in North Central County were eligible for free or reduced-price meals. In addition, the most recently reported (2010-2011 school year) data indicated that $70 \%$ of the students eligible to graduate (Graduation Rate) did so within the expected time frame and that $30 \%$ of the students did not (Dropout Rate).

\section{Western County}

According to the 2010 census, Western County [pseudonym] has a population of approximately 29,211 of which the county seat records 3,255 of those residents. In 
addition, information retrieved from the West Virginia Department of Education web-site (2012) indicated that the Western County school district reported a 2011-2012 student enrollment of approximately 4,997 students. The Western County school district consists of eight elementary schools (serving grades PreK-4), two middle schools (serving grades 5-8), one secondary school (serving grades 9-12), and one secondary/technical center/vocational school (also serving students in grades 9-12).

At the time of this study, the latest reported poverty rate (Free/Reduced Meals eligibility) indicated that $51 \%$ of those enrolled in Western County were eligible for free or reduced-price meals. In addition, the most recently reported (2010-2011 school year) data indicated that $79 \%$ of the students eligible to graduate (Graduation Rate) did so within the expected time frame and that $21 \%$ of the students did not (Dropout Rate).

Table 3.1 is provided for the purpose of illustrating the respective graduation and dropout rates reported for the past five school years for North Central and Western Counties (West Virginia Department of Education website, 2012).

Table 3.1

School District Graduation and Dropout Rate Trend Data

\begin{tabular}{lllll}
\hline & \multicolumn{2}{c}{ North Central County } & \multicolumn{2}{c}{ Western County } \\
School Yr. & Graduation & Dropout & Graduation & Dropout \\
\hline '06 - '07 & $80 \%$ & $20 \%$ & $88 \%$ & $12 \%$ \\
'07 - '08 & $82 \%$ & $18 \%$ & $87 \%$ & $13 \%$ \\
'08 - '09 & $76 \%$ & $24 \%$ & $75 \%$ & $25 \%$ \\
'09 - '10 & $76 \%$ & $24 \%$ & $77 \%$ & $23 \%$ \\
'10 - '11 & $70 \%$ & $30 \%$ & $79 \%$ & $21 \%$ \\
\hline
\end{tabular}

Data contained in Table 3.1 illustrate how both counties experienced a noticeable jump in dropout rate between the 2007-08 and 2008-09 school years. Since that time, the dropout rate has remained at or above $21 \%$ in both locations. However, review of the 
included data suggests that the Western County school district appears to have successfully established a downward trajectory pertaining to the number of students dropping out, while the dropout rate in North Central County continues to rise.

Information of this nature is provided for comparison between the two counties from which the participants in this study have been identified.

\section{Participants and Their Roles}

Patton (2002) addresses the concept of "purposeful sampling" as a means for selecting participants for a study that are viewed as being "information rich" with potential for "illuminating, or offering, useful manifestations of the phenomenon of interest" (p. 40). Information-rich cases are said to be those from which one can gain a significant amount detail pertaining to a particular phenomenon being investigated and are considered useful in gaining a better understanding about issues considered to be of central importance to the purpose of the inquiry.

Criterion sampling, a strategy for purposeful sampling, was used to select participants for this study. The criteria used to identify potential participants included individuals who (a) had resided in a rural West Virginia community for throughout his or her entire lifetime, (b) were enrolled in and attended a public school system in a rural West Virginia community, and (c) who had dropped out of school, rather than persisting through graduation. As such, it was anticipated that the initial context of the stories each participant may share is similar. In addition, participants needed to have been life-long residents of the North Central region of West Virginia.

In an attempt to ensure that multiple categories were included, participants in this study included both male and female candidates, and included: a self-identified former 
dropout who happened to be moving from part-time job to part-time job in an attempt to support himself; a former dropout who after having dropped out subsequently owned, operated, and retired from a successful small business establishment; and two additional individuals who were invited from a list of possible candidates assigned to the regional department of community corrections. In this manner, it was hoped that no single characteristic could be misinterpreted as being the immediate result of a decision to leave school early.

Once the participants were identified, as a part of this effort to capture the essence of participants' stories, open-ended interviews were conducted to elicit the participants' individual recollections of their life journeys prior to their experiences of dropping out. In addition, participants were asked to share a description of their current circumstances. This was done to capture descriptions of their individual life experiences both prior to and after having dropped out of school. Initial contact with potential participants occurred in a variety of ways and a description of the selected participants for my study follows.

One of the participants, Rocky [pseudonym] is a Caucasian male approximately 21-25 years of age. This individual originally made contact with me through a chance meeting, during which he self-identified as a school dropout from the same rural West Virginia School district in which I also happened to have been previously employed as an educator

Our initial meeting occurred as I was checking out of an area store and the cashier indicated that he recognized me as someone who worked in his former high school. My response was to clarify that while I had indeed worked for the school system of which the 
high school in question was a part, I was actually a central office administrator and often visited the high school location. Although our conversation was fairly brief, it included my inquiry as to when he may have been attending that particular school and ended with his sharing that the experiences while at that location were negative and had prompted his decision to drop out.

Subsequent to that initial meeting, approximately one year later, I happened to run into this same individual when purchasing gasoline for my car at a convenience store in a different location. At that time, the previous conversation we had shared seemed to repeat itself as the young man again indicated that he thought he recognized me from his former high school. As a result, I became more interested than ever in pursuing study of the phenomenon of dropping out of school. Inasmuch as this participant actually made contact with me and introduced himself as a previous dropout, his story is an integral part of the life experiences that were to be investigated.

During the second of our coincidental meetings, Rocky shared that since dropping out of high school, he has spent the majority of his time employed in a variety of short term, part-time, low wage jobs and continues to search for employment opportunities of a more stable nature. He also indicated that he was finding it difficult to obtain employment in anything other than a variety of marginal, part-time positions, each of which had offered only limited or non-existent benefits or duration. As a result, Rocky was finding it necessary to move around the North Central West Virginia region constantly in search of additional employment opportunities.

A second participant, Wes [pseudonym], happens to be a relative of a professional colleague. This individual was revealed as a part of a conversation between myself and a 
colleague when discussing my research topic interest. During that discussion my colleague shared that one of her family members had dropped out of a rural school system in West Virginia several decades prior when he was in the eighth grade. In addition, my colleague shared that subsequent to her relative's decision to dropout, he became a successful business owner in a rural West Virginia community. Having revealed this fact, it was suggested that I be introduced to the family member in question and consider him as a possible participant in my investigation of the phenomenon of dropping out.

Wes is a Caucasian male of approximately sixty-seven years of age, is married to his original wife and childhood sweetheart, with whom he shared a home in his hometown location. Wes was the middle child of five children raised by both parents in rural West Virginia. Thus far, I have learned that in addition to perceiving little potential benefit from his time spent in school, at that time circumstances at his home were such that Wes felt a need to find work in order to contribute to the immediate needs of his family.

I also learned that in spite of this early departure from school, Wes was eventually able to establish, own, operate, and subsequently retire from, a small but successful business establishment located in a rural community in which he was born and raised. During that time Wes and his wife of approximately forty-five years, raised two daughters, both of whom have completed their public school experiences and have gone on to pursue college coursework and degrees.

Finally, in order to identify the remaining potential participants for this study, contact was made with the local Circuit Court Judge who is responsible for overseeing a 
number of rural counties located in north central West Virginia. The purpose of this contact was to investigate possible options and procedural guidelines for identifying appropriate candidates for this study. The Circuit Court Judge who endorsed this search is well known and respected both locally and across the state for his expressed, and demonstrated, interest in finding ways to address the school dropout dilemma. Therefore, extensive conversations with him about the purpose of my study were not necessary.

Having discussed our shared interest in studying the school dropout dilemma, I was immediately connected to appropriate support staff of the regional Community Corrections Programs. Because the typical participants in this program have earned a reputation for involvement in some form of illegal activity, it was anticipated that the additional participants would include individuals who reportedly dropped out of school prior to graduation, continued to be between jobs, and who had been sentenced to serve a court-imposed Community Corrections sentence in a rural community of West Virginia. No particular criteria was used with regard to race or ethnicity when identifying possible participants, again so as not to suggest any particular connection exists between those characteristics and the potential for early school leaving.

As soon as a final list of potential participants was prepared, the aforementioned individuals were contacted by of way of further face-to-face introduction or through an initial telephone communication, followed by a letter written to further explain the purpose of my study as well as my interest in having each participate. Once potential participants had been contacted, each was provided an explanation of the process and intent of this study by way of an informed consent invitation letter. Informed consent invitations included a description of the purpose of the study, assurance that there was no 
risk to the participant involved, and a clear explanation that they were free to discontinue informed consent participation at any time and without consequence. (See Appendix A)

Following the establishment of consent, participants were invited to interview sessions during which they were asked to address their individual life histories and experiences. Further descriptions of each participant identified for this study are provided as a part of Chapters 4 - 7 that follow.

Another very important process included as a part of this study required the completion of an application for permission to conduct this research that was submitted to, and approved by, the university Institutional Review Board, formerly known as the IRB and more recently named the Koali-Coeus program (WVU+KC). Required components of the typical IRB/WVU+KC application include: an explanation of the intended purpose and processes to be used in the research study, a literature review that supports the intended study, clarification of the anticipated level of risk to potential participants, as well as clarifications pertaining to the procedures to be used for the collection, storage, and length of retention of all collected data. In addition, copies of all correspondence-related letters (i.e., invitation and consent) between the researcher and the various participants explaining the work to be done, procedures to be followed, and the assurances that a mid-research study option for participants to discontinue participation would be available without consequence, were be included.

\section{The Researcher and His Roles}

In this section I address some of my subjectivities that may have influenced my research including aspects of my own work-related experiences including pre-conceived 
notions about dropping out of school, as well as my initial interest in better understanding the phenomenon. As Patton (2002) points out:

In order for any research strategy to be useful it must be credible. . . Qualitative researchers are often accused of being too subjective as a result of the nature of the qualitative study in that it requires researchers to establish close contact with the subject of the phenomenon under investigation. (p. 51)

Patton (2002) also reminds us of the importance for all researchers to "Adopt a stance of neutrality with regard to the phenomenon under study" (p. 51). Further, Patton (2002) instructs the emergent researcher on the importance of being aware of and honest about one's subjectivities when attempting to establish neutrality by indicating, "Qualitative inquiry, because the human being is the instrument of data collection, requires that the investigator carefully reflect on, deal with, and report potential sources of bias and error" (p. 51).

This is not to suggest that this concept of neutrality carries a requirement for total detachment from the subject being studied as a part of a qualitative investigation. In fact, as reminded by Patton (2002), "Qualitative inquiry depends on, uses, and enhances the researcher's direct experiences in the world and insights about those experiences" ... "[Including] learning through empathy" (p. 51). It is my belief that some of my experiences have contributed to my interest in better understanding the phenomenon of dropping out. Hence, I have developed my own sense of empathy for those who make the decision not to persist in school through graduation. 


\section{Subjectivities and Positioning of the Researcher}

As a result of my previous experiences in the public school system and the responsibilities I had as a part of the positions held during my tenure there, it is possible that my subjectivities and biases have influenced this study to a certain degree. However, my experiences have included more than one vantage point, therefore, contributing better clarity to the lens I used. I have served the public school system as a classroom teacher, as well as a school and or central office administrator for the majority of my work-related career. In addition, I have been both a parent and a grandparent of children enrolled in the public school system for the majority of that time. In each of these capacities, I became increasingly concerned about responsiveness to at-risk students who attend rural West Virginia area schools.

This concern was intensified as a result of disappointment from my having witnessed, or learned about, circumstances involving students at-risk of failure, and what appeared to be routine systemic responses to those individuals that made the decision to drop out. As a result, a personal "sea change" (Webster \& Mertova, 2007, p. 28) has occurred regarding my realization of the importance of better understanding of situations such as this. I now believe that the information actual dropouts can offer with regard to understanding the phenomenon of dropping out has been overlooked. This belief continues to influence my perception of the dilemma resulting when students leave school early, otherwise known as dropping out. In addition, various aspects of my experiences: as a young student, while a teacher and an administrator in a rural public school system, as a part of post graduate employment responsibilities, and my return to 
higher education to pursue a doctoral degree, have influenced my current understanding of things and my perception of reality.

I have always believed that the field of education was where I was intended to be. It simply made sense that learning, and the journey, was where I would spend most of my adult life. During my previous employment experiences, in addition to facilitation of learning for the student learners in my charge, responsibilities included a number of positions that involved the facilitation of learning and leadership of professional colleagues. My role as an elementary school principal involved the provision of professional development opportunities for the faculty. This is not always an easy task when working with some more experienced staff, as they tend not to see change as having any other purpose than to make them uncomfortable. Regardless, it was our responsibility to ensure that the needs of our student learners, as opposed to our own, remained our primary focus.

In many ways, I fear there were numerous circumstances where we failed this seemingly simple task. As I recall, a number of students in our charge simply existed in our school environment as a result. Even though we considered our school to be a place "Where All Children Can Learn," (a fairly popular phrase at the time) these students did not collect the essential tools during their journey with us that would be needed for future endeavors. As I reflect on some of those individuals and our school's apparent insufficient support of them, I must admit that it feels bad. I believe that their somewhat marginalized existence in the community was in a very real sense initially set in motion by the circumstances others imposed on them. It is never an enjoyable feeling to realize that not everyone on our instructional team felt the need to ensure that the student 
learners in his or her charge warranted the extra effort that may have made a difference. This is a sad reality that I fear continues to exist in many educational arenas today. Subsequent to my tenure in the elementary school, I moved to our county's central administrative offices where I was charged with numerous responsibilities including the coordination and oversight of the special education support services for the education of students with disabilities. My tasks included the facilitation and monitoring of student performance records, development of individual education plans (IEPs), and the equally important provision of more professional development initiatives for faculty and staff county-wide. As such, I became even more aware of the multiplicity of needs of individuals (both students' and teachers') with regard to appropriate educational opportunities. Again, I found that bringing about change can be unpopular and often asked, "Is it really human nature not to want to see things from more than one lens?" My final position, prior to retirement from public education, was to serve several years as the director of curriculum and instruction for that same rural county school system and community. As a part of my responsibilities, I was charged with the development and implementation of the county 5-year strategic improvement plan, including coordination of all county and school efforts focused on the prevention of school dropout. One reason for this initiative was our concern that the county somehow continued to earn notoriety for having one of the highest dropout rates in the state. During efforts to coordinate this initiative, I was confronted with an apparent sense of misplaced pride held by a number of colleagues who believed that they usually knew that various children were never going to make it through high school graduation. These colleagues often boasted that they could predict who would be future dropouts. As a 
result, I found that it can be challenging, if not impossible, to instigate a sea change for anyone who may be comfortable with their self-professed ability to predict who would or would not be successful. It became apparent that pride in knowing that these students who are so dependent on the supports we could make available may still fail to graduate was more enticing to those with the ability to prevent that failure than to consider actions other than boasting.

My failure to bring about the change has continued to be frustrating. Even though I had been listening carefully to all the mental reminders to do right always; about how to do what's right by the children; and ensure that no child is left behind, etc., it seems that I simply fell short. While I had implemented numerous professional development opportunities that included an emphasis on making the important emotional connections with our student learners, somehow this was viewed as unimportant.

I found that in many instances, some educators may actually view their students as expendable, considering them to be a never ending commodity of job security rather than individuals with whom to exchange information that could benefit everyone involved. To the contrary, I believe there can be a blending of responsibilities of both teacher and learner. Further, I believe there must first be recognition that the learner is typically initially at the mercy of if and how the teacher views and accepts the responsibility for ensuring that this important relationship is established and sustained without bias.

As shared earlier, since my entrance into the doctoral program at West Virginia University, through what seems to be a couple of coincidental encounters, I met an individual who indicated that he recognized me as someone from his former high school 
and that he had previously dropped out. At that time I took the liberty of asking if he minded sharing the reason for his decision to discontinue his schooling prior to graduating from high school. This young man's espoused reason for his decision to drop out was simply, "Every time I asked for help, nothing was ever done", and this caused me considerable concern. In addition, his response left me feeling ashamed and apologetic on behalf of the school system and concerned that what I was hearing might be more accurate than many realized. This was primarily because our meeting was merely a chance encounter and I knew that the young man had no time to prepare any kind of fabrication. It seems that these seemingly coincidental encounters that occurred convinced me that the phenomenon of dropping out required further investigation.

During my tenure as a public school employee, I witnessed various forms of students' successful or unsuccessful school experiences. A representative sampling of comments made when mentioning school dropout to others suggests what seems to be an interesting cross section of views toward the topic in general. Each of the following were captured during conversations with former colleagues or when attending specific meetings to discuss a student's intent to do so.

One excerpt taken from a casual conversation with a classroom teacher includes: "When you plant potatoes, you get potatoes." While one would hope that this statement was made to illustrate the importance of making strong investments in our students, it can also reveal a belief that students succeed or fail in spite of any educational delivery effort on the part of the educator. As such it also suggests a preference for blaming the victim whenever students fail. 
In another instance, "Nothing you do will prevent a student from dropping out" was a statement made by a school district director of attendance during a discussion of school dropout. The concerning part of this message is that it was made by an individual responsible for ensuring that students attend school regularly. One would hope that this individual actually believes that students need to be in school, rather than sounding the alarm that suggests any effort in that regard is futile.

Likewise, the statement heard from a school administrator that, "These kids are going to dropout as soon as they can. There's no need to address the entire curriculum with them" sends a disappointing message that not all students are worthy of the effort it takes to meet individual needs. The model this leader is setting for his faculty seems to promote school dropout rather than trying to eliminate it.

One additional concerning practice is the acceptance of parental approval of dropping out that is suggested in the statement, "His mother and I dropped out, and we've done 'OK.' If he wants to drop out, that's fine with us." This comment was captured during a conference with parents of a student considering the early school leaving option when the school personnel were negotiating whether early school leaving was in the best interest of that particular student. What seems most disappointing in similar situations is that the school system simply relies more on the parents' approval as the final determinant for dropping out rather than requiring more substantial rationale for such a decision.

While I must admit having been both intrigued and troubled with the aforementioned comments and their possible representation of what may be more prevalent than one might believe. Depending on the circumstances, and the meanings 
constructed of those situations, one's response to each experience can take a variety of paths. When more successful results occur, what seems to have made that success possible is one's ability to navigate the more difficult conditions and capitalize on the positive components of each. In most instances, this is the result of having either the particular needed pre-requisite skills to be successful, a mindset directed toward success, or some combination of both. On the other hand, failures often occur when one is confronted by a need for skills not yet mastered and one's mindset is not focused on the potential benefit that could result from having learned the new and challenging information. Said circumstances are addressed as a part of the research conducted by Jean Piaget (1896-1980) entitled, Cognitive Theory of Development. Additional explanation of Piaget's Cognitive Theory of Development is provided in chapter two of this study.

I maintain that having an understanding of the processes of transition and how learners typically experience what Piaget calls stages of equilibrium or disequilibrium offers potential for identifying connections between students' disengagement and their potential for becoming at-risk of failure as well as the eventual decision by some individuals to drop out. Responses to a student who is experiencing either of these stages can also have an impact on his or her potential for being successful in school. Piaget's cognitive theory suggests that whenever an individual is confronted with a new learning experience, depending on prior knowledge or skill acquisition, he or she may find the new task to be overwhelming. As a result, the individual experiences a state of disequilibrium and can be situated as at-risk of failure. When, however, pre-requisite abilities for learning are in place and subsequent scaffold skills are encountered, a state of 
equilibrium is typically experienced and an increased sense of confidence and subsequent potential for future skill acquisition results. Depending on which state (equilibrium or disequilibrium) a student finds himself or herself it can serve as the force for restoring or destroying one's balance and ability to master the new skill at hand.

Building on Piaget's cognitive development theory, I further believe that when it comes to making decisions to leave school early, timing and response from external supports can also heavily influence decisions of those already at-risk of failure. Although preparedness or prerequisite learning can have significant influence on skill acquisition, there may also be a certain tipping point when a struggling individual no longer views attempting to achieve as a task worth trying. Without the needed support upon which an individual typically relies (i.e., family member, school faculty, or trusted friend), one may find it less frustrating to stop trying rather than re-experiencing feelings of failure. Yet the aforementioned has not been investigated through the lens of those who may have experienced these frustrations.

Prior to beginning official work of investigating the phenomenon of dropping out of school as a part of my doctoral research, I was already becoming interested in the dropout dilemma and wanting to know why it was occurring. My predisposition for wanting to know more about the topic served as an excellent starting point. Additionally, most of the experiences pertaining to the dropout dilemma while working in my former position were disappointing in that I felt the majority of my colleagues viewed dropping out as a phenomenon to be expected rather than problematic. As a result, I have felt a certain obligation to learn more about the dropout phenomenon. 
It is my belief that things happen for a purpose. Hence, the aforementioned encounters only reinforced my resolve to investigate the phenomenon of dropping out of school, as it seems more is involved than mere chance. Further, I believe that an at-risk student's otherness is usually due to circumstances beyond his or her control and has very little to do with one's attitude toward learning. Rather, it is my view that an individual's circumstances such as minimal availability of school supports that can influence his or her decision to disengage with school and eventually drop out.

In addition, it is my constructivist view that each of us continues to construct and reconstruct meaning from the experiences we have. Therefore, I submit that these constructed meanings also change over time as we experience more and reflect on previous situations through a maturing lens. As such, the meanings we construct of one episode can be transformed as additional understandings influence our thinking. To that end, initial reports of participants' life experiences may be altered or embellished during subsequent interview sessions and as additional clarifications are requested by the researcher.

While I do not anticipate that this study will eliminate the occurrence of students making the decision leave school prematurely, I have faith that the information shared by participants in this investigation can contribute to a better understanding of dropping out and provide clarification as to why certain students choose to do so. Although I have no firsthand experience or immediate understanding of dropping out, I believe that any investigation of the early school leaving phenomenon through the dropouts' lens is an appropriate means for enhancing our knowledge of what contributes to it. 


\section{Data Collection}

Gubrium and Holstein (2009) remind us, "Listening and recording carefully and documenting [participants'] actions are critical to data collection” (p. 31). Moreover, Savin-Baden and Van Niekerk (2007) suggest that the role of the researcher is to be "An effective listener" and to see the interviewee as "A storyteller rather than as simply a respondent” (p. 464). In this way, interviewing provides access to the context of people's behavior(s) and thereby provides a way for researchers to "Understand the meaning of that behavior" (Seidman, 1998), as well as how the meaning people make of their experiences "Affects the way they carry out that those experiences" (p. 4).

Kvale and Brinkman (2009) also indicate that interviewing, "Seeks to obtain descriptions of the interviewees' lived world with respect to interpretation of the meaning of the described phenomena" (p. 27). As such, the interview can be seen as the site of a construction of meaning as perceived by the participant who is sharing narratives of life experiences. In addition, Savin-Baden and Van Niekerk (2007) also suggest that, "Meaning-making through story construction and interpretation first happens between the narrator (person who had the experience) and the listener (researcher)" (p. 464). Therefore, consideration of what is being shared by those who have actually lived the experiences is a means for those who have not to better understand them.

In order to capture the essence of my participants' experiences through a series of interviews, I will do more than simply gather their stories. I will also take the time to seek the hidden and possibly overlooked messages available in the stories my participants tell about their lives. In fact, Seidman (1998) suggests, "Interviewing provides access to the content of people's behavior and thereby provides a way for researchers to understand 
the meaning of that behavior" (p. 4), as well as the meaning participants may make of their stories. Thus, interviewing participants about their respective life journeys and experiences that influenced their decisions to drop out may reveal a number of ways to understand these experiences.

\section{Data Sources: Participant Interviews}

Participant interviews are one means for gaining a better understanding of the meanings individuals construct of their real life experiences. Specific details about a topic of investigation can be discovered through an individual's stories about his or her experiences and the constructed meaning he or she has made of each. Seidman (1998) indicates that:

At the root of in-depth interviewing is an interest in understanding the experience of other people and the meaning they make of that experience. . . At the heart of interviewing research is an interest in other individuals' stories because they are of worth. (p. 3)

Seidman (1998) also suggests that in order to understand one's behavior(s), or subjective understanding(s), or meaning(s) that he or she has made of an experience, interviewing may be the best avenue of inquiry, because, "Interviewing allows us to put behavior in context and provides access to understanding their [the interviewee's] action" (p. 5). Thus, because I wanted to understand the educational experience from the perspectives of students who chose to leave school early, interviewing seemed to be the best avenue for my inquiry.

With that in mind, a series of three interviews were scheduled as a part of this study. Utilizing what Seidman (1998) refers to as the "Three-interview series" (p. 9), the 
first interview was focused on the participants' life histories. These interviews involved requests for participants to share stories from their memories of life experiences prior to their decisions to drop out of school. These open-ended interviews were both audio- and video-taped.

During the initial interview each participant was asked to share information pertaining to his or her background, family make-up (i.e., number of family members, placement among siblings) and where he or she grew up and attended school. In addition, each participant was asked to provide accounts of early experiences with family members and friends, within and around their neighborhood, prior to being enrolled in school. The purpose of this process was to understand context for the experiences being reported. Patton (2002) indicates that answers to questions of this nature "Help the interviewer locate the respondent in relation to other people" and "elicits the respondent's own categorical world view" (p. 351). (See Appendix B) Interview two involved a request for participants to focus on and share memories of school-related activities and experiences, as well as any additional family-related occurrences that took place prior to the participant's decision to drop out. This included inquiry of such things as: (1) stories of interactions while a student between or among classmates and or school personnel, (2) memories of activities in which he or she participated or witnessed, both in and outside of school, (3) indications of the value each participant may have placed on schooling and what it may have to offer, and (4) reports of academic successes and difficulties while attending school. (See Appendix C) The third interview addressed participants' experiences after dropping out of school through the present. Each participant was asked to share information about his or her life experiences that have occurred subsequent to the 
decision to leave school early, including sharing reports of his or her current circumstances (i.e., marital status, employment status, home ownership), as well as to making connections between the two periods of time being explored. (See Appendix D)

Subsequent to being recorded, each interview was then transcribed verbatim. As a part of this process, I watched for possible themes that emerged from participant's constructed meanings of the stories each shared. This was in concert with Labov's (1967), structural analysis that is intended to focus on evidence of how participants make sense of and construct meaning in their lives through evaluation and resolution of complicating actions within the stories that are shared.

Following each interview session, an initial transcript was prepared, and each participant was invited to review a draft of his or her respective interview transcript in order for me to assess the accuracy of the ways in which their experiences had been represented. This member-checking opportunity afforded a chance for participants to review the information captured regarding personal histories, life experiences, and decisions prior to and after dropping out of school. In addition, it was useful when trying to identify whether any corrections needed to be made or if additional information needed to be added. Reflection of this nature also assisted in capturing additional details to clarify specific points being investigated. Member checking also provides participants with an opportunity to reconstruct any previously misinterpreted or misunderstood information that, once clarified, may provide additional insights their experiences in school and how these life experiences informed their decisions to leave school early. It was my intention not to attempt to capture many written field notes while individuals were sharing their life experiences, in order to minimize any researcher 
activities that may have been a distraction for the participants. However, if an interviewee appeared to be minimizing information or if his or her story seemed to require further clarification, I requested additional information immediately through the use of additional probing questions. This occurred with caution in an attempt to prevent the probing questions from seriously disrupting a participant's story in any way. Maintaining a focus on the participants and their stories also afforded me with opportunities to observe their demeanor while they shared more personal and or private information.

I made notes pertaining to experiences of interest that seemed to need some clarification or further exploration in order to better understand how participants have made meaning of the events in their lives and how these events might have been connected to their decision to drop out of school. I also planned to engage in reflective journaling immediately following each meeting based on my field notes and impressions taken away from each experience. This was done in order to capture my thoughts and impressions of such things as how I felt the session had progressed, what I noticed about a participant's demeanor, or specific details pertaining to whether circumstances potentially may have influenced by the setting of the interview session and that may have compromised the participant's ability to focus on the topic being covered. This reflective journaling also assisted me in organizing for subsequent interview sessions, as well as to identify additional questions that I felt may enhance this investigation.

As Seidman (1998) states, "Interviewing is a powerful way to gain insight into educational issues through understanding the experiences of individuals" ... . As a method of inquiry, interviewing is most consistent with people's ability to make meaning 
through language" (p. 7). To that end, these open-ended interviews afforded participants the freedom to recount, and therefore construct meaning of, potentially influential episodes that had occurred during school, as well as circumstances and relationships that involved interactions with family members.

\section{Data Sources: Documents}

Permission was sought from participants to investigate the existence of and examine available historical school records pertaining to him or her that may have been archived by his or her former school district. The requested documents included those typically maintained as a part of a student's cumulative record file and that address such things as academic performance, attendance, recommendations for possible placement in remedial or advanced programs, as well as any other teacher referrals. Inasmuch as cumulative records sometime contain confidential information, participants were asked for written permission to access them. (See Appendix E)

In addition to accessing each participant's approval to access his or her cumulative records, in accordance with typical county school district Board of Education procedures, I also submitted that information to the attention of the school Superintendent or his or her designee in order to gain access to the appropriate county's archived materials. It was my intention to compare information that may exist in participants' cumulative record files to corroborate information the participants shared about their school experiences as document analysis of this nature can assist in triangulating information pertaining to each participant's life journey and can enhance analysis and interpretation efforts pertaining to the research questions for a study. Unfortunately, 
however, even though the appropriate permissions and accompanying paperwork were obtained and submitted, no such records were located.

\section{Data Analysis}

Narrative analysis attempts to discover more about how decisions can evolve from the constructed meanings individuals carry from their experiences. Patton (2002) states, "The central idea of narrative analysis is that stories and narratives offer especially translucent windows into cultural and social meanings" (p. 116) and also suggests some questions that may help focus the researcher when considering narrative analysis including: "(1) What does this narrative or story reveal about the person and world from which it came?, and (2) How can this narrative be interpreted to understand and illuminate the life and culture that it created?" (p. 133). Information gained from questions such as these can reveal perceptions and constructed meanings of experiences as close as possible to having actually experienced it first-hand.

To begin I read and re-read the interview transcripts numerous times in order to become familiar with the details shared by participants during their interviews. Then I utilized Labov's (1967) structural analysis via thematic open-coding in order to identify evidence of such things as events and or complicating actions within or among experiences and or relationships that seem to connect to the participants' decisions to drop out.

While various themes can be expected to emerge from shared stories, I watched for stories that may have involved situations during which participants experienced a sense of disequilibrium as a result of missing external support or encouragement to persist, typically received from peers, family members and or teachers. This was done as 
information can be helpful when attempting to identify how participants tend to position themselves in response to the complicating action being revealed. In addition, SavinBaden \& Van Niekerk (2007), tell us that this may be helpful in identifying evidence of possible epiphanies and metaphors discovered by participants, as "Epiphanies are seen as transformational; that is they significantly change people's lives" and that these constructed meanings may prompt these epiphanies or "sudden and dramatic moments" (p. 465).

Examples of possible epiphanies that may be observed include reactions that participants have as he or she attempts to put into words what he or she experienced during the episodes being remembered. Said reactions can be a sudden connection made between his or her circumstances in the past, the decision made at that point, and what he or she now realizes that may have been handled differently. This can prompt feelings of remorse, complacency, or anger depending on how the participant places himself in that memory. Whether or not that same feeling or response to the memory of those same episodes remains or returns, while discussing them can often reveal the intensity of each to either me or the respective participant. In any event, it was be important for me, as the researcher, to explore these responses cautiously so as not to overwhelm the participant or cause him or her to shut down altogether. Doing otherwise would have been irresponsible and potentially unproductive. I anticipated also that the personal nature of these potential episodes or epiphanies may have enhanced the participants' understanding of the possible influences each such experience had on his or her decision of the past and that each may have influenced decisions made since he or she dropped out. 
Table 3.2 delineates the schedule and purposes for conducting interviews, creating transcriptions, and engaging in member-checking sessions. In addition, it reflects the time required for data analysis, interpretation of findings, and preparation of final narrative.

Table 3.2

Time-table/Reiterative Process for Data Collection and Data Analysis

\begin{tabular}{|c|c|c|}
\hline Activity & Purpose & Approx. time \\
\hline Initial contact & $\begin{array}{l}\text { Review study purpose with participants } \\
\text { and obtain participation agreement }\end{array}$ & 1 week \\
\hline Interview 1 & Gather life histories & 1 week \\
\hline Transcriptions & Draft verbatim transcript prep & 2 weeks \\
\hline Member-checking & Review/edit draft for accuracy & 1 week \\
\hline Interview 2 & Collect school-related stories & 1 week \\
\hline Transcriptions & Draft verbatim transcript prep & 2 weeks \\
\hline Member-checking & Review/edit draft for accuracy & 1 week \\
\hline Interview 3 & Explore post-dropout life & 1 week \\
\hline Transcriptions & Draft verbatim transcript prep & 2 weeks \\
\hline Member-checking & Review/edit draft for accuracy & 1 week \\
\hline Consult with Advisor & $\begin{array}{l}\text { Discuss data analysis/coding } \\
\text { procedures and analytic method }\end{array}$ & 1 week \\
\hline Data analysis & Open coding transcripts & 2 weeks \\
\hline Construction of narrative & Preparation of findings & 2 months \\
\hline
\end{tabular}

In summary, "Meaning-making comes from comparing stories and cases and can take the form of inquiring into and interpreting causes, consequences, and relationships" 
(Patton, 2002, p. 478). Watching for possible signs of epiphanies that may occur to participants while sharing his or her stories is some of what was used to help understand how individuals made decisions to drop out of school. Further, while listening to reports of experiences and related circumstances, I also paid attention to the identities each assumed, as well as how he or she expressed his or her thoughts and identities. This was in accordance with the research on identities conducted by Gee (2001), who tells us:

Human beings must see each other in certain ways and not others if there are to be identities of any sort. If an attribute is not recognized as defining someone as a particular 'kind of person,' then, of course, it cannot serve as an identity of any sort. (p. 109)

Throughout this process, attention was given to shared descriptions of specific episodes that reportedly occurred in the past: (a) between the participant and his or her teachers, (b) among the participant and his or her schoolmates, and (c) between or among the participant and his or her family members. This was done in order to capture clues pertaining to possible experiences of disequilibrium that may have triggered or influenced a participant's decision to disengage from school.

\section{Trustworthiness}

Qualitative researchers should conduct their work with integrity that includes an assurance that the work is honest, meaningful, and credible. According to Patton (2002), credible research strategies require that the investigator adopt a "Stance of neutrality with regard to the phenomenon under study" (p. 51). In order to do this, a researcher must approach his or her work not with the intent to prove or disprove something but rather with the intention of remaining open to discovery. As a demonstration of my 
understanding and appreciation of the importance of establishing a sense of credibility or trustworthiness with this study, I have included a description of my subjectivities that identify potential biases, preconceptions, and assumptions, as well as the initial experiences and issues that prompted my interest in better understanding the phenomenon of early school leaving.

It was my intention not to allow my preconceived notions or suspicions about the topic of school dropout to influence my valuation or interpretation of the data being collected. In addition, it was my intention to pay close attention to the participants' demeanor while each was sharing stories from his or her past experiences. These are issues that were considered while analyzing and interpreting interview transcriptions.

Further, I attempted to gain access to and review existing historic records of each participant that may be useful for documenting previously recorded instances during individuals' school experiences. Information of this nature is typically archived as a part of a student's permanent record within the specific school district of attendance. This was done in addition to the preparation of typed transcripts of interviews that were created and member-checked for accuracy. Patton (2002) also indicates that "Neutrality is not an easily attainable stance, so all credible research strategies include techniques for helping the investigator become aware of and deal with selective perception, personal biases, and theoretical predispositions" (p. 51). Therefore, in an attempt to ensure that the participants' personal experiences are accurately captured and interpreted, member checking sessions was scheduled between each of the interviews in order to offer opportunities for participants to reflect on and revise or modify their recollections of their experiences. 
I also sought opportunities for peer review of the data I collected and my interpretations in order to identify details in the data that were overlooked or possible misinterpretations of the data. The intent of this peer review by colleagues was to assist in preventing potential overstatement of findings and help me to identify any potentially unsubstantiated recommendations. All of the aforementioned steps were taken to identify any potential for transferability of the findings and recommendation across other contexts. In addition, it is hoped that the information gathered and shared can be useful for identifying additional topics for study that may have the potential to enhance our overall understanding of the phenomenon of dropping out of school.

\section{Limitations}

Qualitative research seeks opportunities for understanding the topic of inquiry, the constructed meanings that exist, and how they can serve to enlighten others. When addressing this point, Patton (2002) shares, "The essence of this qualitative process is to investigate what people say and the descriptions of events as they are reported or observed" (p. 457). As such, some of the limitations of this study include: (1) data collection method; (2) the subjectivities and positioning of the principal researcher; and (3) positioning of, and interactions between, the researcher and participants, and the possibility that participants may have experienced uncomfortable memories when recalling issues that may have prompted decisions to drop out in the first place and, as a result, became reluctant to continue.

\section{Limitations - Data Collection Methods}

According to Patton (2002): 
Interview data limitations include possibly distorted responses due to personal bias, anger, anxiety, politics, and simple lack of awareness since interviews can be greatly affected by the emotional state of the interviewee at the time of the interview. Interview data [collection procedures] are also subject to recall error, reactivity of the interviewee to the interviewer, and self-responses. (p. 306) Bruner (2004) also cautions, “The story of one's own life is a privileged but troubled narrative in the sense that it is reflexive: the narrator and the central figure in the narrative are the same" (p. 693).

Interviewing can be an effective means for allowing an individual to comfortably revisit the circumstances each is describing. However, there is also a chance that as the time lapse between the actual occurrence of event or circumstances being reported and the more recent interview increases, there may be some compromise regarding the accuracy of the individuals' recall ability, thus skewing that reality. Clandinin and Connelly (2000), refer to this potential circumstance as the "temporal nature of experience" (p. 19). When conducting narrative inquiry it is important to recognize that temporality influences how participants may remember, explain, and redefine their experiences and therefore how we, as researchers interpret the stories being shared (Clandinin \& Connelly, 2000, p. 19). Therefore, while interviewing participants seems to be an effective way to capture his or her constructed meaning of events, it was important to continue to revisit what is being reported if and when any discrepancies seemed to be present in order to minimize the potential for inaccurate reports. 


\section{Limitations - Subjectivities of the Researcher}

According to Clandinin and Connelly (2000), "The field text from narrative inquiry can be shaped by selective interest or disinterest of the researcher or participant, or both" (p. 94). Therefore, having experienced a career in the public school system prior to beginning this study, it seemed clear that any number of the experiences from that time offered potential for influencing how I approached this inquiry, including such things as data collection, data analysis, or interpretation. This may be evidenced by previously described disappointing experiences during which former colleagues espoused their belief that certain students were destined to drop out long before many did so and their apparent satisfaction in doing nothing to support the at-risk individuals.

Acknowledging this reality can be extremely frustrating. However, recognizing this as a potential limitation was helpful in that I was more mindful of the importance of setting aside negative expectations regarding participants' reported life experiences that revealed the existence of similar non-supportive persons.

Furthermore, it was my intention to seek opportunities for review of collected data through member-checking with participants in order to catch possible inaccuracies before proceeding to the data analysis process. In addition, I looked for opportunities for peer review of data analysis and narratives to ensure accuracy and obtain input from respected educational professional colleagues prior to finalizing this work.

\section{Limitations - Positioning of, and Interactions between, the Researcher and Participants}

Clandinin and Connelly (2000) share: 
What may appear as an objective recording of an interview is already an interpretive and contextualized text: it is interpretive because it is shaped by the interpretive processes of researcher and participant and their relationship, and it is contextualized because of the particular circumstances of the interview's origins and setting. (p. 94)

By the very nature of the topic of this research study, it was anticipated that participants may feel that discussing the occurrence of having dropped out might be too personal and uncomfortable. In addition, the power dynamic often perceived by school dropouts and their relationship with others who have achieved higher educational degrees may intimidate the participants and has the potential to suggest to them that they are being judged. I anticipated that navigating these potential barriers may take some time, as trust between participants and the researcher is a critical component of any relationship. Therefore, it was important to invest ample time for the researcher and participants to become acquainted and comfortable with one another prior to engaging in the interview process. While I was concerned that this additional time may delay the actual start of recorded data collection efforts, that need did not occur. Fortunately, each of the participants seemed to be immediately comfortable with the process and was eager to begin without delay. Therefore, the potential to gather data from conversations that occurred prior to recording interviews and that might reveal additional insights into the participants' experiences were captured throughout our interviews and was captured in post conversation reflection and journaling by the researcher. 


\section{Summary}

This chapter provides an overview of the methods and materials that were used to conduct this study. The chapter began with an explanation of why a qualitative inquiry is an appropriate method of inquiry into the phenomenon of dropping out of school and the value that interviewing of participants who have done so can add. In addition, it addresses the purpose of the study, the research questions, the researcher's theoretical perspective and constructivist epistemology, and connects the framework of my study to research done by other researchers considered to be giants in the field.

This chapter also provides a brief review of narrative constructivism and the importance of seeking participants' individual constructed meanings of life experiences as a means for better understanding the phenomenon under investigation. I also describe the criteria used to select participants and their roles in the study, as well as the context wherein each participant was situated. The chapter then addresses data collection methods and procedures, data sources and the narrative analysis methods that were utilized. Finally the chapter addresses the role of the researcher and the possible influences of his subjectivities on data collection and analysis, as well as issues of trustworthiness, transferability, and possible limitations of the study. 


\section{Chapter Four}

The purpose of the next four chapters is to present my findings, filtered through the lenses provided by my research questions. The research questions used to guide this study are:

1. What contributes to an individual's decision to leave formal education prior to graduation?

2. How does the decision to leave school early affect the later life of a school dropout?

In each of the chapters devoted to my findings (Chapters 4, 5, 6, and 7), I first provide a biographical description of the participant, as well as the contexts in which he or she was situated. Next, I identify the themes that emerged from my analysis and I illustrate how these themes were evident in the stories each participant shared. I also describe the understanding(s) each of the participants constructed of the various narratives they shared and the relationships among these narratives which contributed to his or her decision to drop out of school, as well as the influence of this decision on their lives since leaving school early.

In these ways, the themes emerged through my use of structural narrative analysis (Labov, 1967) and provide evidence of how each participant made sense of and constructed their lives through evaluating and resolving the complicating actions of their stories. Further, I explore how their use of language situated them in these narratives and contributed to how they responded to events and the stories they tell about their lives. Each chapter concludes with a consideration of how the ways in which the participants made sense of their lives influenced their choices, as well as the ways in which, according to the positioning theory outlined by van Langenhove and Harre' (1999), they 
positioned themselves and were positioned by others as they made life decisions and constructed their identities.

\section{The Story of Jane}

In this chapter, I explore how Jane's experiences in and outside of school may have contributed to her decision to leave formal education prior to graduation, as well as the consequences of this decision on her subsequent life. Jane chose to tell a number of stories related to her life at home, in school, and since leaving school early during the three open-ended interviews I conducted with her. Her narratives provide opportunities for understanding the relationships and intersections among these circumstances that affected her interpretations of life events and the decisions she made about school and her life.

\section{The Participant}

Jane is a forty-six year old, Caucasian female. She was initially identified as a potential participant in this inquiry from a pool of individuals currently assigned to the Department of Community Corrections. During the introductory meeting, arranged by the Director of Community Corrections with a number of potential candidates for my study, Jane said, "Mister, I hope that machine of yours has a lot of power, 'cause I got lots to tell you" (personal communication, April 29, 2013). Because Jane seemed so eager to tell her story, I invited her to participate in my study.

\section{The Context}

Jane was the youngest of eight children born into a family situation of low socioeconomic circumstances. She grew up in a small, rural Appalachian community, which may have been considered a bedroom community for laborers employed in the mining 
industry. Jane attended elementary school in that same rural community and, due to the school's proximity to her home she was able to walk to and from school.

Jane's elementary school had the highest percentage of families qualifying for free and reduced meals, which qualified the school for Title 1 federal funding. According to the director of federal programs for this school district, these circumstances continue to be characteristic of that particular county and specific community, as the current (2013) free and reduced meals rate for the school district as a whole is $55.69 \%$ and for that specific school it is 69.49\%, (L. Casto, personal communication, September 20, 2013).

The majority of families residing in this area existed on income from blue collar, seasonal labor opportunities. During that time the majority of households were identified as being at-or-below the poverty level. Table 4.1 represents an excerpt from the Poverty Guidelines that existed during the time when Jane was entering school in 1973. Although both of Jane's parents were present, only one was employed. This circumstance, coupled with the fact that the family consisted of ten (i.e., two adults and eight children), it is fairly easy to see how it could be difficult to provide even the basic necessities for the group as a whole.

Table 4.1

United States Poverty Thresholds for 1973

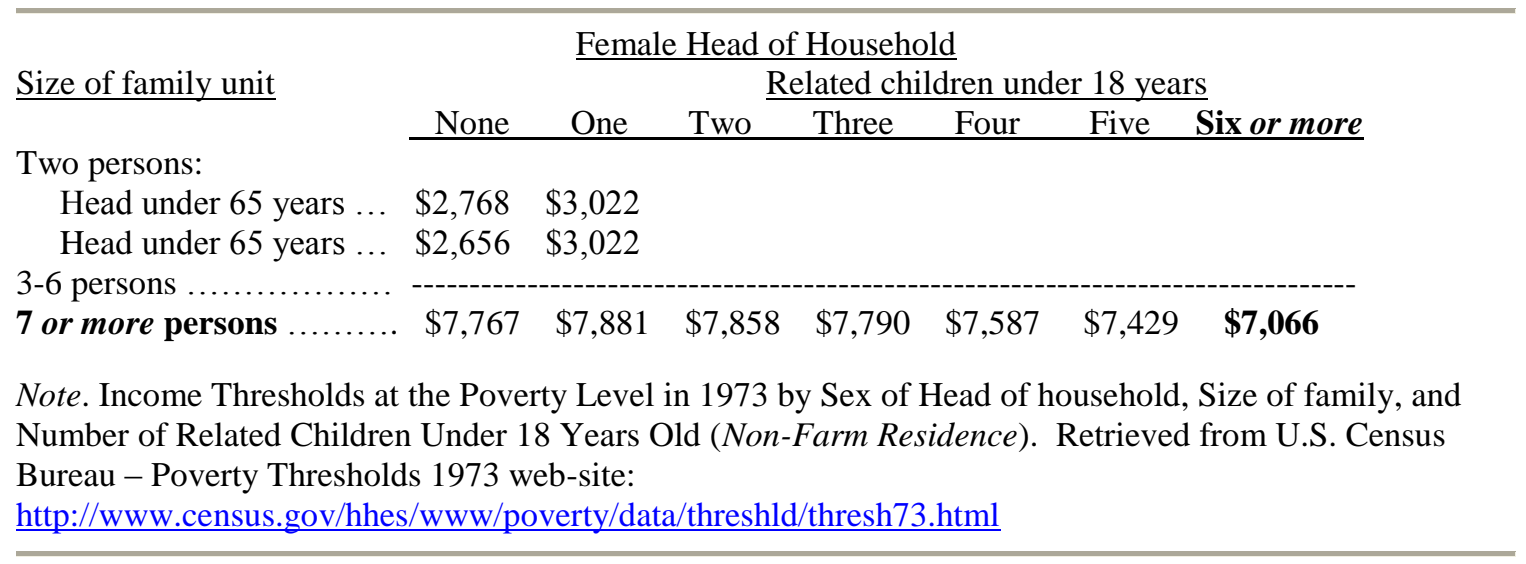


On occasion, Jane was sent to live with an aunt as well as foster families. Although she has never fully understood why her mother made decisions to send her away, Jane continues to view both her mother and those decisions negatively. Perhaps it was her mother's goal to find a means to minimize the hardship that all family members were experiencing at the time. However, this remains a mystery for Jane. While this possibility is more speculation, it was interesting that Jane does not credit her mother for having a positive motive. Because Jane was a child at the time, it is also possible that her mother may have been attempting to ensure improved circumstances for Jane and the other members of the family in the only way she had available. As a result of Jane's lack of understanding, she continues to believe that she was being abandoned.

Jane later attended grades seven and eight in a middle school facility located in the heart of the county seat, a somewhat larger community than that of her elementary school. Both schools were in the same county school district. As a result of a move to a different home that occurred around that time, similar to her elementary school years, Jane was able to walk to and from her middle school as well.

Jane stopped attending school before completing her eighth grade year. After leaving school early, Jane has experienced a number of circumstances including homelessness and incarceration. When I met Jane, although she had been successfully working her way through the Community Corrections Program, the last of our interview sessions had to take place in the regional jail facility as a result of her having violated her probation a mere three days prior to the end of her sentence. According to Jane, her decision to violate the conditions of her probation was prompted by her having been marginalized by those having authority over her at the time. Further, Jane believes that 
those circumstances justify her assumed combative, adversarial stance, even though that stance resulted in additional incarceration.

\section{Overview of Jane's Story}

This chapter first explores the events and circumstances of Jane's life and how her interpretation of these experiences contributed to her decisions and the life she created. A number of themes emerged from my analysis of Jane's narratives and include (a) poverty, (b) marginalization and victimization, (c) abandonment and isolation, (d) combative and adversarial, (e) survival, and (f) care-giving. These themes provide perspectives related to how Jane made sense of life events, how she positioned herself and positioned others in her life, and how she responded to these events and made decisions that affected the course of her life.

Tables $4.2,4.3$, and 4.4 are provided at the beginning of each section of Jane's story and are intended to serve as examples of Jane's varied positioning (van Langenhove \& Harre', 1999). Each table depicts vignettes and themes from separate times in Jane's life including: The Early Years, The School Experience, and Life After Leaving School Early. In addition, they represent the complicating actions, evaluations Jane uses as explanations for those circumstances, and what Jane views as a resolution of each.

\section{Jane's Experiences of Home}

When asked to share stories about her family and her relationships with family members, Jane indicates that she was born into a fairly large family, the youngest of eight. In addition, Jane recalls that the family experienced the loss of three of the eight children, each at an early age. 
The few vignettes provided in Table 4.2 reflect examples of Jane's perception of her placement within her family as well as her rationalizations for why those circumstances may have existed. In each instance, Jane positions herself as either a victim or one who had been abandoned.

Table 4.2

Vignettes and Themes from Jane's Journey - The Early Years

\begin{tabular}{|c|c|c|c|}
\hline $\begin{array}{l}\text { Complicating } \\
\text { Action }\end{array}$ & Evaluation & Resolution & Theme \\
\hline $\begin{array}{l}\text { "When we was eight or } \\
\text { nine years, old, we } \\
\text { was gettin' drunk on } \\
\text { home brew." }\end{array}$ & $\begin{array}{l}\text { "He's (Jane's father) } \\
\text { the one that got us kids } \\
\text { started, uh, on drinkin' } \\
\text { when we was young." }\end{array}$ & $\begin{array}{l}\text { "I liked the buzz .... I } \\
\text { liked the feel of it." }\end{array}$ & Victimization \\
\hline $\begin{array}{l}\text { "My mother hated me } \\
\text { with a passion for } \\
\text { some reason." }\end{array}$ & $\begin{array}{l}\text { "Me and my dad was } \\
\text { real close. I think that's } \\
\text { reason why my mom } \\
\text { hated me." }\end{array}$ & $\begin{array}{l}\text { "My mom kept puttin' } \\
\text { me in foster homes and } \\
\text { group homes." }\end{array}$ & Abandonment \\
\hline $\begin{array}{l}\text { "I'll say I was raped by } \\
\text { my cousin" }\end{array}$ & 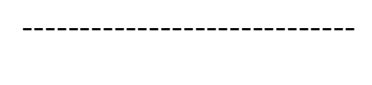 & $\begin{array}{l}\text { "I learned how to survive } \\
\text { in life on my own." }\end{array}$ & $\begin{array}{l}\text { Victimization; } \\
\text { Survival }\end{array}$ \\
\hline
\end{tabular}

According to Jane, her immediate family's dynamics were such that her arrival caused sufficient stress. As a result, Jane eventually begins to view herself as less worthy of attention and as an out-cast from her family. Jane's positioning as a victim of circumstance is evident when she says, "My dad was an alcoholic ... Me and my sisters and brother, we never got along. And my mother hated me with a passion" (Jane, personal communication, April 30, 2013). The resulting adversarial relationship that seems to have been prompted by Jane's belief that she was being marginalized by her siblings and abandoned by her mother was further demonstrated as Jane states,

They refer to me as a 'pain in the ass'. They say I was nothin' but a troublemaker when I was young. And ... that I was no good for nothing and that I would never amount to nothin' and they hated me with a passion .... I was mostly the 
black sheep of the family .... No one really wanted me around. (personal communication, April 30, 2013)

Jane's perception of having been abandoned or isolated by her mother seems to have been bolstered by the fact that at the age of eight, she was sent to live away from the rest of her immediate family, those whom she had come to know as wanting nothing to do with her. Accordingly, Jane shares, “My mom kept puttin' me in foster homes and group homes .... I was always sent away in foster homes, group homes .... all the way up until age sixteen" (personal communication, April 30, 2013).

Throughout our time together, Jane frequently referenced what she saw as an adversarial relationship that existed between her and her family. In some instances it was clear that she felt isolated from the others by the way the others tended to set her up for punishment from her mother. Jane also reveals that her relationship with her siblings and mom were rocky as she explains that, "Every time one of my sisters or brother would do somethin', I would always get blamed for it. I was the one that got beatin's with broom handles, an' mining belts, an' whippa willow tree switches" (personal communication, April 30, 2013).

While Jane's story was intentionally about her, it may be that what she recalls about her childhood may be skewed inasmuch as nothing was shared about how her parents disciplined the other children. Therefore, it may be that Jane's belief that she was marginalized by her family is not as accurate as Jane's memory suggests. When asked how her family spent time with each other, Jane indicates that family activities included occasional family cook-outs, infrequent family camping trips, playing cards or board 
games, and when not involved in one of those activities, staying in their respective bedrooms.

As she describes the activities, it seems that Jane views them as having been limiting, rather than seeing them as having been something typically enjoyed by many families and as opportunities for building relationships and making positive memories. For some reason, Jane seems to view them as otherwise. Perhaps this was due to the strained relationships that Jane describes as existing her siblings and herself.

With regard to opportunities for the immediate or extended family to spend time together, Jane indicates that those were usually limited to such occasions as holidays, caring for an ill relative, or attending a family funeral. However, Jane's perspective of time spent with her family is compelling, especially related to her choice of language when she share, “Because with the family, you didn't do much of anything but clean and figure out how to survive" (Jane, personal communication, April 30, 2013). Jane’s choice of the word survive seems to suggest that her understanding of family was based on her limited memories of enjoyable experiences and that she may have been preoccupied with concern about the frequent episodes of being fostered. Once again, perhaps the possible distraction from feeling abandoned may continue to prevent her from seeing any of the positive experiences that existed when members of Jane's family were together.

Although Jane continues to feel that she was abandoned and or isolated from her immediate family by decisions made by her mother, she also tells of her own preference to spend time alone in the woods. This irony can be detected as Jane reveals, "I used to go to the woods a lot. I would just sit there and look at the trees. Sometimes lay back 
and sleep. Weird, but, it was away from everyone" (Jane, personal communication, April 30, 2013). Therefore, in some instances it appears that Jane's feeling of being marginalized when being isolated from others is instead a choice made by Jane from time to time. In those instances, it may be that Jane sees those opportunities as having been a means to relax and escape from the constant reminder that she was un-liked by her siblings and unwanted by her mother.

As a part of her shared story about relationships with members of her family, Jane reports that she and her father, who was an alcoholic, shared a close relationship, which included drinking "home brew" together, an alcoholic substance that her father made for the purpose of having Jane and her siblings share with him. Interestingly, what may typically seem like an inappropriate activity to be shared between a parent and his or her children, was one activity that Jane views as an opportunity to be together with her father. This is revealed when Jane indicates that,

He's the one that got us kids started, uh, on drinkin' when we was young. They [her father and uncle] would make us home brew .... And when we was eight or nine years old, we was getting' drunk on home brew .... I liked the buzz .... I liked the feel of it. (personal communication, April 30, 2013) According to Jane, this activity was one that her mother did not appreciate. As a result, Jane eventually seems to have positioned herself as an outcast and less worthy of attention from anyone other than her father.

In addition to the fact that her father's frequent state of insobriety typically ensured that he was often unable to find or sustain employment, he also proved to be the role model that Jane chose to emulate, as she became an alcoholic at an early age. 
"When I was about thirteen up until I was about eighteen, I was an alcoholic", (Jane, personal communication, April 30, 2013). Jane's mother, on the other hand, did not take part in any of the vices as a regular practice in her home. To that end, Jane describes her mother as having been "Little Miss Perfect," (Jane, personal communication, April30, 2013), a seemingly unattainable and unappealing model for Jane's future life.

It seems that Jane may have been attempting to eschew her positioning as a victim. Instead however, she understands her choices as demonstrating her power and agency in determining her life, rather than as the consequences of the circumstances of her familial relationships. Jane also believes that affection felt between her and her alcoholic father prompted the response of disdain from both her siblings and her mother. As such, Jane maintained her relationship with her father, and according to her, she believes that this prompted feelings of jealousy in her siblings. Jane expresses her suspicion of this when indicating:

And my mother hated me with a passion for some reason .... Me and my dad was real close. I think that's the reason why my mom hated me .... My sisters and brother didn't like me 'cause I was daddy's girl. I think. (Personal interview, 2013)

Beyond those with her immediate family members, Jane's relationships with others often seem rooted in strong feelings and, many times, position her partners as adversaries, rather than allies. These adversarial relationships also provide models for her subsequent combative relationships and may contribute to the ways in which Jane believes she is positioned by others, as well as the ways in which she positions herself. 
It does not seem obvious that Jane understands that her relationship with her mother was more complicated. While her mother was not inclined to partake in the consumption of alcohol and she may have been overwhelmed with her own plight as the one adult figure in a struggling family unit trying to hold things together, the two issues may not be something that can be easily separated in a child's mind. According to Jane:

When I was eight years old, we kind of lived with our aunt, 'cause my mom said she couldn't take care of kids and plus a drunk .... My mom kept puttin' me in foster homes and group homes .... I was always sent away in foster homes, group homes .... all the way up until age sixteen". (personal communication, April 30, 2013)

It seems that Jane believes that she was sent to live away from the rest of her immediate family, simply because Jane's mother and Jane's siblings wanted nothing to do with her. As a result, Jane sees herself as having been victimized by her circumstances as well as her relationships with her mother, father, and siblings. However, Jane is still not able to understand this from another's perspective, as having been an attempt by her mother to ensure better opportunities for Jane. Instead, Jane believes that her mother simply abandoned on multiple occasions.

Throughout her story, Jane appears to prefer to position herself as an individual with a strong will. Perhaps this is her attempt to demonstrate that she was and is not afraid of anything and ready to assert her power and agency in any circumstance. However, she also positions herself as a victim of her mother's abandonment, and of her siblings' jealousy. It is interesting that she does not view her relationship with her father as victimizing her when introducing her to his "home brew." Likewise, Jane does not 
appear to see the possibly that the alcoholism with which she continues to struggle continues to compromise her future opportunities.

While Jane characterizes her relationships with her family as acrimonious and troubled, ultimately, she has felt a responsibility to family. This is demonstrated when Jane talks about her on and off relationships pertaining to her being fostered without understanding the reason, juxtaposed against her mother's eventual need for support from her. According to Jane:

I asked my mom over and over, 'why?' .... When I was young, I used to tell her that she wasn't my mom and I hated her with a passion.....and then the day came when she was goin' to pass away. (personal communication, April 30, 2013) This suggests that underneath Jane's choice to depict herself as having a hard shell exterior, instead seems to exist a sensitive individual who yearns to be needed and appreciated, and one who also wants the opportunity to reciprocate as a care-giver. Jane's report that she had been sent away from her family on a number of occasions includes a story of being sent to one particular foster home where she lived with a minister and his family. The descriptions that Jane provides of her experiences there seem to have conflicting details. In one instance, Jane tells of how the experience included encouragement to attend church and that she was allowed to be involved in a variety of enjoyable activities while there. However, it should be noted that, even though Jane was given opportunities to develop some of her interests, such as crafts and other similar activities in which she recalls having interest, Jane views her time spent there as just another example of being abandoned by, and isolated from, her family, especially her mother. Even during our recent interview sessions, Jane does not seem to see the 
possible connection between her mother's decision to send her to a foster home and her mother's desire to protect her daughter. It would be interesting to know how Jane's life may have been influenced differently if she had allowed herself to entertain the possibility that her mother was attempting to provide for, rather than deprive, her.

One additional episode that Jane reports, almost as if it were an afterthought, was something that had occurred while she was a child. According to Jane, "I was raped by my cousin. I was about eleven" (personal communication, April 30, 2013). As I listened to Jane share this particular circumstance, her somewhat matter of fact manner in doing so caused me pause. I wondered why Jane could be minimizing such a traumatic experience as nothing more than a normal happening. One conclusion that might be made could be that perhaps it was not the only time this kind of abuse had occurred. In addition, I wondered if she found the experience to be something that she thought to be expected inasmuch as she was a female. I further wonder if traumatic occurrences of this nature could contribute to his or her combative nature and possibly influence the kind of behaviors being described throughout Jane's stories. If so, it seems to me that an episode of this nature would certainly qualify the individual as a victim. Likewise, it may also have heavily influenced Jane's eventual acceptance of the role that seems to be playing out throughout her story. However, Jane does not share any more about it.

Overall, it was interesting to note that Jane first positions herself as self-reliant and afraid of very little, while at the same time revealing what sounds like a constant need to be appreciated and protected. The two opposing positions seem to be a common thread throughout Jane's story, first when she was a child and then during subsequent 
portions of the story she shares. This somewhat common theme can be noted in the sections that follow, as well.

\section{Jane's School Experience}

Similar to the examples given in Table 4.2, the information provided in the following Table 4.3 depicts vignettes and themes from Jane's life during The School Experience. Also, as indicated earlier, the information in Table 4.3 represents the complicating actions, evaluations, and resolution of each in accordance with how Jane seems to have interpreted those circumstances. As can be seen in the following examples, in many instances, Jane seems to be positioning herself as having been marginalized and abandoned. Subsequently, Jane's interpretation of those events appears to be used by her to explain how each prompted her assumed combative and or adversarial stance. In addition, Jane views her response to having been victimized as having been justified as they are what she believes anyone else would have done in an effort to survive those same circumstances.

Table 4.3

Vignettes and Themes from Jane's Journey - The School Experience

\begin{tabular}{|c|c|c|c|}
\hline $\begin{array}{l}\text { Complicating } \\
\text { Action }\end{array}$ & Evaluation & Resolution & Theme \\
\hline $\begin{array}{l}\text { "The clothes I wore was } \\
\text { always hand me downs } \\
\text { w/ holes in "em." .... } \\
\text { "Everybody used to } \\
\text { pick on me." }\end{array}$ & $\begin{array}{l}\text { "We was a very poor } \\
\text { family."... "They was } \\
\text { bullies. I was tired of } \\
\text { people makin' fun of } \\
\text { me." }\end{array}$ & $\begin{array}{l}\text { "I was getting' into } \\
\text { fights." }\end{array}$ & $\begin{array}{l}\text { Poverty; } \\
\text { Marginalization \& } \\
\text { Victimization; } \\
\text { Combative \& } \\
\text { Adversarial }\end{array}$ \\
\hline $\begin{array}{l}\text { 'I was at abandoned } \\
\text { houses, \& stayin' out } \\
\text { along the river banks. }\end{array}$ & $\begin{array}{l}\text { "I'd be drunk or } \\
\text { somethin'." }\end{array}$ & $\begin{array}{l}\text { "I worked the } \\
\text { streets; played the } \\
\text { men, use men to } \\
\text { get a hotel room." }\end{array}$ & Survival \\
\hline $\begin{array}{l}\text { "I wasn't good at school." } \\
\text {...."I was never taught." }\end{array}$ & $\begin{array}{l}\text { "It was hard.".... “My } \\
\text { dad couldn't read and } \\
\text { my mom couldn't } \\
\text { read." }\end{array}$ & $\begin{array}{l}\text { "I still don't know } \\
\text { nothin' about } \\
\text { that." }\end{array}$ & Abandonment \\
\hline
\end{tabular}


When asked about her experiences while in school, Jane's initial response appears to be based on what she recalls as disappointment she perceives to have been due to her apparent situation of being poor. This can be noted when Jane shares that from the time she entered the school program, she was confronted with ridicule from classmates. "Everybody used to pick on me and make fun of me .... they was bullies" (Jane, personal communication, May 6, 2013).

The experience of being ridiculed early in her school years seems to have introduced Jane to how being poor can sometimes be used to marginalize individuals. The stigma that often accompanies poverty is something about which Jane was apparently unaware until it was forced upon her by her classmates. This is demonstrated as Jane recounts what she interprets as the reason for her having been victimized.

According to Jane, “...because of the clothes I wore. They was always hand-medowns and had holes in 'em so they just made fun of me" (personal communication, May 6, 2013). Until that time, Jane's family circumstances, although she may have understood that they didn't have a lot of money, were not perceived by her as unacceptable. However, soon after having been taunted by her classmates, Jane remembers that she became more aware of possible consequences both socially and academically.

Jane views the actions of her classmates as demonstrative of this as she recalls, "They would take and write on the floors and stuff and go tell the teachers that I did it" (Jane, personal communication, May 6, 2013). In addition, Jane reveals her belief that even the adults at the school did little to remedy her situation of being victimized by peers when she states, "They'd [teachers] have their picks, you know? .... the teachers, 
and the principal not doin' nothin' about it [bullying] .... If they wanted to help you, they would help you. And if they didn't, well, so be it" (personal communication, May 6, 2013). It may be that some of the negative interactions between Jane and her classmates, as well as between Jane and the school faculty, were influenced by Jane's pre-conceived notions [positioning], (van Langenhove \& Harre', 1999), regarding the others' possible intentions that contributed to her experiences of dysfunction at school. Jane talks of a belief that she needed to become a fighter early in life, often doing so in order to take up for herself when being picked on as she shares, "I was tired of people makin' fun of me and stuff .... I guess I was afraid of nothing” (personal communication, May 6, 2013).

Perhaps not all of the circumstances were destined to be the negative interactions, however, some may have become so as a result of Jane's assumed combative and defensive stance. These circumstances may have been different had Jane responded in a different manner. Further, it may be that some form of stand-off was being established each time one party or the other responded in the adversarial manner each did so.

In addition, to her difficulties with relationships, Jane also indicates that she felt plagued with academic difficulties, and that the frustrations she was experiencing made focusing on schoolwork all the more unpleasant. With regard to experiences of difficulty when attempting to address school subjects and tasks, Jane seems to again assume the victim and blame others for some of her frustrations. This appears to have been bolstered as Jane seemed to have discovered early on that neither her school environment nor her home were places where she could obtain assistance when trying to understand the requirements of various academic tasks. "My dad and my mom couldn't read" (Jane, personal communication, May 6, 2013). 
According to Jane, school continued to be one bad experience after another as she found herself in predicaments involving academic frustration, as well as her response to that frustration by becoming combative with others. While her combative response to what she perceived as unfair treatment and lack of support usually got her deeper into trouble, this seems to have become Jane's assumed identity (Gee, 2001), and something Jane routinely uses as an excuse rather than attempting to monitor her own behavior.

Jane seems to have experienced of this state of disequilibrium, (Piaget, 1967), in a number of instances both in school from an academic standpoint, as well as socially with regard to her attempts to get along with others. In each instance, it appears that Jane's realization that acceptance by classmates, as well as the availability of the support needed from her teachers and parents, was not regularly accessible. Her sense of isolation or of having been abandoned is revealed as she laments, "If someone hada [sic] took and sit and explained how we do somethin', it might not have been as hard, but .... Just tryin' to figure it out on your own, yeah, it was hard" (Jane, personal communication, May 6, 2013). As a result, Jane's experience of disequilibrium may have also contributed to her combative responses. In addition, this feeling of abandonment seems to be a common thread throughout Jane's story.

It is interesting to note that Jane seems to choose to respond to many uncomfortable or unfamiliar circumstances by adopting an attitude of defiance. She seems to do so even as an adult, perhaps because it is her way of protecting herself from additional disappointment. Somehow, Jane has adopted a survivor stance that, in her mind, can only work as long as she remains guarded against whatever might be threatening her at the moment. 
The stories that Jane relates about her middle school experiences suggest that those experiences also did little to encourage her to respond any differently than she did during her elementary years. According to her, rather than finding a place for herself, making friends with classmates, gaining an increased understanding of academic concepts and tasks, or even a more responsive and supportive staff, Jane indicates that she encountered what she describes as still more hostility. In response to that perception, it appears that, according to Jane, the acts of hostility became reciprocal. In an attempt to justify her combative posturing, Jane states in a matter of fact manner, “I guess I wasn't afraid of nothing" (personal communication, May 6, 2013). This was met by what Jane considers to have been a lack of encouragement or support from the adults responsible for her education and well-being during that time in her life.

Jane recalls that in response to this alleged hostility, when confronted with assignments and expectations of teachers for her to complete them on her own, she told her teachers, " 'F' you. You take 'em home yourself”' (personal communication, May 6, 2013). Further, Jane recounts that although she was in a different school and with classmates from an area different from that of her elementary years, relationships continued to be toxic. "In middle school .... I was getting into fights. I was tired of people makin' fun of me and stuff, so, .... I got to the point I started slammin' 'em up against the lockers" (Jane, personal communication, May 6, 2013).

While the response Jane received, whenever taking things into her own hands for being teased or bullied at school, may have been expected, its fruition seemed only to reinforce Jane's preconception that she would have no support. This can be read into how Jane describes the experience: "I even got to the point where I got kicked out of 
school and the principal told me, "never come back"' (personal communication, May 6, 2013).

While hearing what Jane views as memories of frustration that continue to burden her, "the teachers at school, well I don't know about now, but then, they coulda cared less if you was there or not. You was just takin' up their time” (Jane, personal communication, May 6, 2013), it seems that she suggests that, in her eyes, she had no recourse other than to "want to walk in one door and straight out the other, even in first grade" (Jane, personal communication, 2013). In addition, Jane conveys a belief that a combination of things, including the way she was treated by others, as well as her family, drove her to the point of assuming a combative attitude that fighting back was her only recourse. This can be heard as Jane states, "I was the type, uh, you say somethin' smart to me, looked at me cross ways, or you had an attitude toward me, we was goin' out there on the road, and we was goin' to fist fight” (personal communication, May 6, 2013).

In yet another instance Jane recounts where she had been placed in a center for troubled youth, describing this particular location as a place where they sent kids whom nobody wanted. Once again, Jane's description suggests that she viewed herself as having been abandoned and just another kid who was unwanted. Otherwise, she believes she would not have been sent there. However, while Jane assumes that she was there because she was unwanted at home, she shares a story about her own demonstration of being a care-giver.

Believing it may serve as evidence to this view, Jane describes Jimmy [pseudonym] as a boy that nobody wanted anything to do with. She reports that because Jimmy was having difficulties with his school work, and the fact that she knew a lot of 
her Math facts, Jane befriended Jimmy and began to tutor him in Math. Jane's story includes examples of how she was Jimmy's academic care-giver, as she taught him little tricks that might help him remember math problem-solving skills more easily. When recalling her experience from that particular center, Jane shares,

Once, when I was in the center, I would help Jimmy, a mentally retarded boy that nobody wanted to really deal with or be around. I stepped in and tried to work with him, 'cause I knew my Math. And me and him would get together to try to teach him little odds and ends to teach him his Math. We got along real good. (personal communication, May 6, 2013)

As Jane tells this story, it seems that she is describing someone who prefers to be seen as a tough individual, yet who was actually finding validation through helping others. This made me wonder about Jane's need to be appreciated and how it seems that appreciation may not have been prevalent during earlier experiences and interactions. It would be interesting to know how things may have been different otherwise.

It seems that Jane assumes a lifestyle demonstrative of her acceptance of those negative views such that she has fulfilled the lesser expectations. This becomes fairly clear as Jane tells of her turn to promiscuity and prostitution as a means to survive. "I used to sneak out my bedroom window, two, three o'clock in the morning, lock my door .... I would get with ... men, go out bar hopping" (Jane, personal communication, May 6, 2013). Jane also reveals that, even though she was under age, because she looked older than her actual age, “They [pub owners] didn't ask for IDs or nothin” (personal communication, May 6, 2013). In those instances, unfortunately Jane was a victim of what appears to have been a flawed process. 
Jane's entrance into the adult world and coming of age occurred through what many would view as rather risky and promiscuous behavior. This seems to have occurred in response to her need to take care of herself and the fact that her familial circumstances had deteriorated, in Jane's opinion, leaving her no alternative. Jane reveals this when she states,

I learned how to survive in life on my own .... I had to defend myself .... 'cause every guy I got with, I was their punchin' bag. I had to be able to take up for myself or someone was gonna kill me. (personal communication, May 6, 2013) Being overwhelmed with the difficulties connected to what she views as unsuccessful school experiences, as well as her promiscuous behavior while still a minor and the downward spiral brought about by her numerous failed relationships with male companions, Jane needed to find an outlet. As a result, it appears that Jane's decision to leave school early was something she saw as freeing her from the many negative experiences, condemnation, and ridicule that had allegedly plagued most of her youth.

Much of what was indicated by Jane seems to suggest that she was searching for some sense of empowerment in exchange for always being the victim. This mindset appears to have remained with her through the present. She seems to justify her combative nature when reflecting on difficulties in school and her response stating, "I just got to the point, 'Why even try?' If you can't get no one to sit down and work with you, and, you know, explain to you what you need to do" (Jane, personal communication, May 6, 2013).

In spite of the opportunities for validation available in the aforementioned vignettes involving either the Minister's family and or Jimmy, as Jane continued to rebel 
against expectations, her story suggests that it may be a part of her assumed role and of how she perceives others' opinion of her - that she was, and is, worthless, would never, and doesn't, account for anything, and is unworthy of respect or support. Jane's story tells of a journey where she repeatedly finds herself with little or no respect from others on most fronts, (home - her mother - her siblings, and school - classmates - faculty, as well as other persons of authority, etc.).

It seems Jane's decision to leave school early may have been prompted by her assumption that life would improve. With that in mind, she acted on that assumption prior to the completion of her eighth grade year. Perhaps her inaccurate evaluation of options available and the potential for resolving any of the complicating actions were influenced by her experiences while a pre-teen.

To be accurate, Jane should only be recognized as a school dropout, as she does not meet the definition of a high school dropout. A student is currently not permitted to leave school prior to having reached his or her seventeenth birthday. At the time of Jane's decision to do so, the minimum age of eligibility was sixteen.

In Jane's case, her decision to leave school early did not include a requirement of a parent's authorization to do so. As Jane explains it, she believes that it was her defiant behavior that most likely contributed to her being difficult for her parents, anyone in the school setting, and or the representative from the Welfare Department. When asked to explain how her act of dropping out occurred as early the eighth grade, Jane shares, "My mom started callin' the Welfare, callin' DHHR on me .... She [DHHR rep.] would come out and threaten me that she was going to send me off and all that" (personal communication, May 6, 2013). In addition, when recalling the circumstances involved 
when she was threatened with punishment by the DHHR representative, Jane boasts about having stated, "Well, you know, you gotta do what you gotta do" (personal communication, May 6, 2013). As a result, it seems that leaving school early was a decision made by Jane without being challenged by anyone who may have been able change her mind, as such an individual did not seem to exist.

\section{Life After Leaving School Early}

Although Jane saw dropping out of school as a way out from under the many negatives in her life, it appears that this decision may not have done so and that some of her other decisions since that time have compromised her ability to be successful in a number of ways. These decisions did not improve her life as expected. Instead, it seems that Jane merely exchanged one set of difficulties for another. When asked about what her life has been like since having dropped out of school, Jane indicates, I got into doin' drugs and drinkin'. Uh, ... ended up with some wild and crazy men. Um, ...used to work strip bars. Um, ... slept in abandoned houses and under bridges. Hmmm, ... didn't have much of a life at all. Just doin' whatever came natural ... to me that was natural. (personal communication, June 22, 2013) Similar to the previous two sections, Table 4.4 depicts vignettes and themes from circumstances of Jane's life After Leaving School Early. Once again, information of this nature is also intended to represent the complicating actions, evaluations, and resolution in accordance with how Jane seems to have interpreted of those circumstances.

Included in this table are suggestions that Jane appears to have matured in response to needed decisions regarding the care of her child, as well as when it became necessary to care for her terminally ill mother. Thus, while continuing to feel victimized and abandoned, Jane eventually reveals an assumed position of care-giver. 
Table 4.4

Vignettes and Themes from Jane's Journey - Life After Leaving School Early

\begin{tabular}{|c|c|c|c|}
\hline $\begin{array}{l}\text { Complicating } \\
\text { Action }\end{array}$ & Evaluation & Resolution & Theme \\
\hline $\begin{array}{l}\text { "Um, I use to sell my } \\
\text { body. I used to work } \\
\text { the strips bars." }\end{array}$ & $\begin{array}{l}\text { "Hmm, didn’t have } \\
\text { much of a life at all. } \\
\text { Just doin' whatever } \\
\text { came natural. }\end{array}$ & $\begin{array}{l}\text { "Uh, ended up with } \\
\text { some wild and crazy } \\
\text { men." }\end{array}$ & $\begin{array}{l}\text { Victimization; } \\
\text { Survival }\end{array}$ \\
\hline $\begin{array}{l}\text { "Uh, since I dropped out } \\
\text { of school, I got into } \\
\text { drugs \& drinkin." }\end{array}$ & $\begin{array}{l}\text { "I got around people } \\
\text { that was doin' drugs \& } \\
\text { they was sayin' 'you } \\
\text { need to do this'." }\end{array}$ & $\begin{array}{l}\text { "Most of the time I took } \\
\text { care of myself." }\end{array}$ & $\begin{array}{l}\text { Victimization; } \\
\text { Survival }\end{array}$ \\
\hline $\begin{array}{l}\text { "I was eight months } \\
\text { pregnant in the winter } \\
\text { time, sleepin' outside." }\end{array}$ & $\begin{array}{l}\text { "I couldn't let him live } \\
\text { the kinda life I was } \\
\text { livin'. It was no way." }\end{array}$ & $\begin{array}{l}\text { "That is when I was } \\
\text { gonna adopt him [son] } \\
\text { out." }\end{array}$ & Caregiving \\
\hline
\end{tabular}

Jane's story suggests that she has been living a life of what she considers a survivor's existence, with little to show for it. For as long as she can remember, her experiences have been of survival and combat when it comes to most of her relationships. Likewise, her circumstances appear to have been, and continue to be, the result of multiple poor decisions, such that she continues to wish that things had been different. Of particular interest is that, even at her present age, Jane seems continue to view her journey as being the result of fate. This is evident when Jane reflects, "I get myself in trouble, somehow. Even if I don't mean to, I still do" (personal communication, June 22, 2013).

Unfortunately, even Jane's recent encounters with the law seem to have been mired with argument and a sense of being victimized, while Jane does not appear to be responsible for much of the problem. To that end, Jane continues to offer an explanation for her current circumstances, as well as others throughout her life, as things done to her and devoid of any possible outcomes that she may have put into motion, ever portraying herself as having been victimized. Jane reported that since she has dropped out of school, 
her life has been hard and filled with danger and controversy. From a financial standpoint, Jane has needed to participate in what are typically considered by most people as some demoralizing activities in order to have food and clothes and ensure that she has a roof over her head. This is revealed as Jane reports, "I worked the streets, played the men .... I used to sell my body to be able to eat, have a roof over my head, sometimes" (Jane, personal communication, June 22, 2013). Reportedly, circumstances of this nature started well into her early adolescent years and have continued to repeat throughout her adult life.

At no time does Jane talk about any attempts to find gainful employment as a contributing member of society. Instead, Jane seems to have accepted the notion that she is unacceptable to most others and that her only recourse may be to seek the attention of men by selling her body or participate in some other form of illegal activity as a means to earn money to survive. She demonstrated this when describing her more recent reason for becoming a participant in the Department of Community Corrections program, at the same time blaming others for her incarceration.

Subsequent to her initial sentencing, Jane experienced a recent return to the regional jail for what was considered to be violating her probation. When asked about the more recent incarceration, Jane adamantly shares what sounds like a slightly skewed version of an encounter with her supervisor from the Department of Community Corrections that ultimately landed her in the area Regional Jail.

The following excerpt from our interview is an example of how Jane views her circumstances and suggests that she felt compelled to be argumentative, rather than otherwise with her supervisor. Jane seems not to view any of the combative attitudes that 
continue to be present in this exchange as anything other an appropriate response to being treated unfairly. Instead, Jane's defensive stance seems to be her default recourse, continuing to hold out hope that she will be seen as having power over others rather than appearing weak. Such a defensive stance can be heard as Jane shares, Look at the predicament I'm in now. Um, I got this call tellin' me to be in Sue's [pseudonym] office in ten minutes, or there was goin' to be a nation-wide warrant out for me. And, I'm like, 'I'm two and half hours away.' And she [Sue] told me 'Well, I guess you'll be on the news.' I said, 'Well, I guess that's where I'll be.' And she told me she'd have this person and that person out lookin' for me and she'd have me picked up in two hours. That's when I walked in and looked at her and said, 'Well, it's been eight days, and you ain't got me yet.' Yeah, I was bein' a smart ass. (personal communication, June 22, 2013)

Jane's stories reveal what may seem to some as an almost compulsive need to be in charge. Perhaps this is because she has spent the majority of her life reacting to the actions of others, trying to understand why she has been treated poorly, and buying into a poor self-image, all the while trying to regain control of her circumstances at any cost.

\section{Concluding Thoughts}

When any human being acts and interacts in a given context, others recognize that person as acting and interacting as a certain 'kind of person' or even as several different 'kinds' at once .... The 'kind of person' one is recognized as 'being', a given time and place, can change from moment to moment in the interaction, can change from context to context, and, of course, can be ambiguous or unstable. (Gee, 2001, p. 99) 
Analysis of Jane's story, as reported in this chapter, reveals that individuals can be heavily engaged in any number of activities or experiences, both negative and positive, and still take away some unexpected impressions. In some cases, this may be the result of an assumed persona or stance that prevents the individual from being open to more than one interpretation of any given event.

According to van Langenhove and Harre' (1999), "Fluid positionings, not fixed roles, are used by people to cope with the situations they find themselves in" (p. 17). Possible contributors to this instance of what some may consider temporary blindness can be such things as repetitive discouragement or ridicule, often experienced at an early age and then adopted by the recipient as his or her perception of reality. Further van Langenhove and Harre' (1999), also tell us that "One can position oneself or be positioned as e.g., powerful or powerless, confident of apologetic, dominant or submissive, defensive or tentative, authorized or unauthorized" (p. 17). These opposing circumstances seem to have been occurring as Jane experienced a variety of situations including her belief that she was not wanted by her siblings, that her mother sent Jane away (although possibly in an attempt to protect her from the dangerous influences and ensure a better life), the taunting Jane received from classmates who marginalized her otherness as a poor kid simply because she was wearing old and thread-bare clothing to school, as well as the abuse endured by Jane at the hands of the various men from whom she sought attention and money while attempting to survive on her own.

According to Labov (1997), events shared by the speaker are typically personal and have become part of the speaker's biography (i.e., are emotionally and socially evaluated), and therefore, have been transformed from some raw experience. This seems 
to be easily identified in any number of Jane's accounts. Further, Jane's evaluations of those events seemed to be that she bases her responses on something(s) that she believes were done to her. This is apparent each time she attempts to justify her responses to the actions of others with whom she experienced what she viewed as a negative interaction.

I found that Jane presents as an individual who is strong and ready to fight with just about anyone whom she may feel is about to confront or hurt her. Likewise, just below Jane's seemingly hardened persona seems to be an individual who yearns to be acknowledged as worthy of others' time. In addition, in spite of her effort not to reveal them, what seems to sneak out of Jane's stories are examples of her attempts to please others, to provide for them, all of which seem to exemplify an internal need for her to find, claim, and retain even the smallest amount of dignity.

From her stories I also heard how Jane may not have experienced many opportunities that offered the validation she seeks. This circumstance may have influenced her growth and development in very different ways. Whenever we talked, I found Jane to be respectful of me, the questions I wished to ask, and of my time. At the same time it appears that inasmuch as she has survived a fairly rough life on her own, Jane prefers to be viewed as the bad girl of the group.

While she cooperated during our interview sessions, Jane's circumstances still involved being incarcerated as a result of her having violated the terms of her probation. As a result, this had a negative impact on the successful work that she had done up until just three days prior to her completion of the program requirements being fulfilled by her. Reflecting on this raises my own suspicion that Jane may have been seeking some way to 
prevent herself from having to be on her own again and subsequently having to deal with the very difficult life situations that await her.

When reviewing her accounts of experiences, it seems that Jane's rather subjective response to various events has been influenced by her memories (many being distant), emotion and or some internal feeling or belief (Jane continues to view them as a repetition of affronts). With this in mind, the credibility of stories shared by Jane might be considered with caution, as they seem to be based more on her subjectivity rather than her ability to remain objective. This would be germane to some of the research done by Labov and others that suggests that creditability will be maximized by the objective reporting of events.

As a result of her assumed combative posturing of strength during times of oppression, Jane tends to respond to new and or threatening circumstances in a defensive mode, perhaps because she feels her best defense is a strong offense. This, however, does not serve her well, as it seems her emotionality may be clouding her ability to be objective, (Labov, 1997). Nor has it seemed to have served her best interests in the past. Instead, it is possible that Jane has overlooked many opportunities that may have changed the course of her life thus far as well as possibly influencing her future. For instance, perhaps if Jane had understood that the actions of her mother were a demonstration of a mother's love for her child, Jane might have appreciated those actions for what they were intended sooner, as opposed to when her mother was on her death bed.

It seems that Jane attributes her negative self-image prior to entering school as being due to negative treatment by her siblings such that Jane was not prepared to fend off the typical teasing that often occurs between classmates. This includes the ridicule 
that often accompanies one's otherness. In Jane's case, her argumentative posturing may have set her up for still more ridicule, hence establishing a cycle of negativity - ridicule combative responses - followed by still more ridicule without intervention, etc. This is often the case with regard to children, in most instances simply when the vulnerability of a weaker member of a group is identified as such. Gee (2001) refers to this circumstance when addressing various ascribed identities:

In modern capitalist societies, none-elites are 'encouraged' to accept the inferior identities elites ascribe to them in talk and interaction (ascribed Discourseidentities) as if they were the actual achieved identities of these non-elite people, achieved on the basis of their lack of skill, intelligence, morality, or sufficient effort in comparison with elites. (p. 113)

Along these lines, it may be that Jane arrived at school already portraying herself to be a victim, an action that inadvertently announced her as the weaker, more vulnerable, member of the group.

As Jane shares her memories of her journey to date, the majority of what she shares appears to have a negative tone. Much of what she remembers has some connection to her having been victimized, disappointed, let down, and or set up for trouble by and from others. While the characters in her various reports may change, the majority of Jane's stories seem to cast her as the victim or the one being stripped of any power, and the "others" in the role as exploiter, abuser, and or neglectful person of empowerment. For the most part, her stories are a suggestion of hopelessness and a constant need to search for survival. 
Although Jane does not appear to have experienced encouragement in most instances throughout her story, I wonder how things may have been different had she responded differently. Even though she may believe that she has moved on, the circumstances that she finds herself in more recently and the decisions she has made when confronted with issues of perceived threats, are such that Jane continues to present as combative. In doing so, she seems to justify her many frustrations and actions as something to be expected, a natural response. In contrast, as Jane shares information about her journey, she includes an occasional example of how she found a sense of purpose in serving others. This was noted when telling of her own response to the needs of Jimmy, an apparent outcast whom Jane befriended when at the program for troubled youth.

Perhaps an equally compelling example of her sense of responsibility, even while she continues to portray herself as having become toughened by all that life has thrown at her, is when Jane shares her need to ensure the safety and well-being of her first-born child. This is evident when Jane says,

I was eight months pregnant in the winter time and sleepin' outside. That was when I was goin' to adopt him out. I wasn't gonna live that way. But, finally I got enough money together to get me a place. But, if I wouldn't have got enough to get a place, yeah, I would've adopted him out. I couldn't let him live the kinda life that I was livin'. It wasn't no way. (personal communication, June 22, 2013) Jane reveals a compassionate side that perhaps lingers just beneath the surface and is typically pushed down by the other difficulties that continue to occur throughout her journey. This is detectable when listening to her words and comparing them to her 
actions. Although Jane appears to have experienced difficulty beyond measure, there remains an individual who, given any number of different circumstances, may have a completely different story to share.

As mentioned earlier, it may be possible that some of Jane's mother's decision with regard to "puttin' [Jane] in foster homes and groups homes", (Jane, personal communication, April 30, 2013), was based on attempts to protect Jane from a variety of inappropriate, unsafe circumstances about which neither Jane understood or were revealed in Jane's story. Likewise, it is possible that we hear a similar act of protective maternal instinct being played out with regard to Jane and her own initial maternal consideration to "adopt out" her first born.

As I reflect on the many stories shared by Jane, I am troubled by the many possibilities that may have existed that might have altered her journey in a more positive fashion. For example, while school experiences can sometimes be unpleasant for individuals as each leaves the security of his or her home and each learns to share public spaces; tease and be teased by others; as well as feel the occasional sense of disequilibrium that comes with increasingly challenging academic expectations about which Piaget cautioned, most of us navigate those experiences successfully. However, on a number of occasions Jane's potential for a successful journey seems somehow to have been de-railed.

Understandably, the use of the term successful in this case should be considered a relative one. As Bronfenbrenner's (1979) Ecology of Human Development conceptual model suggests, there are multiple layers, or concentric circles, of influence upon which a developing child relies and that the reciprocal exchanges between the various layers can 
change the way the individual may respond. Further, we learned from his work that children who are raised in an environment that fails to offer a secure sense of belonging often experience emotional and or behavioral difficulties. With this in mind, Jane's story caused me to wonder about which instances may have been imposed on her and which may have been put into motion as a result of Jane's personal search for power over her own circumstances.

The time spent with Jane during each of our interview sessions was both informative and perplexing. Was Jane simply willing to spend the needed time to recount the circumstances of her life journey, thus far, out of respect for me as a researcher? Or, was it because she finally met someone she perceived to be willing to listen, someone who cared enough to give her voice, someone whom she perceived to have the power to report on her perceived evils of those whom she believes had let her down in the past?

At no time did Jane apologize for any of her reported "bad girl" behavior. Nor did she seem to connect that with any of her negative experiences. This was noticed during an exchange that occurred in one of our interviews after Jane had spoken about her defiant attitude with the Department of Community Corrections director. At that time Jane was asked if she felt that she had "won." To this, Jane simply replied, "I didn't win. You never win. It don't matter what you do, you never win" (personal communication, June 22, 2013).

In addition, time spent with Jane has revealed some unforeseen dilemmas. School for many is a worthwhile endeavor. For others, however, it can be a less than successful journey. According to Jane, 
Well, in school, you're an inmate. 'Cause they look at you as a criminal. Or, a bad person or you're filthy, or you're scum. I mean, there's all kinds of different things that they'll call you ... trash. Mmmm, it's just as bad as bein' here [regional jail]. It's weird. (personal communication, June 22, 2013)

Jane makes an interesting connection to what she views as a similarity between the school child and a prison inmate. It makes one wonder what truths there may be in this observation. Could it be that the two separate systems operate in much the same manner? Or was Jane's comment merely an expression of frustration that she experienced when she was at the school and then incarcerated?

With this in mind, it may be worthwhile for educational policy makers and practitioners in our schools to investigate further those assumptions regarding what contributes to students' decisions to disengage from school activities and eventually drop out. In some instances, it seems the disconnect between what we believe to be occurring in our students' educational lives and the circumstances of their personal experiences, both within and outside the classroom, may be more intensely influencing the individuals' ability to be successful academically.

Could it be that, while attempting to ensure that no child is left behind, our current systems are overlooking some equally imperative concepts and practices that could ensure more success in the long run? Perhaps making time to investigate issues that lie behind the otherwise assumed universality of the "ABCs of school dropout" might be an excellent place for revealing still more clear understanding. Indeed, it may require a different way of looking at our students, perhaps on a more individual basis. To that end, 
I posit that many areas pertaining to gaining a better understanding of the school dropout dilemma remain to be investigated.

Jane reminded me that she quit in the eighth grade and, as a result, in her opinion, her outlook on life changed for the better because she "didn't have the family to deal with ... didn't have the students, or the teachers, or the principal ... none of them" (Jane, personal communication, May 6, 2013). Because Jane, “didn’t have someone standin’ around cutin' me down, making me feel bad about myself, saying, 'you're stupid, you're dumb, you're never gonna amount to nothin" (personal communication, May 6, 2013), she strongly believed that she would be free to live her own life and from any future criticism from others. In Jane's case, it seems that has not occurred. With that in mind, it appears that Jane's evaluation of her circumstances prompted her to think, "I never have to be around none of that no more" (Jane, personal communication, May 6, 2013). However, it also appears that Jane's perceived resolution to the problems she was facing have only introduced still more difficulties for her. 


\section{Chapter Five}

The purpose of this chapter is to introduce Wes and the story he shared about his journey. As stated in Chapter 4, I shall first provide a biographical description of the participant, as well as the context in which he was situated. Next, I use relevant and compelling excerpts from my data to illustrate how the participant constructed his understanding of the various experiences and relationships leading up to a decision to drop out of school, as well as reflections of the impact that decision may have had on his life in general. This chapter will conclude with a consideration of how Wes constructed his own identity.

\section{The Story of Wes}

In this chapter, I explore how Wes's experiences both within and outside of school may have contributed to his decision to leave formal education prior to graduation. In addition, Wes was asked to share his understanding of the impact that his decision to drop out may have had on his life from that time through the completion of our time together. Initially, Wes responded to the interview setting in a somewhat reserved manner, as participation in an interview was not a familiar experience for him. However, as he became more invested in the memories that he was sharing, his initial apprehension seemed to fade.

The sequence of stories being investigated with Wes asked that he recall things that had occurred several decades prior. Doing so, according to Wes, may be a difficult task inasmuch as "that was a long, long time ago for me" (Wes, personal communication, August 6, 2013). However, once Wes began to reflect on those distant days, his memories appeared to unfold in a fairly sequential order. 
In an attempt to assist in this sequencing, Wes was asked tell a number of stories related to his life first as a child at home, subsequently during his school years, and finally after having left school early. This was done during a series of three open-ended interviews conducted with him. I posit that narratives provided by Wes provide opportunities for understanding the intersection of circumstances that had an impact his interpretations of life events and the decisions he made about school and life in general.

\section{The Participant}

Wes is a sixty-seven year old, Caucasian male. He was initially identified as a potential participant in this inquiry as a result of a conversation with a professional colleague when discussing my graduate work and pursuit of a Doctoral degree. As that conversation led to my interest in studying the growing dilemma of school dropout through the lens of those who had actually done so, Wes was suggested as someone known by my colleague and who might be an excellent participant for the study.

Eventually, I was introduced to Wes and, once he agreed to participate, interviews were scheduled. The following is a result of the interview sessions shared with him.

\section{The Context}

Wes was the middle child of five children, three boys and two girls. He was born into a farming family of very limited financial income, during a time when most families learned to provide for one another through hard work and ingenuity. Most of what was available came from the family garden and the livestock they raised on the family-owned farm. The only time provisions that could not be produced at home were obtained was during the routine annual visit to a nearby town general market, during which, according to Wes, "We would usually buy a barrel of flour and two or three hundred pounds of 
sugar" (personal communication, August 6, 2013). Otherwise, items needed around the farm were typically repaired or made from other parts or broken items found around the home place.

Table 5.1 represents an excerpt from the U.S. Poverty Guidelines from the approximate time when Wes was first entering school. Although both of Wes's parents were part of the nuclear family dynamic throughout his childhood, it was his mother who maintained the operations around the farm while his father worked away from the homestead. The information found in the following table helps illustrate how little was required to qualify a family as below the poverty level during that time. It also helps clarify why Wes and his family relied as much on their ability to produce their own goods and supplies, rather than purchasing them.

Table 5.1

United States Poverty Thresholds for 1959

\section{Male Head of Household}

$\underline{\text { Size of family unit }}$

Related children under 18 years

None One Two Three Four Five Six or more

Two persons:

Head under 65 years $\ldots \quad \$ 1,670 \quad \$ 1,685$

Head under 65 years ... $\$ 1,499 \quad \$ 1,871$

3-5 persons

6 persons ....

$\$ 33,549 \quad \$ 3,561 \quad \$ 3,485 \quad \$ 3,409 \quad \$ 3,308 \quad \$ 3,359$

7 or more persons $\begin{array}{lllllll}\$ 4,469 & \$ 4,508 & \$ 4,419 & \$ 4,343 & \$ 4,242 & \$ 4,090 & \$ 4,054\end{array}$

Note. Income Thresholds at the Poverty Level in 1959 by Sex of Head of household, Size of family, and Number of Related Children Under 18 Years Old (Farm Residence). Retrieved from U.S. Census Bureau - Poverty Thresholds 1959 web-site: http://www.census.gov/hhes/www/poverty/data/threshld/thresh59.html

While Wes learned to make do with the little that the family had, this did not seem to be something that was viewed as unusual by him and others in his family. As a 
result, he reported that, for the most part, he and his siblings experienced what he felt was a happy childhood. According to Wes,

We used to make our own wagons. Uh, we would take an old steering set off an old Model A Ford or something and, uh, put the steering sector on 'em and we'd take a hoe and maybe dig us a road along the hillside of something. And we'd have fun runnin' them wagons. (personal communication, August 6, 2013) Reportedly, during both work and play activities, everyone participated. In order to help bring in some money for the family, Wes's father found work that required him to be away from the farm and family for the majority of Wes's childhood. “He [Wes's father] worked in Ohio....he walked about, uh, two mile, uh, over to the neighbor's house and rode back and forward with the neighbor....He did that, I don't know, twenty years, fifteen years. Somewhere along there" (Wes, personal communication, August 6, 2013). This meant that Wes's mother was responsible for running the farm. According to Wes, his mother did a good job at keeping everyone under control as she made sure that everyone knew and completed his or her chores and school work. This included her being available to assist with homework even though it was only to a limited degree.

Wes attended school in a small one-room school house located, according to him, within walking distance from the farm. He reported that the school included grades one through eight and typically consisted of approximately twelve to fifteen students across most of the eight grade levels during any one school year. As a result, there were frequent and routine expectations for some of the older students to assist other younger 
members of the class. This freed the teacher to instruct various other small groups on a rotational basis.

After leaving school early, Wes immediately started working. It was shortly thereafter when Wes married his wife, Nina [pseudonym] and they began purchasing their first home, a single-wide mobile home that the two of them set up on Nina's family's home place. From that time on, Wes and his wife have continued to work hard while sharing the responsibilities that came with providing for their two children. After working at a saw mill for a number of years, Wes worked at a rubber production plant. Subsequently, he and Nina decided to take a chance, venture out on their own, and open a local hardware store. They continued to own and operate that store for a number of years, eventually retiring from the family business and settling into a less stressful lifestyle.

In recent years, unfortunately, Nina's health has become a concern and now requires Wes to care for her as the circumstances continue to have an impact on her ability to care for herself as independently as before. The dynamic in their relationship and the manner in which Wes addresses current circumstances was impressive to observe. It was also quite clear during our interview sessions that as both Wes and Nina advance in age, this newer responsibility continues to stress Wes as he worries about how Nina will be cared for in the event that she may survive him.

\section{Overview of Wes's Story}

This chapter first explores the events and circumstances of Wes's life as a child, as a student, his decision to leave school early and what his life has been like since having done so, in addition to how his interpretation of these experiences contributed to 
his decisions and the life that followed. When reviewing the information shared by Wes, a number of themes emerged from my analysis his narratives that include (a) poverty, (b) marginalization and victimization, and (c) resourcefulness. These themes provide perspective related to how Wes made sense of life events, how he positioned himself and others in his life, and how he responded to these events and made decisions that affected the course of his life.

I have organized the findings I present as a series of vignettes provided by Wes related to his life before and in school, as well as his life after he left school early. These themes are identified as a means of capturing the ways in which I made use of Labov's (1997) structural narrative analysis to understand how Wes made sense of and constructed his life through evaluating and resolving the complicating actions of his stories. Further, I explore how his use of language situates himself in these narratives and contributes to how he responded to events in his life and the identities he constructed.

Tables 5.2, 5.3, and 5.4 are provided toward the beginning of each section of Wes's story as examples of the various positions (van Langenhove \& Harre', 1999) he assumes while discussing memories from his journey. The tables demonstrate a series of vignettes representative of specific portions of Wes's story about his Early Years, his School Experience, and his Life After Leaving School Early.

\section{Wes's Experiences of Home}

Acknowledging that memories from as long ago as when he was a child might be somewhat difficult, Wes did an excellent job doing so. Wes's response to questions pertaining to his family, what life was like, his relationship with other family members, and where he fit in includes sharing a number of stories about activities in which he, his 
four siblings, and each parent engaged. He indicates that he was born into what many at that time viewed as a typical rural Appalachian farm family circumstances, the middle child of five. According to Wes,

We grew up in a log house. The main house had a setting room and it had two bedrooms, and then we went out on the, across from the porch into the kitchen. It had a kitchen and a dining room there and also another bedroom on it .... We didn’t have no electricity ‘til I was about twenty-one years old. We had oil lamps, uh, I 'member one time we got, uh, what they called a laddin lamp, and boy, it really gave out the lights a lot better than the old oil lanterns and oil lamps .... That house was there when we bought the farm .... A hundred and thirty-five acres .... The closest neighbor was about two mile. (personal communication, August 6, 2013)

Although Wes was raised on a family farm and his family didn't have a lot of money, Wes does not recall that he or his siblings understood that they may be considered to be poor. Their circumstances were simply what they considered to be normal as far as he knew. As a result, Wes learned at an early age that being resourceful was a part of life. These circumstances seem to have influenced Wes throughout his life, as well.

Table 5.2 contains examples of how Wes's circumstances did not compromise his childhood as he assumes a position of resourcefulness. In addition, Table 5.2 includes an example of how, even when one practices resourcefulness, there may be times when one finds himself or herself to be the victim of circumstances. 
Table 5.2

Vignettes and Themes from Wes's Journey - The Early Years

\begin{tabular}{|c|c|c|c|}
\hline $\begin{array}{l}\text { Complicating } \\
\text { Action }\end{array}$ & Evaluation & Resolution & Theme \\
\hline $\begin{array}{l}\text { "We didn't have no } \\
\text { electricity 'til I was } \\
\text { about twenty-one years } \\
\text { old." }\end{array}$ & $\begin{array}{l}\text { "He [dad] worked } \\
\text { away during the } \\
\text { week. He helped } \\
\text { during the weekends. } \\
\text { Other than that we } \\
\text { kids had it." }\end{array}$ & $\begin{array}{l}\text { "We got along real } \\
\text { good. Everybody } \\
\text { done real good." }\end{array}$ & $\begin{array}{l}\text { Poverty; } \\
\text { Resourcefulness }\end{array}$ \\
\hline $\begin{array}{l}\text { "We went to town } \\
\text { once a year. We } \\
\text { didn't go to the store } \\
\text { and buy a bunch of } \\
\text { groceries like we do } \\
\text { today. We went and } \\
\text { bought like a barrel } \\
\text { of flour and maybe } \\
\text { two or three hundred } \\
\text { pounds of sugar." }\end{array}$ & $\begin{array}{l}\text { "The closest neighbor } \\
\text { was, uh, probably } \\
\text { two mile....I } \\
\text { 'member when my } \\
\text { little sister was being } \\
\text { born, we had to go } \\
\text { stay with my } \\
\text { grandmaw and } \\
\text { grandpaw about a } \\
\text { quarter mile away } \\
\text { until the midwife } \\
\text { come a got us." }\end{array}$ & $\begin{array}{l}\text { "We raised our } \\
\text { gardens and most of } \\
\text { our food.... plowed } \\
\text { the garden with the } \\
\text { horses, sheered the } \\
\text { sheep and sold the } \\
\text { wool. We raised } \\
\text { cattle. That's where } \\
\text { we got our milk. }\end{array}$ & Resourcefulness \\
\hline $\begin{array}{l}\text { "When all the presents } \\
\text { come, everybody got } \\
\text { their presents, but I } \\
\text { didn't get one." }\end{array}$ & --------------------------- & 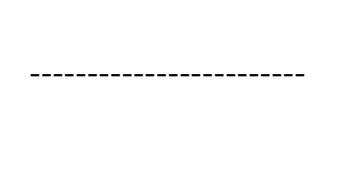 & $\begin{array}{l}\text { Poverty; } \\
\text { Victimization }\end{array}$ \\
\hline
\end{tabular}

Wes and his family lived away from the activity of town or city activity. Accordingly, Wes indicates that activities for he and his family were limited to completing chores and whatever else he and his siblings might conjure up to occupy their time. This often included the tearing apart and recycling of old cars to construct a wagon for entertainment. In addition, Wes reveals some of their creativity when he shares: Yeah, we made a boat .... out of a sheet of tin off one of the old sheds or something. We put boards on both sides of that and bent the ends up .... Well, what we did, uh, we put two boards on it, we took and bent up on the sides, and nailed it real good, and uh, dad had some tire [tar], old black tire? [tar] And we'd put black tire [tar] on there, and sealed 'er off .... We'd take that thing and get 
over on the creek, and we'd uh, sometimes we didn't have no hooks, so we took a pin and, uh, tie that thing on a line and go fishin'. (personal communication,

August 6, 2013)

Wes also shares that while his memory of childhood activities was fairly vague, he recalls a summer during which he and his siblings used to enjoy chasing and catching lightning bugs and the occasional competition among siblings while running up and down the hillsides to see "who could go up and back the fastest" (Wes, personal communication, August 6, 2013).

During our first interview, while Wes was reporting on a particular memory from his childhood, I experienced an uncomfortable sense of sadness on his behalf. As Wes was sharing what was clearly a difficult memory, and one that continued to hurt even this many years hence, he recalls an episode from a Christmas morning when he was approximately six or seven years old. The circumstances included his family's state of poverty and a practice where most of whatever was purchased, if it couldn't be made on the farm, came from a mail-order catalog. This is revealed as Wes reflects, I remember it real well. Uh, everybody told mom what they wanted for Christmas. And, I wanted this, uh, wagon. And, uh, well we'd, she did [get] that outta the mail-order catalog. And when all the presents come, everybody got their presents, but I didn't get one .... It was supposed to be a little red wagon, but it never did come. (personal communication, August 6, 2013)

Hearing this story and watching a grown man work through tears while he tried to put a positive spin on what continues to be a raw memory was difficult for me as a researcher. 
It may be that many might view Wes's family circumstances as destined to be unhappy. It has been my experience that many people who have far more available to them often tend not to appreciate all that they do have. However, in spite of the aforementioned Christmas disappointment that continues to hurt him so many years later, the other stories that Wes shares are descriptions of a family who enjoyed spending time both working and playing together. In addition, rather than relying on external influences or assistance, his family's successful existence on the rural farm seems to have been the result of routine hard work and ingenuity. This lifestyle didn't seem to depress them. Rather, they simply worked together and made things happen.

When asked about his family, Wes tells of fun with his siblings, mainly shared with his brothers, however, while also not suggesting any negatives about his sisters. "We got along real good. Everybody done real good" (Wes, personal communication, August 6, 2013). As a result, the family relationships were very strong.

One of memories Wes shares pertaining to situations that involved Wes and his siblings addresses their having to stay with their grandparents while awaiting the birth of a younger sister. Wes recalls this specific event when he shares,

I 'member the midwife comin' up. And, um, ... I 'member we had to go. Stay up with, uh, my grandma and grandpa who lived in a house about a quarter mile away, or a mile away, maybe less than that. We had to go stay with them until the midwife come and got us. (personal communication, August 6, 2013)

Due to his need to work away from home, Wes's father was not able to assist with running the farm during the week. However, Wes reports that everyone knew and did his or her part in accordance with expectations and respect for both parents. Reportedly, that 
may also have been the result of Wes's mother's stamina as well as her ability to set and maintain strict rules. "She was pretty strict. Mom could give you a good woopin' with whatever she'd get in her hand, belt, switches" (Wes, personal communication, August 6, 2013). Beyond those few stories that Wes shares about his childhood, he repeatedly indicates that he finds it difficult to remember things from so long ago. He does, however, have more positive memories from that time than negative ones.

\section{Wes's School Experience}

The school Wes attended was a part of a rural Appalachian school district located in a western region of West Virginia. It is interesting to note that while Wes estimates that distance to have been in excess of one and a half to two miles, he did not see this as problematic. According to him, that's simply how things were back then.

As demonstrated in the previous section, Table 5.3 is provided to illustrate some of the positioning taken by Wes in the past, in particular during his school experiences. Once again, Wes appears to have built upon his earlier experiences and demonstrates his resourcefulness. This is in spite of the suggestion that he did not enjoy a lot of what school had to offer for a variety of reasons. In some instances, this dislike for school may have been influenced by what Wes describes as an unstructured school routine that was occurring in that setting. Throughout the stories Wes shares about school, are conflicting circumstances, at some times enjoyed by him, while at other times a possible source for his eventual decision to leave school early. In some instances, Wes felt victimized, while in others his resourcefulness helped remedy his circumstances. 
Table 5.3

Vignettes and Themes from Wes's Journey - The School Experience

\begin{tabular}{llcl}
\hline $\begin{array}{c}\text { Complicating } \\
\text { Action }\end{array}$ & Evaluation & Resolution & Theme \\
$\begin{array}{l}\text { "He would turnout } \\
\text { school, and go huntin" } \\
\text { with us." }\end{array}$ & $\begin{array}{c}\text { "I think the parents } \\
\text { didn't like their kids } \\
\text { home." }\end{array}$ & "They got rid of him." & Marginalization \\
$\begin{array}{l}\text { "He [teacher] made us } \\
\text { run all over the place } \\
\text { until we learnt to } \\
\text { spell." }\end{array}$ & $\begin{array}{c}\text { "Uh, I didn't like } \\
\text { school very well." }\end{array}$ & $\begin{array}{c}\text { "I remember that I } \\
\text { would lay in bed and } \\
\text { try to miss school." }\end{array}$ & Victimization \\
\hline
\end{tabular}

As far as Wes can recall, all of his teachers were male, and none remained in that particular school for any length of time. Wes reports that some of this frequent teacher turnover was the result of the caliber of the teaching that took place. One example Wes remembers is that one of his teachers was a fairly young man who enjoyed hunting and that particular teacher's appreciation for hunting was what set the stage for a fairly short tenure in the position there. This is apparent as Wes reveals,

Then we had, uh, I think my third teacher was, I think he might have been the last one I had, too, uh, he was a young fella, Maxwell [pseudonym], and I remember we could talk him into goin' squirrel huntin'. He would turn out school, and go squirrel huntin' with us .... It was a school day, and uh, that didn't last very long. They got rid of him. I think the parents didn't like their kids home or something. But, that didn't last very long, so, they got rid of him. (personal communication, August 6, 2013)

Wes tells a variety of school related instances. He includes episodes where, depending on the particular teacher, he sometimes enjoyed school while at other times he found it to be difficult and something he preferred not to do. In each situation, Wes never 
positions himself as a victim. In fact, he typically places himself somewhere between mischievous and instigator brought about by his own somewhat passive involvement.

Throughout his school experiences, Wes had a number of teacher changes. In some instances, those were disappointing to him, while in others, not so much. Wes recalls that when he was young, one of his teachers happened to live on a farm located approximately two miles from the schoolhouse. Typically, that teacher traveled to and from the school on his farm tractor. Frequently during that time, the teacher would allow Wes to ride on the draw bar of the tractor if he and the teacher happened to meet along the way. Wes seems to think he was allowed to do this because he was the smallest child in the school at the time.

When talking about school work, Wes reports that from time to time he may have experienced difficulties with one or more of his school assignments. Although he did have the assistance from his mother, she was not always capable of doing so as coursework became increasingly challenging. Still, Wes does not view this as something to cause him to assume a victim's stance. Rather, he speaks of the available support, even though increasingly limited, in an appreciative manner.

Wes seems to view one memory from school in which a particular teacher responded to a student's inability to perform as expected as having been something not always what Wes thought to be the appropriate method nor needed at the time. In spite of those seemingly disappointing circumstances, Wes reports that he complied as directed and, as a result, still has only limited negative memories from those experiences. One such episode Wes shares involved he and others not learning to spell as quickly and efficiently as desired by the teacher at the time. Wes reports that in an attempt to remedy 
any apparent spelling deficiencies, the teacher required students who could not spell certain words to act out what the difficult word may have represented. In Wes's situation, he remembers in particular not being able to spell the word run. As he explains,

Uh, I wasn't too good at spelling. And, the word was run. And, he made us run all over the place around the school house until we learnt to spell that word. We circled the school house and kept runnin' until we learnt to spell the word run. I can spell it now. I'll never forget that one. (Wes, personal communication, August 6, 2013)

In another example, Wes shares a seemingly lengthy memory that involved his brother and an episode at school that continues to be humorous to Wes. Wes reports, Uh, I remember the other teacher, uh, Mr. Teens [pseudonym]. I remember, uh, him, 'cause, I think, seemed to me like, uh, my brother, he was probably about seven or eight then, um, we would play up in the woods on our Noon hour. And, uh, me and my brother and two or three other guys was up there, and the teacher was with us, Mr. Teens. And we tied him [his brother] up, up there with grape vines .... He finally got loose and come back down to the school .... Then when we was all outside for the noon recess, he [the brother] went back inside the school and he turned the desks up-side down and took his papers out and messed them all up. That's all I remember about that deal. (personal communication, August 6, 2013)

School for Wes was simply a required activity and one that he found to be less and less interesting as he grew. Eventually, Wes began to find ways to either miss school 
altogether or simply arrive late. In order to do this he made numerous attempts to appear ill and remain in bed. In response, Wes usually found his mother not to be easily influenced, but instead one who insisted that he go to school, in spite of the fact that would be considered tardy. According to Wes,

Uh, I was about, uh, fifteen years old. Uh, I didn't like school very well. I remember that I would lay in bed and try to miss school. School usually took up at nine o'clock. And if I'd lay in bed 'til nine and then get up, mom would make us go anyway. So, we'd be tardy, [chuckling] get there after nine o'clock. (personal communication, August 6, 2013)

Soon, Wes learns that being tardy did not get you less work. Instead, those students who would arrive late were given additional work to complete and they often had to stay after the regular school day session had been dismissed. Although it was not his mother's preference, Wes was finally able to wear her down and convince her to let him stop going to school altogether. As a result, Wes stopped attending school and dropped out rather than continuing to the high school.

While Wes had a strong relationship with his parents and siblings, his decision to leave school early was contrary to the wishes of either of his parents. Their individual and collective preference that Wes should remain in school may also have been influenced by the fact that neither of them had completed high school. Wes indicates that, in those days, it was not routine for school districts to expend much effort into trying to get students who had stopped attending school to return. In fact, as Wes shares his story of that time, he references his understanding regarding the eighth grade as at time when many kids simply stopped attending school and went to work. This is exactly what 
Wes did in spite of the fact that both his mother and father preferred that he remain in school and obtain a diploma. It seems that Wes believed that his decision to leave school early may have been to result of what he understood to be an acceptable practice at the time when he states, "Back in them days, people went to the eighth grade and that was it" (Wes, personal communication, August 6, 2013). Apparently, Wes had also become bored with the school experience and going to work seemed a preferred alternative. However, what he was about to experience may not have been the result of studying and learning from a textbook, however, there would be plenty opportunities for learning that would follow.

\section{Life After Leaving School Early}

As Wes reflect on his life since having left school early, he says, Um, lookin' back on it now, uh, I shoulda went, you know, stayed in school. Obeyed your parents, stayed in school, went to high school, and got a real good education. 'Cause it was hard, uh, when I dropped out of school, we went to work on the farm makin' fifty cents an hour. And, it was real hard, uh, to make, uh, a livin' on fifty cents an hour. (Wes, personal communication, August 6, 2013)

Table 5.4 is provided to illustrate Wes's positioning that was a result of various circumstances in which he recalls finding himself. Included are examples of missed opportunities from Wes having been victimized by financial difficulties along with examples of how Wes has progressed since having dropped out of school. 
Table 5.4

Vignettes and Themes from Wes's Journey - Life After Leaving School Early

\begin{tabular}{|c|c|c|c|}
\hline $\begin{array}{l}\text { Complicating } \\
\text { Action }\end{array}$ & Evaluation & Resolution & Theme \\
\hline $\begin{array}{l}\text { "It was real hard, uh, to } \\
\text { make, a livin' on fifty } \\
\text { cents an hour.".... } \\
\text { "Uh, when I dropped } \\
\text { out of school, we went } \\
\text { to work for fifty cents } \\
\text { an hour." }\end{array}$ & $\begin{array}{l}\text { "Uh, lookin' back on it } \\
\text { now, uh, I shoulda } \\
\text { went, you know, } \\
\text { stayed in school." }\end{array}$ & --------------------------- & Poverty \\
\hline $\begin{array}{l}\text { "When I was, uh, } \\
\text { twenty-one years old, } \\
\text { I got married. I think } \\
\text { we were makin' a } \\
\text { dollar twenty-five } \\
\text { then." }\end{array}$ & $\begin{array}{l}\text { "It was hard to do on a } \\
\text { dollar twenty-five } \\
\text { cents, even back in } \\
\text { those days." }\end{array}$ & $\begin{array}{l}\text { "We managed, somehow } \\
\text { or another, to make it } \\
\text { through." }\end{array}$ & Resourcefulness \\
\hline $\begin{array}{l}\text { "The family built the } \\
\text { house. Yeah, we built } \\
\text { it ourselves." }\end{array}$ & 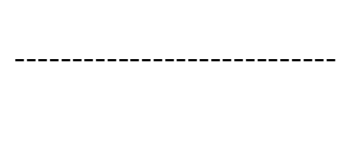 & $\begin{array}{l}\text { "We just drawed us a set } \\
\text { of footers on paper, dug } \\
\text { "em, poured "em, \& built } \\
\text { the house just by sight." }\end{array}$ & Resourcefulness \\
\hline
\end{tabular}

Wes reports that when he stopped attending school he was fifteen years old. Further he indicates that he was able to locate a job almost immediately after leaving school. Over time, Wes found that if one was frugal, and continued to work hard, he or she might be able to save enough money to purchase a vehicle and be able to provide for him- or herself. After a while, Wes was able to do so and purchase his first car for sixtyfive dollars.

Wes and his wife were married when Wes was twenty-one. At that time, Wes was making what he viewed as a significant increase from his first job. At that time he had changed jobs and was working at a local sawmill. With this increase in income, Wes and his wife were able to finance the purchase of a ten by fifty-five mobile home.

Like I said, I went to work on a farm. When I was, uh, twenty-one years old, I got married. I think we were makin' a dollar and a half an hour, then, at the saw 
mill... But, we managed, somehow or another, to make it through. (Wes, personal communication, August 6, 2013)

Wes's employer at that time allowed them to set up their mobile home on the sawmill property without paying for anything other than electric and water bills. From there, Wes moved from a variety of jobs including working at the local rubber manufacturing plant, going to work as a carpenter with a construction company, and eventually helping to set up double wide mobile homes as a part of a home show company located in the nearby state capitol community. Each of these jobs seemed to be preparing him for a business venture decision that he and his wife would make soon thereafter.

Having spent the major portion of his young adulthood working for others and trying to get ahead for himself and his growing family, Wes and his wife decided to take a chance with their life savings and open a retail hardware business. This decision led to a successful enterprise that lasted for approximately seventeen years.

Several years ago Wes's wife suffered an injury while helping to unload some pipe from a delivery truck at the hardware store. Wes seemed to recall that memory as if it had just occurred, rather than being from the fairly distant past. "She was loadin' pipe off of a truck....fell backwards and hit her head.... Hit her head and broke her arm. And I think that's where her sickness started from" (Wes, personal communication, August 6, 2013).

Wes believes that injury may have been the beginning of some of his wife's progressive health related difficulties. As a result, the decision was made to sell the store and retire. Since that time, the two have been living on the limited income from Wes's 
retirement and Nina's disability benefits. Again, while many may see the accident and eventual need to retire as a major setback, instead of positioning himself as a victim, Wes simply includes it in his story as something that happens. This continued to be a theme of his stories.

Wes reports that he and his family eventually purchased a home formerly owned by his great uncle. The story includes an interesting series of occurrences that were involved as a result of that sale. In addition, these seemed to be instances of good timing, forward thinking, and a willingness to work. Once again, we see Wes demonstrating a position of resourcefulness.

Reportedly, Wes's uncle had decided to sell his home. This particular home happened to be in the middle of some property being sold to a corporation that had no intention of salvaging the home. As a result, Wes and his wife made an offer to purchase it and have it raised and relocated to what would become their current place of residence. Timing, ingenuity and a sense of frugality helped the family preserve a century old family home. Wes shared that this entire process was a fairly costly venture, especially with limited income. However, according to Wes, "It was worth every penny" (personal communication, August 6,2013), as initial investments put into motion the renovation and saving of what has turned out to be a valuable piece of property.

Since that time, Wes and his family have continued to make smart decisions. Included in those decisions has been the purchase and sale of vacation property building lots and the recent construction of a beautiful two story vacation home that, other than a very few sub-contracted tasks, was designed and constructed by their own hands. Wes describes this event as follows: 
So, here we are, finally. And they got her finished how many years later? Five years....The family built the house. Yeah, we built it ourselves....Yeah, we just drawed us a set of footers on paper and dug 'em and poured 'em and built the house on the footers. Just by, uh, just by sight and more or less just in our minds what we wanted. (personal communication, August 6, 2013)

During our interview sessions, Wes seems to downplay any possibility that he has been a successful provider for his family. However, as I sat with him on the deck of a beautiful vacation home, enjoying the late summer weather and listening to his many stories, and of how he has used his own ingenuity and work ethic to accomplish things, I felt compelled to remind him of all that he has accomplished, in spite of his previous decision to leave school early. To this he responds humbly while continuing to lament about how he feels things could have been so much better for everyone involved, if only he had remained in school.

\section{Concluding Thoughts}

Wes's story was interesting for a host of reasons. Initially, he was somewhat reserved about participating in an interview setting and sharing stories about himself. He presents as a very humble individual. Once we settled into the interview mode, however, those reservations faded a bit.

As I listened to Wes recall things from his childhood, his memories of school experiences, and then share subsequent stories of more recent times, I found him to be an individual who learned at an early age how to make the best of the situation one is in. Yet, his stories suggest that he has done so without trying to bring attention to himself. This was apparent with almost every story that Wes shared. In some instances, I felt 
compelled to point out what are clear examples of his being resourceful and successful, while he continued not to seek praise for those accomplishments.

In one instance, however, I found myself feeling extremely uncomfortable as I watched Wes become overwhelmed with emotion while sharing a story that includes a great deal of disappointment that occurred during a holiday from his childhood. I appreciated his willingness to share that very emotional moment with me, as it was clear that the memory still causes him a great deal of hurt. Although that story had no influence on his decision to leave school early, it provided another example of how Wes does not position himself as having been victimized by his circumstances. To that end, Wes demonstrates that not all experiences or memories need to be pleasant in order to ensure a person's success. Instead, as demonstrated by his sense of resolve, Wes has learned to build on experiences and reflect on the potential each offers.

Throughout his story, Wes repeatedly describes circumstances where he had learned to appreciate the little things in life. He never once portrays himself as a victim. In addition, it is clear that he understands, and continues to demonstrate, his sense of responsibility for working hard and caring for others. This is illustrated when he says, Uh, lookin' back now, I wish I'd stayed in school and got a good education. It would really, really, uh, really help me and, uh, my family. Lookin’ back, uh, my family coulda been, you know, a lot better off now, and ever'thing, if I'd had a good job and uh, supported them a lot more than I did. (Wes, personal communication, August 6, 2013)

Analysis of Wes's story reveals that while some individuals may exist within circumstances that many might view as unhappy or destined to difficulty due to such 
conditions as limited financial resources, not everyone shares that opinion. In Wes's case, although he grew up a member of a poor farm family, the manner in which he and his family lived doesn't suggest that they were disadvantaged. According to Gee (2001), sometimes we may be "trapped in positions or identities defined by institutional and political working of others" (p. 113). However, this is not something we see in Wes's account of his journey. Instead, throughout his lifetime, Wes and his family have simply learned to make the best of the circumstances and materials they had. Making things work was their understanding of reality or their known.

In many instances, some may try to impose their own negative mindset or narrow lens on others. However, what others may take for granted, Wes and his family seem to have embraced as something that can only be acquired through hard work and ingenuity. In doing so, this seems to have given them a sense of pride of accomplishment. What may also have occurred is that Wes emerged as a man with the ability to construct things and negotiate in the best interest of those around him.

Rather than viewing his life as a major hardship and something done to him, Wes sees himself as a doer. He also seems to view things in simple terms. Because of this simplicity and a sense of work ethic, Wes continues to be a successful provider for his family and a faithful care-giver to his wife. This became apparent almost immediately upon talking with him.

Inasmuch as Wes stopped attending school before entering high school, rather than labeling him as a high school dropout, perhaps the term school dropout would be more accurate. While either term is often one that conjures a negative impression of the 
individual who decides to leave school early, instead, I posit that Wes demonstrates that not all who choose to leave school early are destined to failure.

To be sure, Wes will tell you that his decision to leave school early may not have been his wisest. However, what he has been able to do since that time should be considered more productive and contributive than many who actually complete their educational journey through high school graduation. Wes embraces his circumstances, and the fact that he dropped out, in a productive manner in spite of the fact that it was without a portion of the formal educational program typically viewed by some as the more promising path to success.

Wes's story is one of learning responsibility early and not wavering from that stance. He positions himself as one who learned early that life can be difficult while also understanding that effort and hard work can be the means to rising above many of those difficulties. On several occasions throughout our time together, Wes seems to be sharing stories about circumstances wherein he had proven himself to be self-taught, quite skilled and capable of accomplishing many things. At the same time he did so in a manner that suggests that he does not see his story as one of success. As a result, again I felt compelled to stop him periodically and acknowledge his success and accomplishments, reminding him that he should be proud of all that he has done for himself and his family in spite of the fact that he decided to leave school early. His response to those compliments was to remain humble. That impressed me, as well. Additionally, it seems a shame that he hasn't heard those compliments more often in the past.

Perhaps what may be taken from Wes's story is an understanding that, although traditional formal school programs may work for many, it isn't the only means to success 
for all individuals. It is also a possibility that the way our formal school program tends to address routine interpretations of students' circumstances and or needs may warrant some review as our number of dropouts continues to be of concern.

I suggest that the term successful should be considered a relative one as it seems that some who dropout can find themselves becoming dependent on such things as public support programs, either through social services and welfare, and or incarcerated as they seek ways to survive. We cannot assume, however, that all who decide to leave school early are destined to be unsuccessful and somehow become a drain on society. It seems as though this was demonstrated in Wes's story.

Wes's story is an example of how more needs to be investigated about the dilemma of school dropout, other than categorizing all who do so as following the same path and for the same reason. Further investigation of the at-risk students' circumstances is warranted before placing all who are experiencing poor attendance, behavioral issues, and or coursework failure in the same category and characterizing individuals' stories into what seems to be symptoms of a deeper influence that lies perhaps just below the surface. Perhaps looking at the school dropout through the lens of the potential dropout (i.e., any students known to be at risk of failure) may also reveal some very telling conditions awaiting discovery and serve as first steps to resolving the dilemma in the future. 


\section{Chapter Six}

The purpose of this chapter is to introduce Phil and his journey in accordance with what was shared during our time together in the series of three interviews and how that information addresses this study's research questions. Similar to the process used in the preceding Chapters 4 and 5, I shall first provide a biographical description of the participant, as well as the context in which Phil was situated.

Next, I include relevant excerpts from my data to illustrate how Phil constructed his understanding of the various experiences and relationships leading up to his decision to drop out of school, as well as reflections of the impact that decision may have had on his life in general since that time. This chapter will conclude with a consideration of how Phil seemed to have constructed his own identity.

\section{The Story of Phil}

I first explore how Phil's experiences in and outside of school may have contributed to his decision to leave formal education prior to graduation, as well as the consequences of this decision on his subsequent life up to the time of our interviews. As a part of the interview sharing, Phil told a number of stories related to either his life at home, in school, and or since leaving school early during the three open-ended interviews that I conducted with him. As a result of this process, Phil's narratives provide opportunities for understanding the intersection of circumstances that affected his interpretations of life events and the decisions he made about school and his life after having dropped out.

\section{The Participant}

Phil is a twenty-five year old, Caucasian male. Similar to Jane, the subject of Chapter 4, Phil was initially identified as a potential participant in this inquiry from a 
pool of individuals currently assigned to the Department of Community Corrections. During an introductory meeting arranged with a number of potential candidates for my study by the Director of Community Corrections, my initial impression of Phil was that he was soft spoken and reserved and this soft spoken nature did not change. Throughout our interview sessions together, Phil seemed relaxed and appeared comfortable when sharing his story with me.

Phil is the youngest of three children. He has one brother and a step-sister from his father's second marriage. Phil's parents divorced when he was approximately seventeen. This divorce occurred shortly before Phil made the decision to leave school early.

At the time of our interviews, Phil was the father of three children, with a fourth on the way. Phil occasionally spoke of his responsibility for those children, including his hope that he and his fiancé would soon be gaining custody of all of them as soon as he completed his participation in the Department of Community Corrections program.

\section{The Context}

Phil has spent his entire life in a small community located in north central West Virginia. At one time, this rural Appalachian community was the busy hub of a prosperous railroad company; however, shortly before Phil was born, the economy took a downward turn and the railroad relocated to a different part of the country. That move created a domino effect on the community's economic circumstances, including a significant loss of school enrollment, tax revenue, and bonding potential as many families were forced to follow the railroad industry in search of continued employment. Since 
that time, Phil's hometown has continued to struggle, with the remaining families residing in this area identified as being at-or-below the poverty level.

Table 6.1 represents an excerpt from the Poverty Guidelines that existed during the time when Phil would have been first entering school in 1992. As Phil's father spent the majority of his time intoxicated, the information selected is reflective of a family where a female was considered the head of the household.

Table 6.1

United States Poverty Thresholds for 1992

Female Head of Household

$\underline{\text { Size of family unit }}$ Related children under 18 years

Two persons: None One Two Three Four Five Six or more

Head under 65 years $\ldots \quad \$ 9,395 \quad \$ 9,670$

Head under 65 years ... $\$ 8,480 \quad \$ 9,634$

3 persons ................. \$10,974 \$11,293 \$11,304

4 persons .................. \$14,471 \$14,708 $\$ 14,228 \quad \$ 14,277$

5 persons .................. \$17,451 \$17,705 $\$ 17,163 \quad \$ \mathbf{1 6 , 7 4 3} \$ 16,487$

6 persons .................. \$20,072 \$20,152 \$19,737 $\$ 19,339$ \$18,747 $\$ 18,396$

7 persons $\ldots \ldots \ldots \ldots \ldots \ldots . \quad \$ 23,096 \quad \$ 23,240 \quad \$ 22,743 \quad \$ 22,396 \quad \$ 21,751 \quad \$ 20,998 \quad \$ 20,171$

Note. Income Thresholds at the Poverty Level in 1992 by Sex of Head of household, Size of family, and Number of Related Children Under 18 Years Old (Non-Farm Residence).

Retrieved from U.S. Census Bureau - Poverty Thresholds 1992 web-site: http://www.census.gov/hhes/www/poverty/data/threshld/thresh92.html

Phil attended elementary school in the largest of three facilities within the local school district. Enrollment at the school was approximately 650 students in grades PreKindergarten through four. As a result of the socio-economic circumstances, that particular school reported a large percentage of families who qualified for free and reduced meals, making it eligible to receive Title 1 federal support funding, (L. Casto, personal communication, September 25, 2013). 
Having completed the early childhood program, Phil then attended grades five through eight in a middle school facility somewhat larger than that of his elementary school program. Subsequently, he was enrolled at the local high school until he decided to drop out at age eighteen. Phil lived in a location that made it possible for him to walk to and from his schools. However, whenever possible, he took advantage of transportation provided by the school system to all three locations.

Since leaving school early, Phil has experienced a number of difficult circumstances. These have included finding himself on the wrong side of the law as a result of being involved in the local drug trade and dealing with his own alcohol addiction. In addition, Phil continues to have difficulty finding and retaining gainful employment that could support his attempts to regain custody of his three young children.

Phil's story contains a combination of derailed academic potential, poor decisions and a sense of naivety that seems to have compromised his ability to keep his head above water financially, as well as keep him out of legal problems. Much of what he shares describes circumstances beyond his control, while he is quick to own many of the wrong turns taken that have brought him to his current place in life. These complicating actions are further investigated in the following sections.

\section{Overview of Phil's Story}

Initially this chapter explores the events and circumstances of Phil's life and how his interpretation of these experiences contributed to his decisions and the life he has created. As in the case of the previous two chapters, a number of themes emerged from my analysis of Phil's narratives and include (a) poverty, (b) marginalization and victimization, and (c) naïveté. These themes provide perspective related to how Phil 
makes sense of life events, how he positions himself and others in his life, and how he seems to have responded to these events and made decisions that appear to have affected the course of his life.

I identify themes in an attempt to apply Labov's (1997) structural narrative analysis to understand how Phil made sense of and constructed his life through evaluating and resolving the complicating actions of his stories. Further, I explore how Phil's use of language situates him in these narratives and seems to contribute to how he responded to many of the events in his life as well as the identities he appears to have embraced.

Tables 6.2, 6.3, and 6.4 are provided as examples of Phil's varied positioning. In addition, I have organized the findings I present as a series of vignettes, provided by Phil, related to his life before entering, and while in school, as well as his life after he removed himself from school prior to graduating.

\section{Phil's Experiences of Home}

In accordance with the focus of this section, Table 6.2 provides examples of Phil's circumstances from those years prior to entering school. These excerpts suggest that, as a result of those circumstances, to a certain degree Phil's immediate world was confusing and filled with turmoil. Conversely, he did have what could be considered some stability in the influences available from his grandparents. However, in accordance with what Phil shares, he believes that his involvement in those opportunities was only marginal, and only what he called his way of pleasing them rather than himself. 
Table 6.2

Vignettes and Themes from Phil's Journey - The Early Years

\begin{tabular}{|c|c|c|c|}
\hline $\begin{array}{l}\text { Complicating } \\
\text { Action }\end{array}$ & Evaluation & Resolution & Theme \\
\hline $\begin{array}{l}\text { "My dad, he was a } \\
\text { drunk. My uncles were } \\
\text { a drunk. They'd just get } \\
\text { drunk and fight each } \\
\text { other." }\end{array}$ & $\begin{array}{l}\text { "Just two drunks around } \\
\text { each other." }\end{array}$ & $\begin{array}{l}\text { "The cops would go } \\
\text { over and break "em up." }\end{array}$ & Victimization \\
\hline $\begin{array}{l}\text { "I played Little League } \\
\text { for him [grandfather]." }\end{array}$ & $\begin{array}{l}\text { "Sometimes, I didn't want } \\
\text { to go." }\end{array}$ & ----------------------------- & Naïveté \\
\hline
\end{tabular}

When asked to share about his family and what his life was like, Phil typically has to ponder the question for a short moment before answering. He eventually shares that he had one brother and a step-sister and that the step-sister was from his father's second marriage. As a result of Phil's brevity when answering questions, there were times when additional probing became necessary.

When asked about his childhood and what it was like, Phil provides short descriptors and as such seems to be positioning himself as a victim of the circumstances of that time when he shares, "Chaotic .... My dad, he was a drunk .... My uncles were a drunk .... They'd just get drunk and fight each other .... just two drunks around each other" (Phil, personal communication, April 30, 2013). Phil's role when these episodes would occur was to run down the street and summon the local police, then wait for them to take action.

The complicating action regarding the constant turmoil between the males figures in Phil's life and how Phil and his family resolved it is evident when Phil reports,

We'd run. That's when the jail was right there. We'd run to the jail and tell them, 'hey, they're over there fightin' again' .... Then the cops would go over and 
break 'em up, and tell 'em to go somewhere else for the night, or take 'em to jail,

or whatever they needed to do. (Phil, personal communication, April 30, 2013)

Meanwhile, according to Phil, his mother would be at home, "tryin' to get 'em not to fight, trying to break 'em up" (Phil, personal communication, April 30, 2013).

Phil does not have memories from his childhood that involve recreation and activities outside of his home. In most of the circumstances, it appears that Phil was typically participating more so to please the others than not. This is made clear when Phil confesses, "I played Little League. My papaw was the coach, so I played Little League for him .... I basically played baseball to make my papaw happy” (Phil, personal communication, April 30, 2013).

Phil also shares that, while he practiced with other team members, their time together was limited to that activity only, rather than being playmates at other times. According to him, this was as much Phil's choice as anything else. "I rode bikes and played baseball. That was about it .... We practiced together, but that was about the only time I ever saw 'em” (Phil, personal communication, April 30, 2013). This limited initiative seems to be an accurate descriptor of who Phil may have been as a child. Perhaps this has contributed to who he would become later in his life.

\section{Phil's School Experience}

Phil remembers that from the time he entered school, he found it difficult. $\mathrm{He}$ indicates that, in his opinion, these difficulties were the result of an Attention Deficit with Hyperactivity Disorder - ADHD that compromised his ability to sit still. As a result, Phil took medication when enrolled in school. In addition, Phil shares that he was placed in a classroom for students with learning disabilities. According to Phil, he took this 
medication and received support service placements throughout his school experiences, until he entered high school when those support services were discontinued, and subsequently when he turned eighteen when the medication was discontinued.

While school support services were made available for Phil, his memory is that school remained difficult. This complicating action can be realized when Phil recalls, "Some of it was helping, but some, it really wasn't .... I'd be doin' it and my mind would be off somewhere else .... It was frustrating" (Phil, personal communication, May 6, 2013). To that end, Phil reports that his attitude toward school work and academics in general was marginal. "Some of it I just felt like I had to do" (Phil, personal communication, May 6, 2013).

Table 6.3 is provided to illustrate how Phil's school experience included episodes of marginalization and his reaction to others' alleged distain for Phil's circumstances as a poor child. In addition, it demonstrates some of the poor decisions Phil makes that he believes would eliminate the ridicule that he was experiencing.

Table 6.3

Vignettes and Themes from Phil's Journey - The School Experience

\begin{tabular}{|c|c|c|c|}
\hline $\begin{array}{l}\text { Complicating } \\
\text { Action }\end{array}$ & Evaluation & Resolution & Theme \\
\hline $\begin{array}{l}\text { "The kids would } \\
\text { pick on me and I } \\
\text { would just fight } \\
\text { 'em." }\end{array}$ & $\begin{array}{l}\text { "I didn't have nice } \\
\text { clothes, and all that." }\end{array}$ & $\begin{array}{l}\text { "I would usually get in } \\
\text { trouble.".... "I'd get kicked } \\
\text { out of school \& In-School } \\
\text { Suspension.". }\end{array}$ & $\begin{array}{l}\text { Poverty; } \\
\text { Marginalization \& } \\
\text { Victimization }\end{array}$ \\
\hline $\begin{array}{l}\text { "It [school] was } \\
\text { difficult \& boring. } \\
\text { It was hard for me } \\
\text { to set still." }\end{array}$ & $\begin{array}{l}\text { "I was just ADHD. I was } \\
\text { in a learnin', learnin' } \\
\text { disordered class." }\end{array}$ & $\begin{array}{l}\text { 'I'd be doin' it [schoolwork] } \\
\text { and my mind would be off } \\
\text { somewhere else." }\end{array}$ & Victimization \\
\hline $\begin{array}{l}\text { "I got caught sellin' } \\
\text { drugs. I got sent } \\
\text { away." }\end{array}$ & $\begin{array}{l}\text { "I thought I was a cool } \\
\text { kid."...."One of my } \\
\text { friends wore a wire on } \\
\text { me so he'd get out of } \\
\text { trouble." }\end{array}$ & $\begin{array}{l}\text { "They removed me from my } \\
\text { mom's house and put me in } \\
\text { juvenile placement." }\end{array}$ & Naïveté \\
\hline
\end{tabular}


Phil's memories of his elementary and middle school experiences seem to be divided into two specific areas that included his academic difficulties and his sense of disequilibrium (Piaget, 1997) that did not seem to be improving in spite of the fact that he was receiving support services through the program for students with disabilities, as well as the complicating action of ridicule from other students who marginalized his limited wardrobe. Phil's evaluation of those circumstances seems to suggest that he was comfortable with his resolution when he says, "It was difficult and boring."...."I was usually always in trouble, like when the kids would pick on me and I would just fight 'em, 'cause I didn't have nice clothes, and all that" (Phil, personal communication, May 6, 2013).

Phil attempts to rationalize his inappropriate behavior as having been justified in that he feels that the marginalization imposed on him by his classmates is what prompted him to fight with many of them. Further, he believes that he was punished unfairly. While he accepts the fact that he participated in the fights and that choice was wrong, Phil does not feel that the punishment he received was warranted. This can be noted when he recounts,

Fights would occur in the hallway, out in public, always the same kids. They didn't get punished. The kids, why they didn't get in trouble was because most of their parents were teachers. And they [the teacher/parents] was like, 'he wouldn't do that'. Like I just goin' to walk up and hit 'im for no reason. (Phil, personal communication, May 6, 2013) Phil's perception of how others' responses to different individuals' behavior often 
vary may be an excellent additional study into such things as power that may exist between "classes."

When Phil moved to the high school he found that he was not to remain in the Special Education program classroom. "They said I was capable of doing the same work as everyone else" (Phil, personal communication, May 6, 2013). However, Phil was not as hopeful with the decision, as he soon found many of his classes much more difficult than previous ones. It is possible that these changes created a new complicating action wherein Phil experienced a state of disequilibrium (Piaget, 1967). However, according to Phil, fortunately Phil's program included at least one individual who helped him work through some of his academic difficulties.

When asked about how he felt he was able to progress through his classes on his own, Phil reveals,

Some of the classes got harder. I was still good in, like I still got good grades in like, Science. That was about it. But, that was 'cause that teacher would actually help me. She just like, set down and explained stuff to me that I didn't understand. (personal communication, May 6, 2013) Phil's popularity or acceptance with regard to other students did, however, have a sudden, noticeable change when he entered the high school, as well. This, according to Phil, was due to something that had occurred over the summer break.

At high school, I got better clothes and stuff. That's when I was making money, so I was buying nice clothes .... I was sellin’ drugs .... One of my friends said, 'Try this. Just smoke it like a cigarette.'.... I thought I was a cool kid .... It 
becomes a source of money and you're able to buy nicer clothes .... It made me feel good. (Phil, personal communication, May 6, 2013)

Although Phil had discovered a possible way to be better accepted by his high school classmates, he would soon discover that the decision to become a part of the illegal drug trade would soon be a naïve one. That complicating action would bring him far more than just nicer clothing.

Early into Phil's story about his school experience, he reveals an example of when his poor judgment may have been his downfall. While he shares his version of what occurred, it is important to note that although Phil seems to clearly understand the magnitude of his actions, he also tends to suggest that, had he perhaps taken some additional cautions, the results may not have been as severe. One concern here is that Phil may be missing the point with regard to how he would otherwise resolve the complicating action of being caught selling drugs. Phil reveals this when stating, I got caught sellin' drugs. I was off the school property, you ain't 'posed to have it within a thousand feet from the school. I was about a hundred feet too close .... Well, the cops knew I was doin' it. They couldn't catch me. Every time they'd stop and search me, I'd done sold it all and just have money on me .... One of my friends wore a, he got in trouble, and he wore a wire on me so he'd get out of trouble .... I got sent away. They removed me from my mom's house and put me in a juvenile placement. (Phil, personal communication, May 6, 2013) Indeed, he was selling drugs, an illegal act, however, Phil's choice to sell drugs seemed to be one made to eliminate the ridicule from schoolmates who, according to Phil, were constantly marginalizing him due to his poverty situation and the clothes he 
had to wear as a result. Perhaps had Phil found a different means for raising money that could be used to purchase those newer clothes, he may not have been caught up in what seems to have become a cycle of controversy for him.

Phil's experience while assigned to a juvenile corrections program away from his local high school was what Phil recalls as being successful. This is apparent as Phil reflects, "All the teachers were nice, they'd help ya. When I graduated from the program, I told them, 'Why don't you just let me stay and finish school?' They was like, 'We can’t. You got to go back"” (personal communication, May 6, 2013).

Phil was, however, returned to his hometown high school program after successfully completing his sentence for having been caught selling drugs. At that point, Phil recalls that he would soon decide to leave school early. According to Phil, his decision to leave school early was primarily influenced by the reception he received from his teachers upon his return to his local high school. This is evident as Phil shares, The teachers, they weren't too nice in high school. They just wouldn't help me. And, I had this one teacher ... I had her after gym class and I'd go in there all sweaty and she'd always tell me, 'you stink, you stink.' .... The teachers just, always nit-pickin' on me, to get me in trouble. They like ... someone would do somethin', they'd say it was me. They would find a reason to get me in trouble and send me to the principal's office .... I went to school for probably two days. I had just turned eighteen, so I said, 'Just, fuck this. This ain't for me'. (personal communication, May 6, 2013) Initially, Phil's parents were not happy about his decision to drop out. In fact, 
they reportedly approached the school to ask that Phil not be allowed to do so.

According to Phil, what his parents learned, however, was that due to his age, Phil was to have the final say.

Phil regrets having made that decision. He continues to wish that his resolution to the complicating actions experienced while enrolled in school had been a different one. Phil makes this clear when he laments, "I didn't realize at the time how important school was. I wish I had let them talk me back into going .... I regret it every day, dropping out" (Phil, personal communication, May 6, 2013).

\section{Life After Leaving School Early}

As difficult as Phil's school experiences may have been, his experiences after he having decided to leave school early have seemingly been more so. It seems that Phil has experienced one frustrating event after another, since he left school. One such complicating action is that Phil has found himself without continual employment and as a result, he has not been able to save any money.

According to Phil, some of that trouble started as early as the summer break between his middle and high school enrollment, during which he was introduced to the drug trade. It was at that time when Phil realized that he could sell drugs, make a profit and therefore, have money to purchase new clothes. Table 6.4 is provided to illustrate Phil's positioning since the time when he decided to leave school early. Once again, in a number of instances, it can be noted that Phil continues to find himself being marginalized and the victim of the circumstances. Many of those complicating actions include what appear to be the result of Phil's poor decisions and the fact that he acted on them. 
Table 6.4

Vignettes and Themes from Phil's Journey - Life After Leaving School Early

\begin{tabular}{|c|c|c|c|}
\hline $\begin{array}{l}\text { Complicating } \\
\text { Action }\end{array}$ & Evaluation & Resolution & Theme \\
\hline $\begin{array}{l}\text { "After I got out of } \\
\text { placement, and I went } \\
\text { back to my home } \\
\text { school, the teachers, } \\
\text { just always nit-pickin' } \\
\text { on me." }\end{array}$ & $\begin{array}{l}\text { "They would find a } \\
\text { reason to get me in } \\
\text { trouble." }\end{array}$ & $\begin{array}{l}\text { "They'd say it was me } \\
\text { and send me to the } \\
\text { principal's office." }\end{array}$ & Victimization \\
\hline $\begin{array}{l}\text { "I got fired from my } \\
\text { job." }\end{array}$ & $\begin{array}{l}\text { "One of the managers } \\
\text { didn't put it in the } \\
\text { logbook." }\end{array}$ & ---------------------------- & Victimization \\
\hline $\begin{array}{l}\text { "I violated probation } \\
\text { and went back to jail.", } \\
\text { "I got caught drinkin'." }\end{array}$ & $\begin{array}{l}\text { "Every day I went to } \\
\text { work I was drinkin'. } \\
\text { By the time I'd get } \\
\text { home, I was so drunk I } \\
\text { couldn't even stand." }\end{array}$ & $\begin{array}{l}\text { "They put me on the } \\
\text { program." }\end{array}$ & $\begin{array}{l}\text { Victimization; } \\
\text { Naïveté }\end{array}$ \\
\hline "I stabbed someone." & $\begin{array}{l}\text { "I was drunk and my } \\
\text { cousin and this guy } \\
\text { started fightin'. And, } \\
\text { he got my cousin } \\
\text { down." }\end{array}$ & $\begin{array}{l}\text { "I did eighteen months } \\
\text { in regional, then I } \\
\text { went to prison for } \\
\text { twenty-four months." }\end{array}$ & Naïveté \\
\hline
\end{tabular}

When asked about what he has been doing since he dropped out, Phil indicates that he spent most of his time "getting high" (Phil, personal communication, June 5, 2013). While Phil doesn't recall a lot about that time, he does recall that, approximately five or six months after he had dropped out, he was hired for his first of many jobs. "I worked at, uh, Ronnie's [pseudonym] junk yard. I worked there probably three or four years" (Phil, personal communication, June 5, 2013). This circumstance was complicated by what Phil referred to as a poor relationship that he had with his father. "With my dad, it wasn't so good .... 'cause my dad was always drunk, and in and out of prison .... For sellin' drugs” (Phil, personal communication, June 5, 2013). Phil's work history includes what might be described to be multiple unsuccessful attempts toward gainful employment. Perhaps this has been influenced by some 
examples of poor judgment while working. One complicating action involved circumstances where Phil was also engaging in high risk behaviors including drinking on the job and maintaining his involvement with the drug trade. As a result, Phil has been fired, arrested, or both.

An additional complicating action includes Phil's on-going naïveté regarding what may be contributing to his difficulties. What seems to be most troublesome is the fact that, even after being fired and or arrested for those inappropriate behaviors, subsequent to his arrests, Phil has reportedly continued to drink. Therefore, Phil has continued to violate his probation, for which he has been returned to jail.

It seems that what has been occurring is a cycle of difficulty from which Phil may not be able, or willing, to escape. This seems apparent as Phil reveals the following:

That's all they do out there. He [the boss] don't really watch 'em .... Every day I went to work, I was drinkin'. I'd sell weed to buy my alcohol and to get me back and forth to work. 'Cause I didn't have a license or nothin' .... By the time I'd get hone, I was so drunk I couldn't even stand .... I got caught drinkin'. That violated my probation. I violated my probation and went back to jail and they put me on the program. (personal communication, June 5, 2013).

Phil expresses frustration as he recounts his experiences both with regard to his difficulty retaining employment and his inability to stay out of trouble. His story suggests that although he has made numerous poor decisions, in his mind he should not be criticized inasmuch as they have been when he was under the influence of either alcohol or the drugs he happened to be abusing at the time. Further, Phil expresses a belief that some of the actions he has taken were also what many others might do under 
similar circumstances. Phil seems to demonstrate this view when providing his account of an event that resulted in his placement in the Department of Community Correction program, where we first met. According to Phil,

I went to prison. I stabbed someone. I was drunk and my cousin and this guy started fightin' and he got my cousin down, and, I, I stabbed him. I got arrested for that. I did eighteen months in regional, then I went to prison for twenty-four months .... Well actually I probably only went two weeks, then my mom went my bond and got me out. Then, I went to court two months later, and they sentenced me to three to fifteen. No less than three years, no more than fifteen. (personal communication, June 5, 2013)

It seems that Phil is missing a very important point regarding the possible connection between his actions and his responsibility for those actions. Perhaps, if he were to reflect differently, his actions would differ as well. Even more recently, Phil's employment record has also been compromised by a number of poor decisions on his part. As indicated from what he shares in the following statement, Phil appears to be caught between his need to comply with what might be considered to be conflicting requirements:

I got fired from my job. While I'm on community Corrections, I have to turn in a schedule every Friday. But, up there [previous job site] I couldn't get my schedule until like Saturday. So, I couldn't turn it in until Monday. And, they wanted me to work Memorial Day weekend, and I told 'em, 'I got to turn in a schedule before I can work.' And they was like, 'Oh, you're fine, that's fine.' And, so, I didn't go to work on Memorial Day. They fired me for that .... I talked 
to one of the managers the night before and he was like, 'alright, I'll put it in the logbook.' And he never put it in the logbook. (Phil, personal communication, June 5, 2013)

\section{Concluding Thoughts}

If I'd stayed in school, I think I would know a lot more than I do now. I might have got my act together and not become an alcoholic, not become using drugs all the time. 'Cause I think the reason I started drinkin' was to forget all the memories from school, from where everyone picked on me. That's when I started drinkin'.... I regret it every day, dropping out. (Phil, personal communication, June 5, 2013).

As much as he would like to remake some of his previous decisions, Phil realizes that many of his circumstances have been the result of his own actions. As we finalized our interviews I was beginning to feel as if Phil does have some understanding of how he has arrived where he is. Most importantly, it seems that Phil understands that he can have more control over his situation, providing he is thoughtful about the decisions he makes. This is evident when he says, "Just go to work. Dang, I miss my job!" (Phil, personal communication, June 5, 2013).

While Phil's illegal activities may have resulted in numerous encounters with law enforcement, Phil was not quick to learn his lesson. These experiences, along with the punishments and difficulties that have accompanied them, however, did eventually bring Phil to understand that things may have turned out differently had he made alternate choices. 
Although Phil is an example of how poor decisions can lead to unpleasant consequences, it is important to acknowledge that sometimes things may be the result of outside influences. Phil reports that he had a couple of very supportive teachers when in school, in many cases, helping him to fit in and succeed academically. At the same time, Phil was also left unsupported as a few of his teachers reportedly kept him and other students aware of when drug dogs were scheduled to be present on the school grounds.

Those teachers may not have intended to enable Phil's drug trade involvement. However, their attempt to protect him from being removed from school by "tipping him off', did nothing to prevent his downward behavioral practices. Although, Phil was wearing an ankle bracelet that prevented him from moving very far from approved locations, (i.e., home and work), he wears the bracelet/monitor openly. Phil is also continuing to work his way to regain custody of his children, and wants to provide a safe home for them.

During the earlier portion of Phil's story it appears that he occupied a role of pleasing (or trying to please) others. The personality that I witnessed throughout each of our interview sessions was of an individual who is sensitive or passive, as opposed to being aggressive. One impression that he made during our time together was that Phil tends to position himself as a follower. This was demonstrated through such activities as: playing baseball primarily for his grandfather, who was coaching the team; doing his chores for his mother in order not to disappoint her or earn a scolding; attending church with his grandmother more because she wanted him to than because it interested him; and occupying his free time on his Gameboy®, etc. In addition, in almost every instance, it seemed that Phil's motivation was driven more by compliance than enthusiasm. 
Similarly, although there was no pressure to do so, I am suspect that Phil's agreement to be a part of this research study may have been as much an attempt to please his supervisor, rather than decline the invitation.

In addition, Phil's story contains many examples of where poor decision-making has resulted in some of the complicating actions with which he has had to deal. As a result, it appears that Phil could have avoided some of his difficulty situations simply by not acting on impulse.

Phil reveals that he had observed disruptions to an otherwise low-key world as a child. These disruptions were often episodes that involved his father and uncles drinking and fighting, followed by the police being called. In spite of this dysfunctional nature of the issues occurring within and or around his home environment, Phil does not appear to have been impacted negatively.

Further, it seems that Phil's experience with divorce may have imprinted on him in such a way as to bring him to believe broken commitments should be considered a common practice. This is demonstrated when Phil shares that he wasn't bothered by the numerous occasions when severed relationships occurred. Likewise, it appears to be occurring with Phil's own relationships. During our interviews, Phil and his fiancé were awaiting the birth of Phil's fourth child. The two were also awaiting news of a pending decision that may grant them full custody of the three children from Phil's first relationship. As such, Phil seems to understand the importance of being responsible for one's actions and thus positions himself as the responsible party.

Conversely, although Phil's mother and grandparents made a number of attempts to ensure that he experienced things outside the dysfunctional atmosphere brought about 
by his father's alcoholism, it appears that Phil's somewhat narrow world may have imprinted on him. As a result, Phil seems to have found what he views as a safe place by simply staying out of his father's way and practicing behaviors intended to please others around him. This is demonstrated by his response to his grandmother's attempt to expose him to more positive experiences as Phil shares, "I went to church with my grandmaw .... She kinda made us go. Sometimes, I didn't want to go .... I just wanted to sleep in" (Phil, personal communication, April 30, 2013).

Contrary to the aforementioned attempts to provide positive examples for him, Phil's exposure to alcohol abuse seems to have contributed to his own alcoholism. Again, it appears that his introduction to alcohol and drug abuse was initiated by his friends wherein Phil simply obliged. Additionally, Phil's propensity to trust resulted in his being busted through the ulterior motives of a "friend."

While many would like to believe the drug trade activities that got Phil into trouble are limited, Phil reveals that the practice of drug abuse is far more pervasive. $\mathrm{He}$ demonstrates this when sharing that, "It was more like the whole high school .... I still walk by the high school and see people doing' it .... It's anybody" (Phil, personal communication, May 6, 2013).

Phil regrets his decision to leave school early. In addition, it was difficult to hear him share his disappointment in realizing that only one of all of his teachers cared enough to be concerned that Phil had acted on his decision to drop out. "She was about the only one that thought that I should stay in school. But, I was like, one teacher out of how many wants me to stay?" (Phil, personal communication, June 6, 2013). 
Time spent with Phil has revealed some unforeseen dilemmas, one being the importance of helping students realize sooner than later that making a decision to leave school early may initially appear to be a good thing. However that decision can have far reaching effects on future decisions and compromise possibilities for future opportunities. According to Labov (1997), events shared by the speaker are typically personal and have become part of the speaker's biography (i.e., are emotionally and socially evaluated), and therefore, have been transformed from raw experience. This seems to be easily identified in what Phil has to share.

Although Phil does not appear to have received much guidance during many of the events about which he speaks in his story, I wonder how things may have turned out differently had he been able to make fewer naïve choices. As I reflect on the many stories shared by Phil, many seem to be somewhat similar to those revealed by Jane, another of the participants in this study, from chapter four. I am troubled by the many possibilities that may have existed that might have altered Phil's journey in a more positive fashion. Once again, although school experiences can be unpleasant for individuals as some may be teased and or experiences the state of disequilibrium (Piaget, 1997) that comes with increasingly challenging academic performance requirements, somehow most of us navigate those experiences successfully. This was not Phil's response, however, and as a result it seems that his potentially successful journey may have been disrupted. It would be interesting to see how Phil's circumstances may have been different had some of his previous decisions been different or if the influences occurring during his childhood had been framed differently. 
Phil appears to be someone who may be stuck in a set of circumstances from which he may never exit. His early years seem to have contributed very little to prepare him to be on his own. In fact, the alcoholism and apparent dysfunctional home environment to which he was exposed from a very young age seems to have imprinted on him in such a way as to pre-dispose him to becoming a part of that identity as he continues to deal with his own alcoholism and drug addiction issues. Likewise, Phil's family's financial circumstances did nothing to help him develop into a self-confident individual. As a result, it seems that those circumstances may have contributed to Phil's decision to become involved in the illegal drug trade as he sought to find a way to have decent clothes to wear to school and therefore fit in with the others, thus escaping the episodes of ridicule that he knew as a child.

While Phil tries to model what he believes is characteristic of a good individual more recently, doing so previously was not always easy. In fact, it seems that in order to overcome some of the low expectations imposed on him, Phil continues to search for a way out from under the pressures that accompany that stigma. In the past, Phil has viewed drugs and alcohol as offering that possibility for him. However, he is quick to share that those practices have only made it more difficult for him to experience the success that he has witnessed others enjoying.

It is apparent that Phil may be the product of a very poor environment and therefore is a victim of circumstance. Poor in the sense that, not only were the financial circumstances of his family sparse, but also those around him provided very limited positive examples, models or redirection whenever he engaged in inappropriate behaviors. As a result, Phil may never realize the many benefits of success beyond the 
minimal opportunities that such things as low paying jobs, multiple marriages and having to pay child support may offer.

The time spent with Phil during each of our interview sessions was both informative and perplexing. I often found myself wishing that I was able to rewrite some of what I was hearing, in order to influence a different outcome. Unfortunately, this was not a possibility.

As mentioned in earlier chapters, perhaps it would be worthwhile for educational policy makers and practitioners in our schools to investigate further those assumptions regarding what contributes to students' decisions to disengage and eventually drop out. However, this can only happen when our present system takes a better look internally in addition to merely characterizing the behaviors of our students through what may be considered a blame the victim lens. 


\section{Chapter Seven}

This chapter introduces Rocky and his story from childhood, during his school experience, and his subsequent journey from the time he made the decision to leave school early through the present. In similar fashion as with the other participants of this study, information gathered from Rocky was the result of our time together during a series of three interviews that investigated the participant's journey and the meaning he took away from each of the many experiences he shared. This included what Rocky constructed from those experiences and how each may have impacted his life. Using the same format as in Chapters 4, 5, and 6, I first provide a biographical description of the Rocky, as well as the context in which he was situated.

While doing so, I also include excerpts from my data to illustrate how Rocky constructed his understandings of the various experiences and relationships leading up to his decision to drop out of school. Further, I include Rocky's reflections of how each decision may have had an impact on his life since he dropped out. Last, this chapter will conclude with a consideration of how Rocky seems to have constructed his own identity.

As mentioned in earlier chapters, I believe the themes that emerged through my use of structural narrative analysis (Labov, 1967) provide evidence of how each participant made sense of and constructed his or her life through evaluating and resolving the complicating actions of his or her stories. In addition, in this manner, I explore how participants' use of language situated them in these narratives and contributed to how they responded to events and the stories they tell about their lives. The chapter concludes with a consideration of how the ways in which Rocky, in particular, seems to have made sense of his life may have influenced his choices, as well as the ways in which he 
positioned himself and or was positioned by others as he made life decisions and constructed his identity.

\section{The Story of Rocky}

Throughout this chapter, Rocky's experiences in and outside of school and how those experiences may have contributed to his decision to leave formal education prior to graduation, as well as the consequences of that decision on his subsequent life, are explored. As a part of our interview sessions, Rocky shared a variety of stories related to his childhood prior to entering school, experiences while in school, as well as what life has been like since having left school early. All of this information was the result of a series of three privately conducted open-ended interviews between Rocky and me, as researcher. In many instances, Rocky's narratives help reveal understanding of the intersection of circumstances that seem to have affected his interpretations of life events and the decisions he has made about school and his life in general.

\section{The Participant}

Rocky is a twenty-two year old, Caucasian male. Rocky has a twin brother. In addition, he and his twin brother have a sister, two years their elder. The three grew up in a small rural town located in the central part of a rural region of Appalachia in North Central West Virginia. According to Rocky, the members of his immediate family were once active members with their local church. This included a grandfather who served as a pastor for a Wesleyan Methodist congregation near his home. In addition, Rocky had a number of extended families that lived in close proximity to where he grew up. As a result, there were many opportunities for family gatherings. 
Rocky was included in this study as a result of our introduction that occurred by coincidence. In fact, it was that coincidental encounter that ultimately influenced decisions pertaining to my selection of a research topic for this inquiry. Our initial encounter occurred when Rocky happened to recall having seen me when I was in one of his previous schools. Subsequent similar encounters followed a few years later, making it seem to this researcher as more than mere coincidence. Thus, Rocky was asked to be a participant in order for the inquiry to delve into his and others' stories about the circumstances that may have influenced decisions to leave school early. Information obtained from the stories Rocky shares are used to understand what may have contributed to his decision to leave school early, as well as how that decision has affected his life.

\section{The Context}

Rocky is a member of a family of low socio-economic circumstances. He was raised by both parents in a small, rural Appalachian, community. Within close proximity to Rocky's family home were a number of other close relatives' homes, all of which were located in an area considered to be somewhat removed from the nearby town. As a result, Rocky became very close to his immediate relatives and did not spend much time with others who were outside that immediate family influence. This is revealed as he shares, “As a kid, I was kind of a hermit, I guess. I didn't really socialize with other kids. I lived by myself”' (Rocky, personal communication, April 26, 2013).

However, Rocky also recalls that this rather close community atmosphere included the occasional family fight between some of the members of older generation siblings. For the most part, these arguments occurred between Rocky's father and his brothers, Rocky's uncles. According to Rocky, these less peaceful episodes led to a 
number of instances where various family members became angry for one reason or another and, as a result, made the decision to change the spelling of their particular branch of the family's last name. Because of that, confusion pertaining to which families may or may not be related, as well as a need for clarification regarding the origin of the family name, often occurred.

Rocky grew up in a family neighborhood that was what many would consider a blue collar community. As a result, most households typically operated with income ator-below the poverty level. Table 7.1 provides an excerpt of the poverty guidelines that existed during that time. This information represents the approximate time when Rocky was first entering school.

At that time, although Rocky was living with both of his parents, his father was suffering with a disability that prevented him from working. This left his mother's income as the only financial resource for the family of five. Unlike the information representative of the years when other participants in this study were entering school, the information available that pertains to when Rocky was enrolling does not differentiate between male or female heads of the household. Regardless, the information provided in Table 7.1 is intended to establish a context appropriate to that time, which was approximately 1995 . 
Table 7.1

United States Poverty Thresholds for 1995

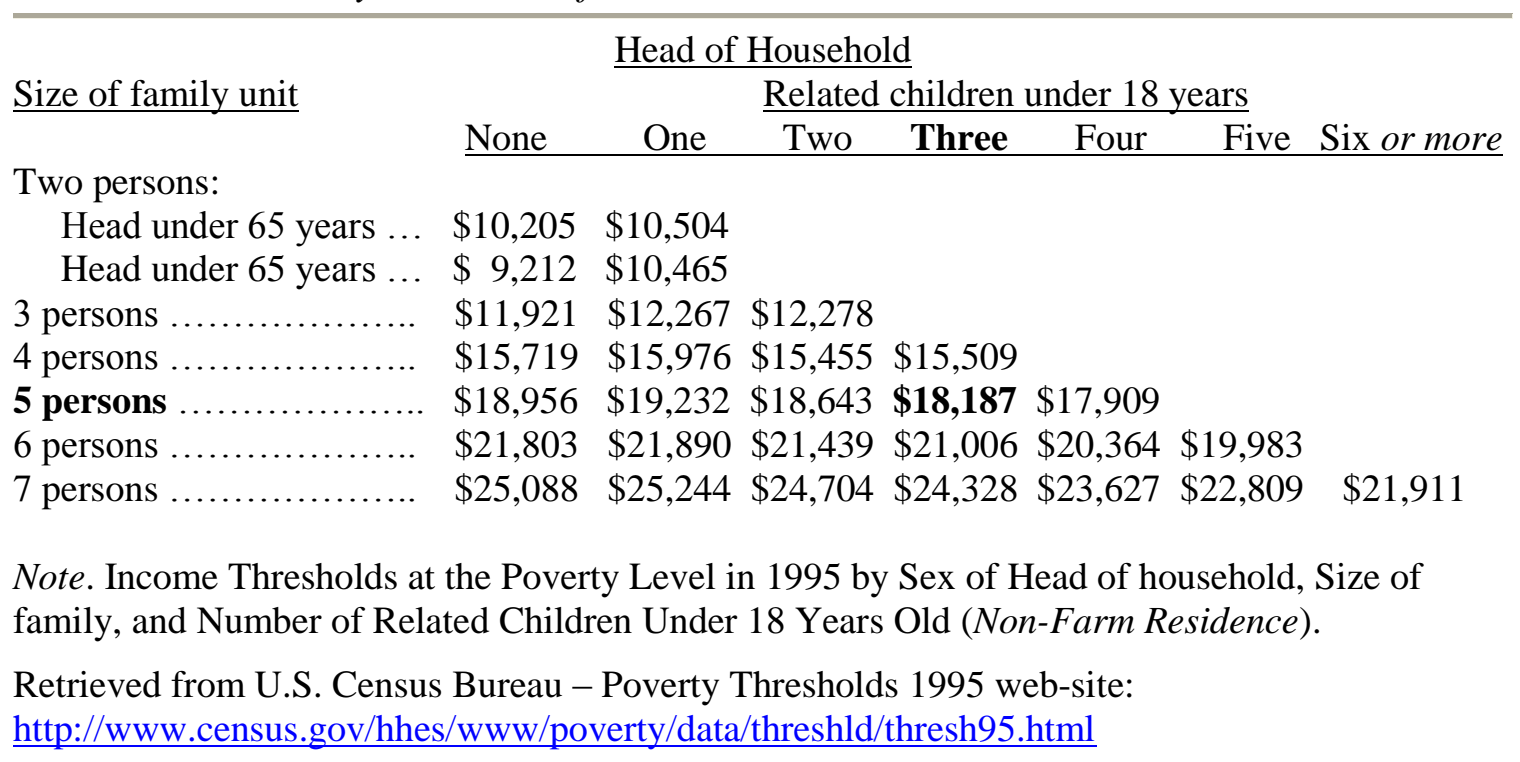

Rocky attended school within his regular attendance district throughout his school journey. This included attendance of Kindergarten through Fourth grades in the largest of three elementary schools in the district, with an approximate enrollment six hundred fifty students, and his Fifth through Eighth grades in the only Middle School, that consisted of an approximate enrollment of seven hundred students, in his county of residence (L. Casto, personal communication, October 4, 2013). In addition, Rocky attended his last year in formal education at the only high school of his home county school district. That program hosted a student enrollment of approximately seven hundred fifty in grades nine through twelve (L. Casto, personal communication, October 4, 2013). It was during his attendance in this secondary program when Rocky made his decision to leave school early.

In Rocky's view, prior to his decision to leave school early, his journey was one of success and enjoyment. This was in spite of the fact that his family lived in a location 
that could not access such things as cable TV, internet services, etc. When speaking of childhood activities, Rocky indicates,

We didn't have cable or nothin' like that, 'cause they couldn't cross the railroad tracks, or somethin' like that .... so we would play outside, go swimmin'.... And, in the winter, we'd go sled ridin' and stuff. I was always outside. (personal communication, April 26, 2013)

However, as he continues to recall things from his past, Rocky reveals that, at some point later in his life, this seemingly carefree story begins to unravel and expose circumstances that were not as much fun as they are difficult. Accordingly, it is clear that once Rocky became aware of, and made a decision to embrace, his own sexual orientation, and others' response to that identity was not supportive, Rocky's otherwise successful journey began to deteriorate such that he felt a need to dropout. After leaving school early, however, Rocky soon went on to complete his GED exam in a fairly quick length of time. This demonstrates that academic difficulties were not what had influenced his early departure from the formal school experience.

\section{Overview of Rocky's Story}

This chapter first explores the events and circumstances of Rocky's life and how his interpretation of these experiences contributed to his decisions and the life he created. When analyzing Rocky's narratives a few potentially conflicting themes emerged that primarily include (a) poverty, (b) marginalization, (c) isolation, and (d) resourcefulness. These themes provide perspective related to how Rocky makes sense of life events, how he has positioned himself and others in his life (Gee, 2001), as well as how he typically responds to those life events and or has made decisions that have continued to affect the 
course of his life through the time of our interview sessions. I have organized the findings I present as a series of vignettes provided by Rocky related to his life before and in school, as well as his life after he left school early. Tables 7.2, 7.3 and 7.4 are included as samplings of those varied positions. Further, the vignettes represented are used as a means of capturing the ways in which Labov's (1997) structural narrative analysis can help to understand how Rocky has made sense of and constructed his life through evaluating and resolving the complicating actions throughout his stories. I also explore how Rocky seems to situate himself in these narratives and how he has often responded to events in his life as well as the identities (Gee, 2001) Rocky seems to have constructed.

\section{Rocky's Experiences of Home}

Table 7.2 reveals a few complicating actions representative of the earlier experiences of Rocky's journey prior to his enrollment in school. For the most part, his story includes episodes of isolation, in part due to the close relationships of his more immediate extended family, as well as being due to the inaccessible proximity of otherwise routine services such as having TV in the home. However, unlike the other participants' circumstances, where poverty seemed to have a sizeable impact on each of their personal descriptions, Rocky doesn't seem to connect the reasons for his family's apparent isolation and limited access to such things to anything other than his family's remote location and accessibility. To Rocky, his was a normal existence that just happens to have been removed from the mainstream. 
Table 7.2

Vignettes and Themes from Rocky's Journey - The Early Years

\begin{tabular}{|c|c|c|c|}
\hline $\begin{array}{l}\text { Complicating } \\
\text { Action }\end{array}$ & Evaluation & Resolution & $\begin{array}{l}\text { Positioning } \\
\text { Theme }\end{array}$ \\
\hline "My dad never worked." & $\begin{array}{l}\text { "He }[\mathrm{dad}] \text { was disabled } \\
\text { because he had a heart } \\
\text { condition." }\end{array}$ & $\begin{array}{l}\text { "He [dad] had heart } \\
\text { surgery that fixed it, and } \\
\text { now he works." }\end{array}$ & Poverty \\
\hline $\begin{array}{l}\text { "We didn't have cable or } \\
\text { nothin'....We didn't } \\
\text { have computers of stuff } \\
\text { like that." }\end{array}$ & $\begin{array}{l}\text { "They couldn't cross the } \\
\text { railroad track, or } \\
\text { somethin' like that, and } \\
\text { we were really strict } \\
\text { Wesleyan Methodists." }\end{array}$ & $\begin{array}{l}\text { "We didn't have TV until } \\
\text { we were older.... so, we } \\
\text { played outside." }\end{array}$ & $\begin{array}{l}\text { Poverty; } \\
\text { Isolation }\end{array}$ \\
\hline $\begin{array}{l}\text { "I didn't really socialize } \\
\text { with other kids." }\end{array}$ & $\begin{array}{l}\text { "As a kid, I was kind of a } \\
\text { hermit, I guess ....I didn't } \\
\text { want to play a video game } \\
\text { or nothin' like that." }\end{array}$ & "I lived by myself." & Isolation \\
\hline
\end{tabular}

When asked about his family, Rocky's initial description of where he fit in and the general dynamics of his immediate and extended family suggests that a close bond existed among those who lived nearby. This includes some explanation of possible confusion with regard to what many may view as an oddity pertaining to the common spelling of Rocky's family name. Rocky attempts to clarify this when he shares, "West Lake [pseudonym] is like the Smith [pseudonym] community. Pretty much everyone up there is a Smith .... All the Smiths and Smyths [pseudonym] on West Lake are related" (Rocky, personal communication, April 26, 2013).

At the same time he indicates that, while that was true for the most part, the spelling of his family name was often changed as a result of an occasional falling out among brothers of his father's generation. "So that's why there's Smiths and Smyths. [Laughing] Because they had a bunch of fights and change their names a bunch of times" (Rocky, personal communication, April 26, 2013). It is interesting to note that Rocky 
shares this information almost as if it was a common practice and that he assumes most families have similar experiences.

In an attempt to delve further into his immediate family, what life was like, his relationship with other members, and where he fits, Rocky indicates that he was born the younger of a set of male twins and that they had one sister. Rocky's father suffered with a disabling heart condition for the majority of Rocky's childhood. This limited his ability to contribute financially to the family income.

In addition, when offering a description of his family's circumstances, Rocky also indicates that activities for his family were typically limited as a result of the family's limited income. As Rocky explains it, "We didn't have cable or nothin' like that, 'cause they couldn't cross the railroad tracks, or somethin' like that. And we were really strict Wesleyan Methodists. So, we didn't have TV until we were older, or whatever" (personal communication, April 26, 2013). According to Rocky, the only activities allowed included such things as 'playin' outside, swimmin', huntin', and helping with the gardening with my grandmother" (personal communication, April 26, 2013).

For the most part, activities, other than helping out around the house, were typically those that didn't involve others outside his more immediate family. In addition, Rocky mentions that he had been allowed to have pets, a responsibility he allegedly enjoyed a lot. "I loved pets when I was young. I was obsessed with reptiles. My parents let me keep whatever I wanted" (Rocky, personal communication, April 26, 2013).

This seems to be an area of genuine interest for him, as Rocky reports that it led to a childhood aspiration: "I was going to be a herpetologist. I was going to study reptiles" (Rocky, personal communication, April 26, 2013). Further, this activity seemed to allow 
Rocky the solitude that he enjoyed while also serving as a means to minimize his isolation from others. Sometime later those aspirations faded as a result of his parents' divorce. Subsequent to his parents' divorce, activities that occupied Rocky's time consisted primarily of those that didn't require multiple participants. "As a kid, I was kind of a hermit, I guess. I didn’t really socialize with other kids. I lived by myself. I didn't want to play video games or nothin' like that" (Rocky, personal communication, April 26, 2013).

\section{Rocky's School Experience}

Rocky's initial memory from his earlier school days was that he enjoyed being

there. "Kindergarten was awesome" (Rocky, personal communication, June 28, 2013). However, his next few statements suggests that the enjoyable experiences, about which he had just referred as being "awesome," soon faded into reports of less pleasant experiences. His subsequent memories became an introduction of a number of other marginalizing experiences based not on his family's financial limitations, as in the case of Jane, Phil, and Wes, whom I described in previous chapters, but instead on issues of socialization, distancing and isolation. As a result, Rocky experienced first-hand the complicating actions of what it is like to be bullied by other students due to his otherness.

Table 7.3 provides excerpts from experiences occurring during Rocky's time spent in school. It was during this time in Rocky's journey when he began to understand the reality of being marginalized. While he had previously known isolation as a circumstance chose by him, the experiences he had once he entered his ninth grade year were to introduce him to an entirely new understanding of the concept. 
Table 7.3

Vignettes and Themes from Rocky's Journey - The School Experience

\begin{tabular}{|c|c|c|c|}
\hline $\begin{array}{l}\text { Complicating } \\
\text { Action }\end{array}$ & Evaluation & Resolution & Theme \\
\hline $\begin{array}{l}\text { "The kids made fun of } \\
\text { me a lot. A lot a lot." }\end{array}$ & $\begin{array}{l}\text { "In second grade, or } \\
\text { somewhere in there, I } \\
\text { gained a lot of weight, a } \\
\text { lot of weight. And I was } \\
\text { pretty big." }\end{array}$ & $\begin{array}{l}\text { "Most of the teachers } \\
\text { didn't do anything } \\
\text { about it." }\end{array}$ & Marginalization \\
\hline $\begin{array}{l}\text { "I got kicked in the back } \\
\text { of the head when I was } \\
\text { on the steps." }\end{array}$ & $\begin{array}{l}\text { 'I was different from them. } \\
\text { I'm gay. I've never been } \\
\text { attracted to women, ever. } \\
\text { They say that seventy-six } \\
\text { percent of all twins, one } \\
\text { of 'em is gay. I didn't get } \\
\text { as much testosterone in } \\
\text { the womb, or somethin'.' }\end{array}$ & $\begin{array}{l}\text { "The principal asked } \\
\text { me if he could pray } \\
\text { with me and, you } \\
\text { know, maybe the kids } \\
\text { would leave me alone, } \\
\text { if I could get better." }\end{array}$ & $\begin{array}{l}\text { Victimization; } \\
\text { Marginalization }\end{array}$ \\
\hline $\begin{array}{l}\text { "I was fifteen years old, } \\
\text { and then, uh, the guy } \\
\text { who I was seein', his } \\
\text { parents caught us." }\end{array}$ & $\begin{array}{l}\text { "My parents, they were } \\
\text { very against it, they were } \\
\text { very religious." }\end{array}$ & $\begin{array}{l}\text { "My parents couldn't } \\
\text { help me after they } \\
\text { found out I was gay." }\end{array}$ & Isolation \\
\hline $\begin{array}{l}\text { "I was ready to go off } \\
\text { myself, just to take my } \\
\text { life. I wanted my life to } \\
\text { end." }\end{array}$ & $\begin{array}{l}\text { "I knew I wasn't goin' to } \\
\text { graduate.".... "If you're } \\
\text { not exactly the way } \\
\text { you're supposed to be, } \\
\text { then you might as well } \\
\text { just not be here." }\end{array}$ & $\begin{array}{l}\text { "I was a really anxious } \\
\text { individual in school. } \\
\text { Really anxious all the } \\
\text { time. I always had my } \\
\text { defense up." }\end{array}$ & Isolation \\
\hline
\end{tabular}

The aforementioned episodes occurred at various programmatic levels. However, it was during his high school experience when Rocky was confronted with bias more than during any other time. As a result, it becomes clear as to what may have prompted Rocky to begin thinking about leaving school early. In fact, Rocky credits those episodes as having had an intense influence on most of the decisions he made then and since.

Rocky recalls that he began gaining weight during his early primary grades and, as a result, became the target of ridicule from his peers. Further, Rocky perceived that his teachers were doing nothing when he was being ridiculed by his peers. When he allegedly became argumentative with his teachers about this hurtful treatment by his 
classmates, he was separated from the others and placed in what he called ISS or InSchool Suspension. When reflecting on this experience, Rocky was noticeably irritated even this many years later. According to him,

I gained a lot of weight .... The kids made fun of me a lot. A lot, a lot .... Most of the teachers didn't do anything about it .... It was pretty rough .... They put me in ISS when I was in Kindergarten .... It didn't have no windows. It had one light. There was no chairs in that room, there was a tile floor. That was ridiculous .... If my mom would've knew that they did that, she probably woulda kerked [an unfamiliar term believed to be similar to become extremely upset or angry] out. (Rocky, personal communication, June, 28, 2013)

When talking about those negative interactions with classmates and school personnel, it seemed that those initial experiences of isolation may have only been the prelude for additional episodes that would follow. It seems that the marginalization to which Rocky was being exposed may have been due to his otherness as an overweight member of his class. To that end, Rocky positions himself as the victim.

At the same time, Rocky's reflection on that experience also seemed to flow into an attempt on his part to make sense of how it was occurring at such an early age and then continued to occur as he became older, yet for different reasons, when he says, "Let's see, it just got worse from there. It really did. I guess, I don't know, um, ... I'm gay, and I didn't really know it back then, but I acted different from everybody else. You can see it" (Rocky, personal communication, June 28, 2013).

Almost as if predicted by Rocky, school eventually became one bad experience after another for him when it came to socialization with others. Not only was he an 
individual who did not feel comfortable participating in a lot of group activities, but sometime during his later middle school years, Rocky suspected that his sense of feeling different, having different interests, may have something to do with his sexual orientation. This is evident as he recalls, "Honestly, I've never been attracted to women, ever. But kids don't understand that. And, I was different from them. They called me 'faggot' (Rocky, personal communication, June 28, 2013).

Rocky expresses a sense of disillusionment regarding some of negative interactions between his classmates and certain members of his school faculty when sharing,

It didn't help whenever I went to school. They were like no support .... I didn't understand that. I got kicked in the back of the head when I was in the stairway up in the middle of the school .... I went to the principal's office and he asked me if he could pray with me and, you know, maybe the kids would leave me alone, if I could just get better. (Rocky, personal communication, June 28, 2013) While Rocky does not suggest that his circumstances with school had anything to do with it, it was also around this time when Rocky's parents divorced. Subsequently, each parent did eventually remarry and remain in close proximity.

As mentioned in earlier chapters, Piaget (1968) introduced as a part of his Theory of Cognitive Development that students tend to experience the occasion of what he called a state of disequilibrium. Rocky seems to have experienced this state of disequilibrium in a number of instances in school. However, this state of equilibrium does not seem to be pertaining to his academic capabilities as much as it does from a social standpoint. Instead, it seems that somewhere his response to marginalization may have been 
influencing his decisions in spite of the fact that he was progressing successfully with his academic endeavors. Rocky reveals that his decision to drop out was prompted as much by the lack of others' action as anything else.

Somebody shoulda stepped in, at some point, and did something, because it was not my fault .... After that, it all went downhill pretty quick .... I just decided one day, that I don't have to be here. I think I'll stop goin'. (Rocky, personal communication, June, 28, 2013)

Accordingly, Rocky believes his school system failed him. This is apparent when he states,

The school system messed up. Big time, big time. I get really animated and angry when I talk about it, 'cause it brings up a bunch of stuff. Can't tell you how many times I went home and just buried my head in a pillow and just sobbed. (Rocky, personal communication, June 28, 2013)

Rocky shares memories of frustration from his past that continue to be disappointing to him. He reveals his belief that once he realized and embraced his own sexual orientation, the response he received from his classmates and faculty, as well as his family, led him to understand that he was on his own from that time on. This is evident as he reflects, "I never wanted to drop out of school. Honestly. I just knew I wasn't going to graduate" (Rocky, personal communication, June 28, 2013).

Further, Rocky realizes that his being gay was something that his parents simply could not accept. As a result, he feels responsible for his family's announcement that they could no longer continue to attend their church. As a result, Rocky's ill-placed sense of ownership can be noted when he laments, "My parents couldn't help me after I 
found out that I was gay. They were very against it. They were really religious and we pretty much had to quit going to churches because of it" (Rocky, personal communication, June 28, 2013).

Although Rocky finally discovers who he is and begins to understand that he is comfortable with it, what happens next is that he also soon experiences a very different response from others. While his is a very personal one, Rocky's story illustrates that not everyone finds it possible, or chooses to be supportive of others' openness to certain differences. This is demonstrated when Rocky shares,

They [Rocky's parents] were really put off by it [his non-traditional sexual orientation]. When I went home, I got beat, if you want to know the truth, I got beat. And then, I went to school and I got beat some more. And then the teachers told me that I was a problem child ..... That's what happened. I was stuck in a rut .... I can't get close to people, because I know eventually, they're going to go and do somethin' that's not right to do to a friend. (personal communication, June 28, 2013)

Rocky's response to what seems to have been on-going instances of marginalization, both at home and in school, suggests that he may have given up on obtaining his high school diploma through more traditional means. However, as the subsequent portion of his story reveals, his decision to leave school early would not deter his interest in academics.

I didn't care. I knew I was gay for a long time. I mean, you gotta come to copes with it .... I was terrified .... If you're not exactly the way you're supposed to be, 
then you might as well just not be here. (Rocky, personal communication, June

28, 2013)

\section{Life After Leaving School Early}

Rocky shares a story that describes both difficulty and varying degrees of accomplishment when he reports,

For about three or four months, I was like, 'man, there's nothin' I can do' .... It's gotten a little better over the years, but not much ... now, I'm not able to save money and put something aside ... Free time activity? That hasn't happened in the last month .... No benefits, nothin'. (Rocky, personal communication, September 3, 2013)

Table 7.4 provides a look into where complicating actions may have existed in Rocky's journey since he acted on his decision to leave school early. Included are examples of both frustration through the isolation that can accompany an inability to obtain and retain employment, as well as a demonstration of resourcefulness when caught up in the former circumstances.

Table 7.4

Vignettes and Themes from Rocky's Journey - Life After Leaving School Early

\begin{tabular}{|c|c|c|c|}
\hline $\begin{array}{l}\text { Complicating } \\
\text { Action }\end{array}$ & Evaluation & Resolution & Theme \\
\hline $\begin{array}{l}\text { "It wasn't very easy for } \\
\text { me to get a job back } \\
\text { then." }\end{array}$ & $\begin{array}{l}\text { "I didn't care about the } \\
\text { way I looked. I didn't } \\
\text { think it was a good } \\
\text { decision at first." }\end{array}$ & $\begin{array}{l}\text { 'I was doin' my own } \\
\text { thing. For about three or } \\
\text { four months, I was like, } \\
\text { 'man there's nothin' I can }\end{array}$ & Isolation \\
\hline $\begin{array}{l}\text { "I never have a hard time } \\
\text { getting' a job, never. } \\
\text { Everywhere I've worked, } \\
\text { you know, I've left with a } \\
\text { grade 'A' reputation." }\end{array}$ & $\begin{array}{l}\text { "I dress for the part, I'm } \\
\text { warm. I think you've } \\
\text { gotta have the } \\
\text { motivation to go and get } \\
\text { the job you want." }\end{array}$ & $\begin{array}{l}\text { do'." } \\
\text { "I can always get a job, never } \\
\text { have trouble getting' a job." }\end{array}$ & Resourcefulness \\
\hline
\end{tabular}


Rocky's ability to obtain employment has been what he views as successful. However, he is also discovering some of the short-comings of not having a high school diploma. He can recite a litany of names of places where he has found employment opportunities, as indicated in the following: I went to a transportation and communication union .... I started working on designing air brakes for the railroad .... I don't see myself as a stewardess, but I took the training anyway .... I got my job back at McDonald's, I got an interview with Shop 'N save. I worked for Shop 'N Save for a year and a week .... I started working at the hotel downstairs as the GM [General Manager]. (Rocky, personal communication, September 3, 2013)

Yet, the length of the aforementioned list, and the frequent turnover between each of these opportunities, suggests a certain level of transiency on his part.

In many instances, the benefits available at each job seem to have been minimal or non-existent. At the same time, Rocky does not appear concerned that as he ages, his need for some sort of retirement planning may not be met. Instead, he boasts of an ability to move about at will between any of the jobs he has had in the past. This apparent bravado is exposed when he states, "Everywhere I've worked, you know, I've left with a grade 'A' reputation. I could go back to any job I've ever had and get me a job" (Rocky, personal communication, September 3, 2013).

Life after leaving school early for Rocky has been a fairly brief length of time. What he has accomplished during that time has been impressive in that he was to obtain his GED fairly quickly, as well as successfully pursuing additional training through such 
programs as JobCorps. Currently, Rocky is working as the general manager of a small travel lodge establishment in his home town.

Unfortunately, he views the treatment there as unacceptable. Perhaps he finds himself in this situation as a result of his employer's poor view of someone who did not complete high school in the traditional manner. Rocky did not reveal this. However, he did suggest that he felt as if he was being taken advantage of at this particular work location. "They're really screwing me. It's bull. I make way less money than I ever did ... You can see I'm a little stressed" (Rocky, personal communication, September 3, 2013).

In an interesting twist, even though Rocky shares a distrust for his current employer, he shared that his former JobCorps contact has recently inquired about having Rocky participate in a photo advertisement that includes he and his current place of employment as a way promoting the success of both the JobCorps program as well as one of its program graduates. "They want to come to the hotel and take a picture on me in front of the hotel and use it for their pamphlet .... 'cause it boosts the program .... I think there's a hundred and forty centers, nation-wide" (Rocky, personal communication, September 3, 2013). Rocky shares this news with an obvious sense of pride, while chuckling that he dislikes his job at the very location where the promotional photos were to be taken.

\section{Concluding Thoughts}

I don't know what to say, but, I was ... ready to ... go off on myself, just take my life. I wanted my life to end .... People don't know how low you are. I don't like 
to talk about that, but I was pretty low. I was at that point for a long time.

(Rocky, personal communication, September 3, 2013)

Analysis of the aforementioned statements that Rocky shares, reveals his sense of abandonment both in the earlier portion of his journey while in elementary school as a result of his apparent weight gain, and again when he was struggling to make things work after accepting his sexual orientation prior to leaving school early. In both instances, an otherwise capable student found himself being marginalized for circumstances of otherness for which he receives ridicule. This was compounded by the fact that his expectations of being supported by those around him with the authority to assist him fell short.

Rocky’s somewhat eager manner in initiating our original conversations with regard to his recognition of me from his former school captured my attention from the start. I was caught up in how he seemed desperate to have me acknowledge my own memory of him from an earlier time, although I must admit that I could not, and what seemed to be his sense of embarrassment over having to reveal that he had dropped out. I found the opposing issues to be an interesting conflict. This, as well as my general interest in understanding the dropout dilemma in general, is what helped me continue attempts to maintain contact with Rocky whenever he seemed to be fading in and out of the picture, as I progressed through the data collection process.

While Rocky was the first of the participants whom I identified for my study, he was the most difficult when it came to finding convenient times for each of our interview sessions. I can't say that Rocky was avoiding the topic, or that he was the least bit reluctant to talk once we were in an interview setting. It just seems that he was the most 
distracted as a result of his personality and his constant shifts from job to job, as well as his many free time activities.

As I analyze the stories he shares, Rocky impresses me as being carefree and one who seems to live in the moment. Although he has been able to move from job to job, making minimum wage and relocating to various living locations, Rocky presents as the most confident of all the participants in this study. Interestingly, this is so in spite of the fact that when asked about such things as savings and or employment benefits, (e.g., health insurance), Rocky shares that he has neither. While these circumstances may trouble many individuals, I did not detect any concern from Rocky in this regard. Instead, he seemed to boast of his perceived ability to return to any former place of employment if and whenever he felt the need. Rocky bases this on what he reported to be his having left any place of employment after exemplary job performance. Of major concern is that I do not detect any concern about planning for his future. This seems evident when he brags:

I never have a hard time getting a job, never. I mean, I dress nice, I dress for the part. I'm warm. I can always get a job, never have trouble getting' a job. I think you've gotta have the motivation to go and get the job you want. (Rocky, personal communication, September 3, 2013)

While there is merit in his belief that it takes motivation to obtain a particular position of employment one may wish to have, I am concerned that Rocky may be a little naïve about his future. To be fair, Rocky might be congratulated for sticking to his goal to obtain a GED. In fact, he did so in what many may consider to be a very quick 
manner. "I was out of school for maybe three months before I went back and I got my GED” (Rocky, personal communication, September 3, 2013).

When it comes to Rocky's memories from school experiences, although his are negative more so only while in high school and he feels that they were the direct result of his newly public non-traditional sexual orientation, (i.e., being gay), he presents as someone who believes that he is better off away from that environment. Furthermore, Rocky seems satisfied with how things have turned out. Additionally, he does not appear to harbor any resentment toward those whom he views as the individuals who let him down. He merely sees them as uninformed and lacking awareness of how marginalizing others can be hurtful.

In Rocky's view, he has moved on. This comes across as a sense of tentative bravado, while not be arrogant. Further. although dropping out of school may have appeared to be Rocky's way out of the oppressive nature he experience while attending school, it seems that it placed him in a predicament with regard to employability.

In spite of what some people may view as multiple disappointments, throughout his story Rocky seems to position himself in an optimistic light. Although he may have mentioned an occasional bump in the road such as his parents' divorce, the fact that his activities were fairly limited and his family lived in an area well removed from other nonmember "family" communities, I did not notice any sense of remorse on his part. When this observation was brought to his attention, Rocky states,

Most people, when they do an interview, or whatever, they would, like, want to talk about all the negative stuff they had. But, I just never think about that stuff. I 
haven't had a bad day since October. I never have a bad day. I never think about bad things. (personal communication, April 26, 2013)

In this manner, Rocky appears to prefer positioning himself as someone who is more inclined to see the glass as half full than one who sees the glass as half empty. When I heard this, I wondered about how he was able to put his life's circumstances that led him to decide to leave school early aside. Perhaps it was something that he feels would be the best means to move on, rather than dwelling on the negatives and having that influence his future activities and relationships with others. This seems to demonstrate a certain level of maturity that not everyone attains by his age.

Rocky is forth-coming with his stories about life before school, during his school years, as well as since his decision to leave school early. I did find, however, that the more time spent with Rocky, the more he seems to be someone who is more comfortable with his current circumstances than many would expect. Rocky's story tells of an individual who appears to have been experiencing what was a potentially successful journey when he was young. However, that situation was disrupted during his early teen years as a result of his revelation to others of his sexual orientation.

Being gay does not always prompt a positive response. This often includes both one's acquaintances as well as members of one's family. What Rocky found was that, although he had embraced his sexual orientation, few of the people upon whom he felt he could rely for support and encouragement (parents, school faculty, etc.), were willing to do so. Therefore, Rocky indicates that he made the decision to remove himself from what he views as having been toxic environments that he discovered as a result of his coming out. Since that time, Rocky has been successful in obtaining additional training 
as well as earning his GED. In addition, he seems to have found a means to survive on his own. As a result, he presents as being fairly satisfied with his own accomplishments. However, Rocky's current situation may not be sufficient as he advances in age and those circumstances offer no guarantee for future stability. 


\section{Chapter Eight \\ Discussion}

In chapters 4, 5, 6 and 7, I presented my findings for each of the four participants who were a part of my research study. In this chapter I consider how the individuals' stories were used as a context for making sense of and constructing narratives of their lives, as well as their identities. Therefore, the purpose of this chapter is to look across the four participants' stories and discuss how each was shaped by the contexts in which he or she was situated and how those contexts may have influenced the understandings they constructed, the relationships they developed, and the ways in which their experiences shaped the life narratives they constructed and lived. These stories make important contributions to better understanding why some young people choose to leave school early. I end the chapter with a discussion of the possible implications of my findings for additional research of current and potential policy and practice considerations in the field of education and in general.

\section{Rethinking the Dropout Dilemma}

Bronfenbrenner (1979) tells us that human relationships can influence an individual's directionality toward both positive and negative destinations. His insight helps us recognize the importance of establishing relationships with our students and thoughtfully observing our students' progress throughout their developmental stages, both prior to and during their educational journeys, so that we might intervene or advocate for particular students when necessary.

Each of the journeys shared in this study include examples of how circumstances may have influenced the individuals' sense of directionality. Some of my participants revealed how their experience of various complicating actions prompted equally varied 
resolutions based on the particular understanding they developed of the circumstances at the time. As participants built on the understandings they constructed based on their own evaluations of those circumstances, individual positions became more apparent. In some instances it seemed that participants were able to resolve the circumstances of their lives in ways they evaluated as successful. For example, Wes used his ingenuity and sense of work ethic to build a life for himself and his family. Rather than becoming embittered because of the limited resources available to him, Wes methodically demonstrated his own resourcefulness and made decisions that benefitted him. In contrast, other participants viewed the circumstances of their lives as barriers and positioned themselves as lacking power and agency. This is especially evident in Jane's story as she continues to dwell on the negative memories of interactions with her family, her former schoolmates, and her teachers. Ultimately, it seems that the ways in which participants chose to resolve and evaluate the complications in their lives had a profound effect on the lives they created and the identities and relationships they constructed.

I believe that becoming familiar with the various versions of drop outs' understandings of what may have influenced their decisions to leave school early could provide another perspective related to the school dropout phenomenon. Likewise, I suggest that one should not assume that students who make the decision to leave school early and follow through with that decision, are doing so as a preference. Rather, in many instances, theirs is a journey that may have offered them no alternative. I now turn to exploring the differences and similarities among my participants' stories. 


\section{Differences and Overlapping Circumstances}

While each of the participants in this study shared different complicating actions or circumstances, there were some noticeable similarities with regard to the ways in which they resolved and evaluated those circumstances. All four participants shared how poverty and marginalization influenced their lives in and outside of school. I begin by discussing how poverty and being marginalized were experienced by each of the participants and then turn to a discussion of how the participants' experiences influenced their decision to leave school early.

\section{Poverty}

Poverty, as it was understood by society, seemed to affect the lives of all of my participants in some way and influenced the identities they constructed and the decisions they made. At least three participants found themselves frequently being reminded of their impoverished circumstances by those around them. Jane and Phil shared how their classmates positioned them as poor based on their apparel. According to Jane, "We was a very poor family. The clothes I wore was always hand me downs with holes in "em" (personal communication, May 6, 2013). Similarly, when referencing how others treated him because he was from a poor family, Phil shared, "I didn't have nice clothes and all that" (personal communication, May 6, 2013).

However, Wes seemed far less aware of the fact that others felt his family's limited financial resources were supposed to be barrier to his chances for happiness or success. "We didn't have no electricity 'til I was about twenty-one years old .... We got

along real good ... Everybody done real good" (Wes, personal communication, August 6, 2013). In all instances, my participants did not necessarily position themselves as poor 
until someone outside of their family evaluated their life circumstances as impoverished based on, for instance, the clothing the participant wore. Unfortunately, poverty continues to affect the lives of Jane and Phil and influences the ways in which they understand and respond to current experiences.

\section{Marginalization}

Although poverty continues to plague some of the participants, I found experiences of marginalization to be prevalent across each of their individual stories. Each of the participants in this study shared stories of being marginalized in school. Both Jane and Phil shared experiences of being taunted by others for the worn clothing they wore to school. Each of them reacted to that marginalization by becoming combative, which resulted in them being positioned by school officials as being the instigators, rather

than the victims that they understood themselves to be. Moreover, Jane may have viewed the inaction of her teachers and principal to her stories of victimization as abandonment similar to the ways in which she positioned herself when her mother placed her in foster care. Thus, Jane's resolution to her marginalization was to shun any possibilities for friendships, rather than risk further rejection by her peers.

Phil then chose to resolve the complicating actions of his life by making decisions that he believed would result in the acceptance of his peers. Instead his actions led to adjudication, addiction and continued poverty. Phil shared, "I got caught sellin' drugs .... One of my friends wore a wire on me .... I got sent away...in a juvenile placement" (Phil, personal communication, May, 6, 2013). He also felt further marginalized when the peers who victimized him experienced minimal consequences for their behavior. 
These peers were family members of the faculty at his school which, Phil believes, contributed to the fact that their behavior was not questioned or addressed.

Marginalization also played a role in Rocky's circumstances. Even though he was doing fairly well academically and socially during the early portion of his youth, Rocky began experiencing an enormous amount of negativity from most everyone he knew immediately after he revealed his sexual orientation. "I got kicked in the back of the head ... The principal asked me if he could pray with me and, you know, maybe the kids would leave me alone, if I could get better" (Rocky, personal communication, June 28, 2013).

According to Rocky, this victimization by his classmates, faculty, and the school principal was due to his otherness, his identity as a gay man. However, rather than positioning himself as combative and adversarial, Rocky eventually yielded to the marginalization and withdrew himself from the oppressive atmosphere at his school. Wes, on the other hand, simply disliked school as it did not seem to be meeting what he felt he needed at that time in his life. Instead, his priorities included assisting in efforts that could ensure his family's financial stability. According to Wes, the only school subjects that were useful were those that prepared him for work. Otherwise, he felt he was wasting his time attending a school that offered frequent teacher turnover and little learning that was of interest to him. "I didn't like school very well. I remember that I would lay in bed and try to miss school" (Wes, personal communication, August 6, 2013). However, Wes now believes that if he had remained in school and had earned his high school diploma that his ability to provide for his family would have been enhanced. 
Poverty and marginalization seem to have been the primary influences on each of the participants' decisions as young individuals when considering whether or not to remain in school, and subsequently making the decision to leave school early. Unfortunately, for three of the four individuals included in this study it seems that their decision to drop out may have been initiated far earlier than the actual act. In fact, it makes sense that each of these individuals may have started down the path to dropping out at a very early age rather than when most believe many students are contemplating doing so. It is difficult to imagine how these decisions may have differed had someone been alert to the individual students' decline.

\section{Rationale for Leaving School}

With regard to rationale for leaving school, Jane continues to view that decision as having been her only means for survival. She felt abandoned by her family and school official and positioned herself as a victim of her circumstances. Jane chose to become combative with those who marginalized her as he felt that this provided her with some control of her life. Thus, she made the decision to leave school early, as it had already abandoned her. Furthermore, even today, she does not necessarily seem to understand how that decision provided opportunities for the people she encountered to further victimize/marginalize her.

Unlike Jane, rather than stepping away from others, Phil made a decision to seek a way to become accepted by schoolmates. He felt he did so when he found a means to raise money and transform his wardrobe through his involvement in the drug trade. While Phil believed his decision to sell drugs would provide him with the means to 
become popular in school, it further marginalized him as he was positioned as a criminal in our justice system.

Somewhat different from Jane or Phil, Rocky's inability to be successful in academic pursuits was not the deciding factor in choosing to leave school early. Instead, his decision was influenced by the reaction he received once he shared his sexual orientation with others. Rocky shared that, initially, all of marginalization and responses he experienced as a result of his sexual orientation led him to contemplate suicide. He spent many nights sobbing into his pillow and wondering what was wrong with him as a result of those many episodes of ridicule for something over which he had no control (Rocky, personal communication, June 28, 2013). Therefore, rather than persevering in an environment that had grown toxic, he made the decision to leave and pursue other alternatives for completing his education.

Conversely, Wes felt that he would be better able to make a living and provide for his own family once he was out of school. His decision to leave school early was somewhat more acceptable during the times in which Wes grew up. He was not the only person in his area that stopped going to school after finishing grade eight and this decision did not have the stigma or the consequences that it does today. However, Wes now wonders if he should have made the decision to persevere in school through graduation.

Thus, all four individuals decided to drop out of school for different reasons, and each of my participants differ with regard to how he or she presently feels about that decision. Rocky views his decision as having freed him from an oppressive environment created by the students and faculty at his school. Since that time, Rocky has obtained his 
GED and he has been able to find employment. What he has also discovered, however, is that his opportunities for employment beyond short-term, minimum wage jobs continue to be few. This also means that Rocky's opportunities for such things as future savings, healthcare and a sense of security or independence may also be in jeopardy.

Phil's circumstances also continue to be precarious. While he regrets his decision to leave school early, Phil realizes that most of his current difficulties are not necessarily influenced by that decision. Instead, he understands that he has made other poor that have contributed to his current circumstances. Phil does, however, lament having dropped out as he feels his decision to do so disappointed his parents and his grandparents. In addition, he believes that decision continues to compromise his ability to obtain and keep gainful employment that would assist him and his family. As a result, Phil is quick to share that he believes having earned his diploma would have been the better decision.

Finally, although these behaviors include participation in a variety of illegal activities and the resulting terms of incarceration, Jane views her decision to do so as proof that she has overcome previous marginalization and abandonment by others. As a result, Jane does not lament her decision to leave school early. Instead, she sees school as one of many poor experiences imposed on her and from which she has escaped.

Each of my participants tells a very different story, yet many similarities seem to exist just under the surface. While what can be done to address each student's needs may never be fully understood, it seems there is an enormous amount that might be discovered through continuing to investigate the circumstances that lead to an individual's decisions to leave school early. These investigations might also reveal ideas for addressing the 
needs of each student early in their school careers, rather than waiting until he/she has made the decision to drop out.

\section{Conclusions}

The following section contains the over-arching statements that have resulted as a part of this study. These statements are representative of what the various stories have revealed about the way society has continued to operate schools and school districts. This includes operating through a deficit model and blaming the victim whenever specific students do not respond to traditional school structures as the majority of students do. Ultimately, these practices and the ways we do school have somehow minimized the school dropout dilemma.

\section{Predicting early school leaving requires more than merely keeping track of student attendance, behavior and coursework failure.}

While the symptoms of poor attendance, inappropriate behavior, and coursework failure (Balfanz, 2011) are strong predictors of potential dropouts, they should also serve as alarms that prompt immediate investigation into what may be contributing to those circumstances for particular students. Phil shared that he was disappointed when only one of all of his teachers cared enough to be concerned that Phil had acted on his decision to drop out. "She was about the only one that thought that I should stay in school. But, I was like, one teacher out of how many wants me to stay?" (Phil, personal communication, June 6, 2013). Phil was engaging in inappropriate behavior, which should have served as an indicator that he needed additional support; instead it seemed to have positioned him as someone who was not capable of being successful in school. 
Rocky also felt marginalized and unheard, which led to poor attendance and ultimately feeling he had no choice but to give up. Rocky shared,

Every time I went to the office to report that I had been thumped in the stairwell during class change, nothing was ever done. Even when I found someone who would listen to me, they would say that they would report what I was saying, but nothing ever happened. (personal communication, Fall, 2010)

I also have to wonder if our inattention to the needs of some students is an unintended consequence of meeting criteria established in the No Child Left Behind Act of 2001 and achieving annual yearly progress (AYP). It is possible that making AYP is prompting a form of academic natural selection and those students who demonstrated the least potential academically are in various ways, both subtly and not so subtly, being discarded.

When school personnel seem to encourage any student to leave school early through their inaction and apathy, rather than counseling him or her and providing for his/her needs, they, and the school system they represent, are complicit in this inappropriate act. As Noddings, (2005) suggests schools should have "one main goal, a goal that guides the establishment and priority of all others, it should be to promote the growth of students as healthy, competent, moral people" (p. 10). Therefore, we need to consider addressing the psychological and social needs of students as an important educational goal and as part of creating opportunities for academic progress to take place. Rather than simply tracking student attendance, behavior, and test scores, teachers might spend their time learning about student needs and then creating classrooms and schools in 
which those needs are addressed and students leave school able to fully and successfully engage with life.

\section{School systems sometimes ignore the basic needs of students as individuals in an attempt to herd the masses through a curriculum that is often not relevant and meaningful.}

According to a report shared through A Nation at Risk (National Commission on Excellence in Education, 1983), it seems the issues that continue to drive our schools often ignore an important factor - that of the impact the act of dismissing the emotional needs of students can have on students' learning. This has continued to frustrate stakeholders including students, parents, as well as teachers, who are typically impacted by the school experience. Characterizing the successfulness of school programs based on such things as student performance on an annual summative assessment alone presents an on-going conundrum that is multi-faceted.

In order for schools to be successful, there must be constant reflection on the needs (academic, social, emotional) of students and what schools might do to meet those needs and prepare students for their future lives. Noddings (2005) reminds us, It is time to take full account of the social changes that have swept through the second half of the twentieth century. If the traditional family is now an anachronism, or if, for whatever reasons, families cannot meet the needs for caring, other institutions must fill the need. (2005, pp. 13-14)

Thus, teachers must consider how they will create learning environments in which all students feel welcome, valued, and respected, regardless of their personal circumstances. Rocky sought such an environment when he disclosed he was gay. Instead, teachers and 
administrators positioned him as a deviant other and did not provide him with support that valued who he was. He shared, "The principal asked me if he could pray with me and, you know, maybe the kids would leave me alone, if I could get better" (Rocky, personal communication, June 28, 2013).

In addition, we may need to rethink our curricula, pedagogies, and assessments. Most of the participants in this study did not experience academic success. We must also help students understand the relevance of a strong academic foundation and their future lives so they will value the time they spend in school. In particular, Wes did not view the curricula of his schooling as relevant for his needs to provide for his family. Jane shares stories of helping others to make sense of academic tasks, yet her teachers not seem to be able to meet her needs in making sense of the content she experience in school.

Likewise, she also needed to feel accepted by teachers and classmates, rather than abandoned and marginalized by them. Ultimately, we need to see beyond the facades of particular students and hear their cries for acceptance and methods of instruction that promote and support their learning.

\section{Schools must work with other stakeholders in the community to support students in an} effort to encourage them to stay in school.

Rethinking how schools address the emotional needs of students is not something that can be done by classroom teachers alone, as it will take a concerted effort that includes school personnel at all levels working together with other agencies willing to share expertise in human development and resource management. This need becomes most apparent when reflecting on the individual issues with which both Jane and Rocky seemed to be dealing, yet seemed to be missed opportunities for those around them to be 
supportive. I believe there is great danger in missing those students whose individual issues, while hidden in full view, are allowed to go unattended.

Jane shared that she actually entered school having already become an alcoholic as a result of her exposure to the home brew provided by her father. It makes sense that this circumstance had an impact on Jane's ability to function in the typical school setting, both academically and socially. Yet Jane's story reveals that her interactions with and among others at school were routinely confrontational. Perhaps if the response to Jane's inability to get along with others and fit in included an assessment of why it was difficult for her to do so as well as consideration of what might be done to assist her, her subsequent circumstances may have been very different.

Likewise, had Rocky been valued simply as an important member of the school population rather than being marginalized as a result of his sexual orientation, perhaps his decision to leave school would have been thwarted. In addition, this alternate circumstance may have freed him to successfully obtain the traditional high school diploma and perhaps even continue pursuit of additional degrees. His school performance prior to his decision to leave suggested that these unattained opportunities were once possibilities.

Both Jane and Rocky are examples of missed opportunities for their school and community agencies to provide support. The coordination of resources (both human and financial) can be a valuable tool if handled in proactive ways. This includes actively seeking ways to identify and respond to students who may not fit in or appear disinterested in going with the flow of the school organization and or may not be performing academically as expected. 
One important factor to keep in mind is that the youth who are making decisions to leave school early typically do not have sufficient knowledge to help them understand the possible consequences of doing so. This was true of the participants in my study as each lacked the ability to foresee how removing himself or herself from the immediate frustrations with school might have any connection to the circumstances of their future lives. In most instances, my participants made the decision to leave school early as a result of their perception that they are not valued by the people whom they viewed as having been responsible for ensuring their safety and educational success. In fact, Jane's perception of school may be especially prescient for understanding how school dropouts experience school. She shared,

In school, you're an inmate. 'Cause they look at you as a criminal. Or, a bad person or you're filthy, or you're scum. I mean, there's all kinds of different things that they'll call you - trash. You could take the school and put it here [regional jail] and it'd be the same .... Students can tell when the teachers is cuttin' 'em down and other students is doing things to 'em that ain't right. (personal communication, June 22, 2013)

Students who are repeatedly marginalized by their peers and teachers and who do not find a way to connect with the learning often make the decision to leave school at a very early age. "In the real world, children are too often valued only for their achievement. They become resources" (Noddings, 2005, p. 13). As a result, students who are unable to do well on our current assessments are often positioned as not able to learn, lazy, unproductive and a burden to society. These perceptions influence the ways in which teachers design instruction for them and the ways in which they interact with 
students identified as low SES. These students often accept these positionings and choose to remove themselves from school in search of acceptance and opportunities for success.

\section{Implications}

While concern exists pertaining to the importance of recognizing school dropout as the Silent Epidemic (Milliken, 2007), as well as trying to increase understanding of what contributes to it and how to address it, doing so is not about placing blame. Until many of the challenges that confront schools and students are addressed in ways that encourage rather than blame victims of each circumstance, many students will make the choice to leave school early. Moreover, no one answer seems to exist regarding what contributes to the school dropout dilemma. As Rumberger (1987), stated, "Timely identification is important ... The earlier a student with a high risk of dropping out is identified, the more likely it is that a sustained effort at dropout prevention will be successful" (p. 117). While the ABCs of school dropout may be considered characteristics of school dropouts, much more telling information lies beneath the surface as contributors of those characteristics and it is these contributors and those individuals who make the decision to leave school early that deserve further consideration and study.

Over a quarter century ago, Rumberger (1987), alerted us to the fact that "Most research on school-related factors has focused on students' behaviors and performance in school. Little attention has been given to the influences of schools themselves - their organization, leadership, teachers - on students' decisions to drop out" (p. 110). We must rethink the ways we do school, what is available to those enrolled, and who might be able to offer the needed services and supports for families and students alike if we are going to 
stem the tide of young people who choose to leave school early. What is not needed are more platitudes such as closing the achievement gap, leveling the playing field, No Child Left Behind, and the like.

Although, there is a definite need for change in both policy and practice within our school systems, there is also a need for collaborative attention by a combination of agencies beyond those that typically address educational issues. Further, addressing the school dropout phenomenon is not something that can be handled by classroom teachers, alone. Instead, it will require a concerted effort among a variety of agencies willing to share expertise related to human development and resource management.

As conditions and requirements within our schools change, many of the personal circumstances of the students attending them continue to present barriers that need to be address. Investigating ways to address those barriers should be an on-going commitment, as well. Therefore, further study of these various circumstances would broaden our understanding of the dilemma and possibly suggest additional actions to help address them. The school dropout dilemma is not unique to any particular trait or personality. American schools continue to work under the deficit model, therefore, unless change occurs both in and outside of our schools, early school leaving will continue to occur.

The following information is provided for consideration when desiring to take on the growing dilemma for school dropout. While not intended to be an exhaustive list, it is offered as a result of the stories shared by participants of this study and their reasons for leaving school early. Present day issues with which our students are dealing are far more complicated than during earlier times. An understanding of these issues is an integral part of what any individual who works with children need to possess. We must work 
together to not only understand why students wish to leave school, but also to address the challenges they are facing so that school is a place that welcomes them and meets their needs so they are able to lead good lives.

\section{Emotional Connectivity}

Most of the participants in this study shared experiences of not feeling accepted and valued in their classrooms and school communities. They chose to resolve these complicating actions in their life stories by leaving school early. Indeed, Bronfenbrenner (1991) suggests that establishing a bond of trust between the developing individual and the various influential persons that may surround him or her is of the utmost importance. Establishing such a bond encourages most students to put more effort and time into their learning experiences. Moreover, the prevalence of white, middle class values in designing and enacting curriculum may also contribute to the fact that some students feel disconnected from school. This disconnect might compromise any possibilities for trust to be established between teacher and student.

One possibility for supporting students as they develop trust and rapport with their teachers and peers might be to establish a mentoring program to support students as they become full-fledged members of the school community and to address any of the concerns individual students might have as they navigate developing relationships that support their learning. In an ideal world, a program of this nature should include assignment of manageable cohorts of student to each of the faculty and staff working at the particular school. Once specific student cohorts have been identified, mentors should be provided with appropriate professional development training that is focused on providing faculty with the mentoring and coaching skills they need to be successful with 
students. Subsequently, mentors should be expected to make regular contact with each of his or her assigned students.

Initially, mentoring meeting times should be scheduled during times carved out of the school day. These meetings should engage students in discussions of a general nature to establish a sense of belonging for all involved. In addition, mentors should seek opportunities for periodic, unscheduled contacts with each of his or her assigned students. These opportunities should be handled in such a way so as not to appear scripted or forced. Instead, they should be seen as a mentor's genuine interest in the students and their well-being. In addition to the mentoring discussion meetings and the frequent contacts made between mentors and students, opportunities for routine counseling sessions should be established for every student each school year in grades five, seven, nine and eleven. Further, counseling should also be available for parents as well as students.

Periodic follow-up faculty and staff meetings that are focused on such things as mentoring practices, as well as how to respond to the needs of students should also be scheduled. In order to encourage meaningful participation in mentoring, building administrators should ensure that faculty and staff understand that their regular attendance at these sessions is expected. In addition, information that could influence a student's academic progress should be shared with appropriate staff and remain confidential between those individuals. In addition to establishing mentoring procedures for all students, it is also recommended that routine home visits occur for all students in grades Pre-Kindergarten, Kindergarten and Five. 


\section{Shared Communal Effort and Responsibilities}

Currently, our school facilities are typically in use during the daylight hours. As a result, there are many hours of possible programming that could occur in support of the community. This could include any variety of programs viewed as supportive and necessary for the particular community, and expand beyond just the student population enrolled there. As a result, rather than individual agencies operating as separate programs that constantly need to locate replicative funding for such things as facilities maintenance, etc., buildings should be available for various organization to use during non-school hours. Building use should be available for more than the typical nine month school year. In addition, shared funding that is earmarked for facilities maintenance should be practiced. In so doing, this shared routine expense would stretch the limited resources of each.

In addition to providing academic coaching, the additional hours could include services that are typically only available during the school day and therefore inaccessible to students and/or parents when they are otherwise attending class or working. Such services could connect at risk students with adults with who could help them to address the issues in their lives that may be interfering with their ability to learn (i.e., alcoholism, drug abuse, mental health issues). These services might also help students with limited peer group support to learn how to resolve conflicts and connect to others, their peers, as well as the influential adults in their lives.

\section{Issues of Accessibility}

As McDill, et al. (1985) suggests: 
Participation in extracurricular activities builds a normative attachment to the school, and also provides an avenue for success for students who do not perform well in the classroom. It is precisely those students who are most at risk of dropping out. (p. 426)

However, many students, who would be interested in participating in these activities, are often dependent on the daily bus transportation which is only available during a very narrow window. This narrow window does not, however, extend to include the needed pre- and post- extracurricular activity timeslots, nor do many of these students' parents have the ability to provide transportation to practices and events. Of equal importance, most school systems appropriately restrict practices where students who have their own cars transport others to and from events. As a result, it becomes virtually impossible for those without transportation to participate and a feeling of being a part of the school community. This can isolate those students and create a sense of marginalization as membership of school clubs and other organizations are formed.

If the revenue created through the cooperative use of the facilities by other agencies, as described in the previous section, could be earmarked for additional transportation, those students who need transportation to and from extra-curricular activities could be accommodated. In this manner, more students could take advantage of additional opportunities offered at the school, including not only participation in social clubs and on sports teams, but also needed counseling and remedial services.

\section{Shared Decision Making}

In order to effectively address the silent epidemic of school dropouts, shared decision-making is a key component to any collaborative effort. As a part of the 
aforementioned recommendations, communities and systems that are genuinely interested in addressing the school dropout phenomenon, should actively pursue opportunities for shared decision making among stakeholders. Decisions that impact the lives of all members of a community should be made as a result of soliciting input from more than just those in charge of programming. Instead, forums for reviewing the status of school programs, student performance and services which are in place to respond to needs that are discovered by those responsible for student learning and general welfare issues should become common practice for communities.

When needs are discovered, the combined effort of school personnel, community agencies, as well as members of the general public should be engaged in seeking ways to address them. Rather than simply acknowledging that a concern exists, it should be the intent of all stakeholders to help determine what may be contributing to a particular dilemma and to begin seeking solutions that address it in a cooperative, collaborative manner.

\section{Personal Reflection}

The reasons for an individual's choice to pursue a particular pathway continues to be a complex question we can't escape The stories explored in this inquiry provide evidence of this as the participants shared the various ways in which they identified, resolved, and evaluated the challenges they faced in their lives. In each of their narratives, the participants seem to tell of opportunities missed by themselves and the other people who are a part of their stories. In addition, the responses of my participants to the complicating actions of their lives varied and was influenced by any number of factors, which complicated their choices and evaluations of their narratives. Many times 
their lives were influenced not only by the ways in which they were positioned by others, but also by their choices to accept or resist that positioning. We would be better served by exploring the understandings and circumstances that underlie a decision to leave school early, rather than assigning blame and labeling the person who made the decision as unworthy of support and redirection.

As I bring this particular study to a close it is important to note that what has been discovered from the stories shared by the participants is not something to concern us for a while and then forgotten. I have spent a good deal of time listening to and revisiting concerns raised in the narrative shared in my participants' journeys that led to early school leaving only to learn more each time I returned to them. These stories, and the data each provides, help to clarify what can influence an individual to drop out.

I have also included what should represent only a few suggestions for further study of what many consider the silent epidemic of school dropout. Hopefully this needed awareness can be a source of inspiration for additional attention on behalf of the growing numbers of students deciding that a high school diploma is just not for them. Considering how our school programs are structured might be an appropriate step in the process. Does one size ever really fit all? Is it necessary that every individual go through the same educational program in order to be considered a success? Does there have to be only one set of essential components of preparedness into which everyone must fit? If so, for what would that preparedness be?

Finally, addressing the dropout dilemma is not about placing blame. Instead, it is about finding ways to ensure success for learners from diverse lifestyles and cultures, of all learning styles, and at all readiness levels. Our goal should be to constantly seek an 
understanding of what it means to be successful, as that understanding seems to be in a continual state of change. Further, as cautioned by Rumberger (1987) so many years ago, "The dropout problem is unlikely ever to go away. But concerted and cooperative efforts by educators, policy makers, and educational researchers can improve our understanding of the problem and help reduce its incidence" (p. 119). With this in mind, poly-vocal perspectives need to be invited into the discussion and recognized when attempting to discover more timely definitions of success, as not everyone can perform, or demonstrate his or her knowledge and capabilities in the same manner. Ultimately, all stakeholders, including students who are at risk for making a decision to leave school early, should be invited to participate in this conversation.

Rethinking how learning opportunities need to be structured in order to ensure more frequent occurrences of success stories is essential. It is understandable that finding ways to address this task may require an enormous investment of time, energy, and resources, both human and financial. However, with all that we know about what has not worked thus far, surely it is possible to discover ways that can provide meaningful and effective next steps in addressing the early school leaving phenomenon. Not attempting to do so could be even more costly. 


\section{Appendices}

Appendix A: Letter of Invitation and Informed Consent ..................... 220

Appendix B: Script - Interview One: Experiences At Home ................ 221

Appendix C: Script - Interview Two: School Experiences .............................. 222

Appendix D: Script - Interview Three: Life After Leaving School Early ............. 223

Appendix E: Letter of Authorization to Review School Records ................... 224 


\title{
Appendix A: Letter of Invitation and Informed Consent
}

\author{
Early School Leaving: A Narrative Inquiry of the School Dropout
}

Good Afternoon,

Thank you agreeing to talk with me about the research study that I am currently doing. As mentioned during our initial introduction, my name is John E. Stallings, Jr., and I am presently a Doctoral Candidate at WVU pursuing an Educational Doctorate degree in Educational Leadership Studies.

I am conducting this research study as a part of my doctoral work at West Virginia University with supervision of Dr. Paul E. Chapman, an associate professor in the Department of Educational Leadership Studies, College of Education and Human Services.

I was hoping to include you as a participant in this study and therefore need to share some brief background as well as what it is that will be involved in this study, including your role in the process.

- This research study is intended to investigate previous students' decisions to leave high school prior to graduation.

- I am interested in hearing from individuals who have made the decision to leave school prior to graduating.

- There are many theories about what may influence a student not persist in school through high school graduation. In addition, there are many individuals who think they know why students are disengaging from school and dropping out.

- However, very little is known about the dropout phenomenon through the eyes of those who have actually done so.

I believe that hearing about school experiences and dropout through the stories from those individuals who have actually experienced it can be very helpful in providing others a better understanding of what may be influencing decisions to leave school early.

My goal is to learn about your experiences as a part of discussion with you and through a few interviews during which I will ask you to share information about such things as: your life as a child, (your immediate and extended family, where you grew up, etc.); what you can recall about your experiences in school, (where you attended school, what it was like to be a student, etc.); as well as share information about your life since you made the decision to leave school early.

Your participation in this project will be greatly appreciated and will involve approximately three private, recorded, one-hour interview sessions, during which I will ask that you share stories and memories from your past.

- Your involvement in this project will be kept as confidential as legally possible.

- You must be 18 years of age or older to participate.

- In order to protect your privacy, and prevent the possibility that any information you share could lead back to your identity, I will replace actual names (your name, town and school locations, etc.) with pseudonyms.

- In addition, all information gathered during this study will be stored electronically and or maintained in a locked file that is accessible only to me as the researcher.

- Your participation is completely voluntary.

- When participating in this project, you may skip any question that you do not wish to answer and you may discontinue at any time.

West Virginia University's Institutional Review Board acknowledgement of this project is on file.

We'll schedule our discussion and interviews at a convenient time and location as soon as possible. Until that time, should you have any questions about this research project in general, please feel free to contact John E. Stallings, Jr. at: (304) 288-9883 or by e-mail at: John.Stallings@ mail.wvu.edu 


\section{Appendix B: INTERVIEW QUESTIONS/PROMPTS \\ Early School Leaving: A Narrative Inquiry of the School Dropout \\ [INITIAL INTERVIEW SESSION - Experiences At Home] \\ DATE TIME: \\ LOCATION:}

Thank you agreeing to talk with me about the research study that I am currently doing.

As mentioned during our initial introduction, I am conducting this research study as a part of my doctoral work at West Virginia University.

\section{Open-Ended Prompts:}

1. Please tell about yourself:

- What was your family like?

- What did mom and dad do?

- Did you have any siblings?

- How many were there?

- Where did you fit in the line (i.e., oldest, youngest, middle)?

- Did you know your grandparents? If so, please tell me about them:

$\checkmark \quad$ Where did they live?

$\checkmark \quad$ Did you see them often?

$\checkmark$ What memories do you have of them?

- Where are any of those family members now?

2. What did you like to do when you were young?

3. Did you have any pets? If so, please tell me about them.

- What kind of pet(s) was it/were they?

- What kind of responsibilities did you have as a result of owning the pet(s)?

4. What kinds of things did you do to occupy your time (i.e., hobbies, clubs or sports)?

5. What did you think you might become or do once you were grown?

When might we be able to meet again? Date: Time:

Date: Time: 


\section{Appendix C: INTERVIEW QUESTIONS/PROMPTS \\ Early School Leaving: A Narrative Inquiry of the School Dropout \\ [INTERVIEW SESSION \#2 - School Experiences]}

DATE TIME:

\section{LOCATION:}

Before we get started with today's discussion and interview, I wanted to take just a few minutes to review the transcript that I prepared from our last meeting and allow you to help me make sure that I captured what you shared accurately. I don't want to include anything that may be incorrect.

Now that we've reviewed that information, let's continue with our interview discussion questions.

\section{Open-Ended Prompts:}

Please tell about your life as a student:

- Where did you attend school?

- How did you typically get to and from school?

- What was it like at your school(s)?

- What do you recall as being your favorite activities or subjects at school?

- How did you get along with the other students at your school?

- What were the teachers and other staff like at your school?

- How did you do with regard to school work and academics in general?

- When did you start to feel like you might be leaving school early (dropping out)?

- What do you remember that may have influenced that decision?

- What kind of response did you get when you decided to dropout:

- From your friends?

- From your teachers?

- From your parents?

- From others in the community?

When might we be able to meet again? Date:

Time:

Date:

Time: 


\section{Appendix D: INTERVIEW QUESTIONS/PROMPTS \\ Early School Leaving: A Narrative Inquiry of the School Dropout \\ [INTERVIEW SESSION \#3 - Life After Leaving School Early]}

DATE TIME:

\section{LOCATION:}

Before we get started with today's discussion and interview, I wanted to take just a few minutes to review the transcript that I prepared from our last meeting and allow you to help me make sure that I captured what you shared accurately. I don't want to include anything that may be incorrect.

Now that we've reviewed that information, let's continue with our interview discussion questions.

\section{Open-Ended Prompts:}

Please share a bit more about what you were talking about when last met:

[Insert areas needing additional information]

Please tell about your life since having dropped out of school:

- Where are you living?

- What have you done with your time since you dropped out?

$\checkmark \quad$ Are you currently employed?

$\checkmark \quad$ Where are you working and what at are you doing?

$\checkmark \quad$ What benefits are included with this position?

$\checkmark \quad$ What opportunities for advancement exist for you in this job?

- What do you do with your free time?

- What is your marital status?

- What has it been like since you made the decision to leave school early?

- What might you like to share with others about your decision to leave school early and the impact it has had on your life, if any?

I would like to meet with you again so that we can review the transcripts I prepare one more time to ensure that what I am capturing is accurate with you.

When might we be able to meet again? Date: Time:

Date: Time: 
Appendix E: Letter of Authorization to Review School Records

\section{ACCESS TO RECORDS AUTHORIZATION}

To Whom It May Concern,

Please accept this Access to Records Authorization form as official authorization to access and review any existing permanent record files (original and or digitized and stored electronically) on behalf the participant listed below. This individual is currently participating in a research study being conducted by John E. Stallings, Jr., West Virginia University Doctoral Candidate, as a part of a Program of Study dissertation.

$\mathrm{I}$, , grant permission for John E. Stallings, Jr. to access and review any existing permanent records (original and or digitized and stored electronically) pertaining to my school enrollment (including attendance, referral for or results from evaluation, comments, and or recommendations for educational placement or other support services) issued by his or her teacher(s), administrator(s), school counselor(s) and or other faculty or service provider(s).

I understand that granting permission for making this information available for review will be for the purpose of triangulation of information otherwise shared as a part of the research study in which I am participating only.

In addition, I understand that any information obtained will remain a part of the confidential nature of this research study as much as legally possible.

Further, once this particular research study has been completed and the required time-line for maintaining any such research-related information has expired, this permission will also terminate.

Signature of Study Participant

Signature of Researcher
Date

Date

Name of School District or Agency:

Address (if known):

Office use:

Date request received:

Date records released: 


\section{References}

Alliance for Excellent Education (2009). Understanding high school graduation rates in West Virginia. Retrieved from: http://www.all4ed.org/publication_material/understanding_HSgraduates

National Commission on Excellence in Education (1983). A Nation at Risk. Retrieved from: http://www.ed.gov/pubs/NatAtRisk/index.html

Au, K. H. (1998). Social constructivism and the school literacy learning of students of diverse backgrounds. Journal of Literacy Research, 30(2), 297-319.

Balfanz, R. (2011). Back on track to graduate. Educational Leadership, 68, 54-58.

Barton, P. E. (2006, February). The dropout problem: Losing ground. Educational Leadership, 63(5), 14-18.

Bennett, C. I. (2011). Comprehensive multicultural education: Theory and practice. Boston: Pearson Education, Inc.

Boostup.org, (2013). Attendance counts. Retrieved from: http://www.boostup.org/en/facts/attendance

Boostup.org. (2013). Dropout rates. Retrieved from: http://www.boostup.org/en/facts/statistics

Boostup.org. (2013). Why students drop out. Retrieved from: http://www.boostup.org/en/facts/reasons

Brendtro, L.K. (2010). The vision of Urie Bronfenbrenner: Adults who are crazy about kids. Reclaiming Children and Youth, 15(3), 162-166.

Bronfenbrenner, U. (1979). The ecology of human development: Experiments by nature and design. Cambridge, MA: Harvard University Press. 
Bronfenbrenner, U. (1979). Conceptualization of the ecology of human development model. Retrieved from:

http://www.google.com/search?q=bronfenbrenner's+theory\&hl=en\&tbo=u\&rlz=1 I7GCNV_en\&tbm=isch\&source=univ\&sa=X\&ei=gOoaUaG0IMikqwHno4GoCg \&ved=0CDAQsAQ \&biw=1280\&bih $=626$

Bruner, J. (2004). Life as narrative. Social Research, 71, 691-710.

Christle, C. A., Jolivette, K., \& Nelson, C. M. (2007). School characteristics related to high school dropout rates. Remedial and Special Education, 28(6), 325-339.

Clandinin, D. J. \& Connelly, F. M. (2000). Narrative inquiry: Experience and story in qualitative research. San Francisco, CA: Jossey-Bass Publishers.

Corrigan, M. W., \& Chapman, P. E. (2008). Trust in teachers: A motivational element to learning. Radical Pedagogy.

Croninger, R. G., \& Lee, V. E. (2001). Social capital and dropping out of high school: Benefits to at-risk students of teachers' support and guidance. Teachers College Record, 103(4), 548-581.

Crotty, M. (1998). The foundations of social research: Meaning and perspective in the research process. Thousand Oaks, CA: Sage Publications USA.

Czarniawska, B. (2004). Narratives in social science research: Introducing qualitative methods. Thousand Oaks, CA: Sage Publications, Inc.

Denzin, N. K., \& Lincoln, Y. S. (2005). The Sage handbook of qualitative research. Thousand Oaks, CA: Sage Publications, Inc. 
Drewry, J. A., Burge, P. L., \& Driscoll, L. G. (2010). A tripartite perspective of social capital and its access by high school dropouts. Education and Urban Society, 42(5), 499-521.

Freire, P. (2005). Teachers as cultural workers: Letters to those who dare teach. Cambridge: Westview Press.

Gallagher, C. J. (2002). Stories from the strays: What dropouts can teach us about school. America Secondary Education, 30(3), 36-60.

Gee, J. P. (2001). Identity as an analytic lens for research in education. Review of Research in Education, 25, 99-125.

Retrieved from: http://www.jstor.org/stable/1167322

Gragg, W. L. (1949). A drop-out or a high-school graduate? The Education Digest, 15(1), 30-31.

Grbich, C. (2007). Qualitative data analysis: An introduction. Thousand Oaks, CA: Sage Publications, Inc.

Guba, E. G., \& Lincoln, Y. S. (1990). Can there be a human science?: Constructivism as an alternative. Person-centered review, 5, 130-154.

Gubrium, J. F., \& Holstein, J. A. (2009). Analyzing narrative reality. Thousand Oaks, CA: Sage Publications, Inc.

Hamre, B. K., \& Pianta, R. C. (2001). Early teacher-child relationships and the trajectory of children's school outcomes through eighth grade. Child Development, 72(2), $625-638$.

Hansen, J. B., \& Toso, S. J. (2007). Gifted dropouts: Personality, family, social, and school factors. Gifted Child Today, 30(4), 30-41. 
Hardy, S., Gregory, S., \& Ramjeet, J., (2009). An exploration of intent for narrative methods of inquiry. Nurse Researcher, 16(4), 7-19.

Horvat, E. M., \& Davis, J. E. (2011). Schools as sites for transformation: Exploring the contribution of habitus. Youth \& Society, 43(1), 142-170.

Kansas City Schools (1946), Why pupils leave school. The Education Digest, 11(7), 5254

Kvale, S., \& Brinkmann, S. (2009). InterViews: Learning the craft of qualitative research interviewing. Thousand Oaks, CA: Sage Publications, Inc.

Kozol, J. (2006). Rachel and her children: Homeless families in America. New York: Three Rivers Press.

Labov, W. (1997). Some further steps in narrative analysis. The journal of narrative and life history, 1-13. Retrieved from: http://www.ling.unenn.edu/ wlabov/sfs.html

Layton, L. (2012, March 19). High school graduation rates rise in U.S. Washington Post Newspaper. Retrieved from: http://www.washingtonpost.com

Legters, N., \& Balfanz, R. (2007). Do we have what it takes to put all students on the graduation path? New Directions for Youth Development, 127, 11-24.

Lezzotte, L. W. (1997). Learning for all. Chattanooga, TN: Effective School Products Publishers.

Littky, D. (2004). The big picture: Education is everyone's business. Alexandria, VA: Association for Supervision and Curriculm Development.

McDill, E. L., Natriello, G., \& Pallas, A. M. (1985). Raising standards and retaining students: The impact of the reform recommendations on potential dropouts. Review of Educational Research, 55(4), 415-433. 
McLeod, S. (2009). Jean Piaget. Cognitive theory, 1-8.

Retrieved from: http://www.simplypsychology.org/piaget.html

Milliken, B. (2007). The last dropout: Stop the epidemic! New York: Hay House, Inc.

Noddings, N. (2005). The challenge to care in schools: An alternative approach to education. New York: Teachers College Press.

National Child Labor Committee (1951). School heads weigh draft and dropouts. The Journal of Education, 134(5), 148.

National Commission on Excellence in Education (1983). A nation at risk.

Retrieved from: http://www.ed.gov/pubs/NatAtRisk/index.html

Patton, M. (2002). Qualitative research and evaluative methods. Thousand Oaks, CA: Sage Publications, Inc. USA.

Phelan, P., Davidson, A. L., \& Cao, H. T. (1992). Speaking up: Students' perspectives on school. Phi Delta Kappan, 73(9), 695-704.

Powers, W. (2004). Move beyond the numbers to involve faculty in student retention. National On-campus Report, 32(17), 6.

Rumberger, R. W. (1987). High school dropouts: A review of issues and evidence. Review of Educational Research, 57(2), 101-121.

Savin-Baden, M., \& Van Niekerk, L. (2007). Narrative inquiry: Theory and practice. Journal of Geography in Higher Education, 31(3), 459-472.

Seidman, I. (1998). Interviewing as qualitative research: A guide for researchers in education and the social sciences. New York, NY: Teachers College Press

Sparkes, A., \& Smith, B. (2008). Narrative constructionist inquiry. In Holstein, J. A., \& Gubrium, J. F. (2008). Handbook of constructionist research (pp. 295-314). New York, NY: Guilford Press. 
Tozer, S. E., Violas, P. C., \& Senese, G. (2008). School and society: Historical and contemporary perspectives. New York, NY: McGraw Hill Publishers.

U.S. Department of Education (January 1984 \& 1986), State Education Statistics, Washington, DC: U.S. Department of Education. [As reported in Rumberger, R. W., (1987). High school dropouts: A review of issues and evidence. Review of Educational Research, 57(2), 104.]

van Langenhove, L., \& Harré, R. (1999). Positioning theory: Moral contexts of intentional action. Malden, MA: Blackwell Publishers, Ltd.

VanMann, M. (1990). Researching a lived experience: Human science for an action sensitive pedagogy. State University, NY: New York Press.

Webster, L., \& Mertova, P. (2007). Using narrative inquiry as a research method. New York: Routledge Publications.

West Virginia Department of Education. (2012). School district graduation and dropout trend data. Retrieved from: http://wvde.state.wv.us/

Zabloski, J., \& Milacci, F. (2012). Gifted dropouts: Phenomenological case studies of rural gifted students. Journal of Ethnographic and Qualitative Research, 6, 175190. 


\section{Biographical Sketch}

John E. Stallings, Jr. completed his undergraduate degree in elementary education at West Virginia University in Morgantown, WV (May 1975). Over the course of the next thirty-four years, John served the Taylor County, WV Board of Education and community as an elementary school teacher while completing his Master's degree in Education Administration (May 1979). Subsequently, John served the Taylor County school district as an elementary school principal, the Coordinator of Special Services, and finally as the Director of Curriculum and Instruction/Federal programs. Following John's retirement, in 2009, he began serving the West Virginia University Benedum Collaborative Five-Year Teacher Education Program as an adjunct instructor as well as a liaison between WVU and partnering professional development schools. John is currently serving as the Interim Director of the Benedum Collaborative program. The primary focus of John's doctoral work has been on early school leaving, more commonly known as school dropout, what influences individuals to do so and how that decision impacts them. John and his wife, Margaret, have raised two sons, Ryan Andrew and Drew Tanner, as well as two grandsons, Beckett Hunter and Sawyer Ryan. In his spare time, John enjoys traveling, reading, and gardening, spending time with his grandsons, as well as participating in occasional vocal performance opportunities. 